\title{
EFFECT OF AEROGEL ON THE THERMAL PERFORMANCE OF CORRUGATED COMPOSITE SANDWICH STRUCTURES
}

\author{
A Thesis \\ presented to \\ the Faculty of California Polytechnic State University, \\ San Luis Obispo
}

In Partial Fulfillment

of the Requirements for the Degree

Master of Science in Mechanical Engineering

by

Jacob Dillon Chess

December 2018 
(C) 2018

Jacob Dillon Chess

ALL RIGHTS RESERVED 


\section{COMMITTEE MEMBERSHIP}

TITLE: Effect of Aerogel on the Thermal Performance of Corrugated Composite Structures

AUTHOR: Jacob Dillon Chess

DATE SUBMITTED: December 2018

COMMITTEE CHAIR: $\quad$ Eltahry Elghandour, Ph.D.

Associate Professor of Mechanical Engineering

COMMITTEE MEMBER: $\quad$ Richard Emberley, Ph.D.

Assistant Professor of Mechanical Engineering

COMMITTEE MEMBER: $\quad$ Kim Shollenberger, Ph.D.

Professor of Mechanical Engineering 


\begin{abstract}
Effect of Aerogel on the Thermal Performance of Corrugated Composite Sandwich Structures Jacob Dillon Chess
\end{abstract}

Current insulation solutions across multiple industries, especially the commercial sector, can be bulky and ineffective when considering their volume. Aerogels are excellent insulators, exhibiting low thermal conductivities and low densities with a porosity of around $95 \%$. Such characteristics make aerogels effective in decreasing conductive heat transfer within a solid. These requirements are crucial for aerospace and spaceflight applications, where sensitive components exist among extreme temperature environments. When implemented into insulation applications, aerogel can perform better than existing technology while using less material, which limits the amount of volume allocated for insulation. The application of these materials into composites can result in enhancing a material's thermal and mechanical properties when exposed to mechanical testing.

The main objective of this study was to perform theoretical and experimental analysis on a corrugated composite sandwich structure integrated with aerogel insulation by studying its effective thermal conductivity. The aerogel material used was Pyrogel XT-E, a silica aerogelbased fiberglass insulation manufactured by Aspen Aerogels. Theoretical models of the corrugated composite sandwich structure were constructed in ANSYS Workbench based on geometry from a previous study. The main goal of the theoretical models was to analytically and computationally study the effective thermal conductivity of this sample; the conditions of these simulations were modeled after the experimental setup. Additionally, two insulation studies were performed using the thermal models. The first study was performed on a flat plate structure to 
determine the optimal thickness of Pyrogel XT-E in a flat plate orientation. The second study compared multiple types of common insulation materials to Pyrogel XT-E when integrated into the corrugated composite sandwich structure model. As expected, aerogel particles and Pyrogel XT-E outperformed all insulation materials and had the lowest effective thermal conductivity. Experimental data was obtained using a test enclosure and a heating element source with an integrated temperature control circuit that was designed and built for this study. This experimental data was compared to the theoretical data obtained from the thermal model simulations. The corrugated composite sandwich structure did not perform as well as expected due to thermal bridging along the composite corrugation. Its effective thermal conductivity was much higher than that of the flat plate structure, even though the effective Pyrogel XT-E layer in the corrugated composite sandwich structure was more than twice as thick as the layer in the flat plate structure. Despite thermal bridging, the corrugated composite sandwich structure exhibits superb thermal resistance, which adds to its impressive strength. Thermal conductivity results from this study can be used to design efficient materials for high structural and thermal stress applications. 


\section{ACKNOWLEDGMENTS}

I would like to begin by thanking my thesis advisor, Dr. Elghandour, for leading me through the process of completing my thesis. From describing to me the initial project to helping me effectively showcase my results, he was there to lead me in the right direction. Dr. Elghandour also encouraged me to submit my research to the SAMPE and CAMX conferences, which were amazing experiences for me to partake in.

I would also like to thank my other thesis committee members, Dr. Emberley and Dr. Shollenberger, for their continued support. Dr. Emberley was a huge help in walking through problems I ran into throughout my research, as discussing the roadblocks and looking at possible methods and solutions was instrumental in collecting thorough data.

Dr. Shollenberger's assistance on my CFD course project for played a big role in understanding the heat transfer in the geometry I was working with. Dr. Shollenberger also helped me define the main goals of the project, which allowed me to start this research with a clearer head.

I would also like to acknowledge everyone at Cal Poly who helped me throughout my research, especially Dr. Ridgely and Charlie Refvem. Without their help I would not have been able to wire my temperature control circuit. Additionally, I would like to thank Jalen Mano for his assistance in making my carbon fiber and understanding the geometry he studied to set up my model. I would like to thank Jose Urizar for lending me the test enclosure to be able to test my samples. 
Finally, I would like to sincerely thank my friends and family for supporting me throughout my life and in obtaining my master's degree. I am nothing without them, and none of this would have been possible without their continued love and encouragement. 


\section{TABLE OF CONTENTS}

Page

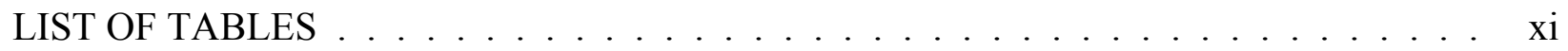

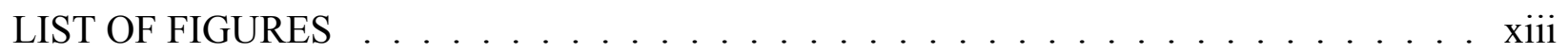

\section{CHAPTER}

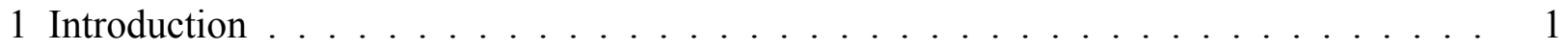

1.1 Statement of Research . . . . . . . . . . . . . . . . . . 2

1.2 General Approach . . . . . . . . . . . . . . . . . 2

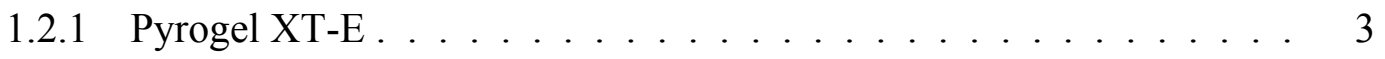

1.2.2 Theoretical Model . . . . . . . . . . . . . . . . . . 4

1.2.3 Experimental Method ................ 5

1.2.4 Scope of Thesis ................... 5

2 Literature Review . . . . . . . . . . . . . . . . . . 7

2.1 Aerogel Manufacturing Techniques . . . . . . . . . . . . . . . 7

2.1.1 Sol-gel Process . . . . . . . . . . . . . . . . 7

2.1 .2 Aging ....................... 8

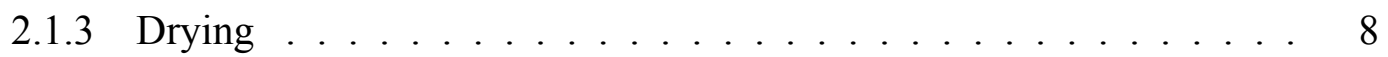

2.2 Aerogel Design . . . . . . . . . . . . . . . . . 9

2.2.1 Hydrophobic Aerogels . . . . . . . . . . . . . . . . 10

2.2.2 Raw and Organic Material . . . . . . . . . . . . . . . 10

2.3 General Applications of Aerogel . . . . . . . . . . . . . . . . . 11

2.3.1 Thermal Insulation Applications . . . . . . . . . . . . . . 11 
2.4 Experimental Methods for Determining Thermal Properties . . . . . . . . . . 16

3 Theoretical Model . . . . . . . . . . . . . . . . . . 18

3.1 Thermal Resistance Analysis . . . . . . . . . . . . . . . . . . 18

3.1 Heat Diffusion Equation Derivation . . . . . . . . . . . 20

3.2 Flat Plate Sandwich Structure Sample . . . . . . . . . . . . . . 23

3.3 Corrugated Composite Sandwich Structure Sample . . . . . . . . . . . . . . 31

4 Experimental Setup \& Method . . . . . . . . . . . . . . . . 36

4.1 Experimental Setup . . . . . . . . . . . . . . . . 36

4.1 .1 Test Enclosure . . . . . . . . . . . . . . . . . . . . . 37

4.1 .2 Sample Housing . . . . . . . . . . . . . . . . 38

4.1 .3 Heat Source . . . . . . . . . . . . . . . . . . . . 39

4.1.4 Data Acquisition ... . . . . . . . . . . . . . 40

4.1.5 Temperature Control . . . . . . . . . . . . . . . . 41

4.2 Sample Preparation . . . . . . . . . . . . . . . . . 42

4.2.1 Pyrogel XT-E Flat Plate Sample . . . . . . . . . . . . . . 43

4.2.2 Corrugated Composite Sandwich Structure Sample . . . . . . . . . . 43

4.3 Experimental Method . . . . . . . . . . . . . . . . . 46

4.3.1 Sample Geometry . . . . . . . . . . . . . . 46

4.3.2 FluxDAQ+ DAQ System Configuration . . . . . . . . . . . . 46

4.3.3 Sensor Application . . . . . . . . . . . . . . . . 47

4.3.4 Temperature Control Configuration . . . . . . . . . . . . . . . 49

4.3.5 Sample Housing Configuration . . . . . . . . . . . . . . 52

4.3.6 Running a Test . . . . . . . . . . . . . 53 
5 Theoretical, Numerical, and Experimental Results \& Discussion $\ldots \ldots$. . . . . . . 55

5.1 Theoretical \& Numerical Analysis Results . . . . . . . . . . . . . . . . 55

5.1.1 Finite Difference Model of Flat Plate Sandwich Structure $\ldots \ldots$. . 55

5.1.2 ANSYS Model of Corrugated Carbon Fiber Structure . . . . . . . 61

5.1.3 Sample Performance Comparison . . . . . . . . . . . . . 65

5.2 Experimental Results \& Discussion . . . . . . . . . . . . . . . . . . 69

5.2.1 Flat Plate Sandwich Structure . . . . . . . . . . . . . . . 69

5.2.2 Corrugated Carbon Fiber Sandwich Structure . . . . . . . . . . 71

5.3 Discussion of Results and Uncertainty . . . . . . . . . . . . . . 73

5.3.1 Experimental Uncertainty Analysis . . . . . . . . . . . . . 74

5.3.2 Uncertainty Due to Heat Flux Measurement . . . . . . . . . . 75

5.3.3 Uncertainty Due to Thickness Measurement . . . . . . . . . 78

5.3.4 Uncertainty Due to Temperature Measurement . . . . . . . . . . 79

5.3.5 Uncertainty of Thermal Conductivity . . . . . . . . . . . 80

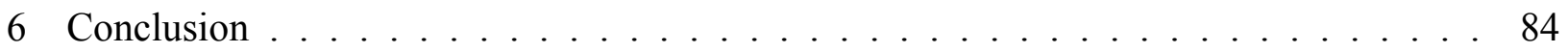

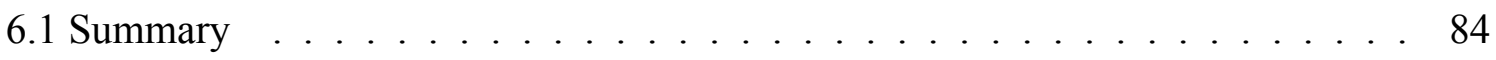

6.2 Future Work . . . . . . . . . . . . . . . . . . . . 85

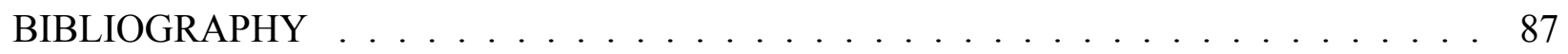

APPENDICES

A. Aspen Aerogels Safety Data Sheet (SDS) for Pyrogel XT-E . . . . . . . . . . 90

B. Pyrogel XT-E and Material Handling for Experimental Procedure $\ldots . . . .995$ 


\section{LIST OF TABLES}

Table

Page

1.1 Material Composition of Pyrogel XT-E Aerogel . . . . . . . . . . . . . 3

3.1 Finite Difference Method Boundary Conditions for Flat Plate Sample . . . . . . . . . 29

3.2 Material Properties for Flat Plate Models . . . . . . . . . . . . . . . . . . . 30

3.3 Analysis Settings for Flat Plate Model with 1mm-thick Pyrogel XT-E . . . . . . . . 30

3.4 Analysis Settings for Flat Plate Model with 2mm-thick Pyrogel XT-E . . . . . . . 30

3.5 Analysis Settings for Flat Plate Model with 3mm-thick Pyrogel XT-E . . . . . . . . . 30

3.6 Analysis Settings for Flat Plate Model with 5mm-thick Pyrogel XT-E . . . . . . . . . 31

3.7 Material Properties for Corrugated Carbon Fiber Sample . . . . . . . . . . . . . 33

3.8 Material and Thermal Properties of Comparison Insulation Types . . . . . . . . . . 35

4.1 Cure Cycle for Flat Carbon Fiber Plate . . . . . . . . . . . . . . . . . . . 45

4.2 Thermocouple Type Key for PID Controller . . . . . . . . . . . . . . . . . . 51

5.1 Steady-State Results of the Flat Plate Sample . . . . . . . . . . . . . . . . . 56

5.2 Time Step Sections for Transient Flat Plate Simulations . . . . . . . . . . . . . 56

5.3 Material and Thermal Properties of Insulation Types $\ldots \ldots$. . . . . . . . . . 65

5.4 Thermal Conductivity of Insulation Materials $\ldots \ldots \ldots$

5.5 Thermal Conductivity for Flat Plate Sandwich Structure . . . . . . . . . . . . . 70

5.6 Thermal Conductivity for Corrugated Carbon Fiber Sandwich Structure . . . . . . . 72

5.7 Thermal Conductivity Test Results with Pyrogel XT-E . . . . . . . . . . . . . . 74

5.8 Heat Flux Relative Uncertainty for Flat Plate Sandwich Structure . . . . . . . . . . . 77

5.9 Heat Flux Relative Uncertainty for Corrugated Carbon Fiber Sandwich Structure . . 77 
5.10 Sample Thickness Measurement Relative Uncertainty . . . . . . . . . . . . . 78

5.11 Change in Temperature Relative Uncertainty for Flat Plate Sandwich Structure . . . 80

5.12 Change in Temperature Relative Uncertainty for Corrugated Carbon Fiber Sandwich

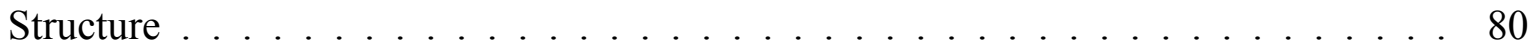

5.13 Relative Uncertainty of Thermal Conductivity for Flat Plate Sandwich Structure . . . 81

5.14 Relative Uncertainty of Thermal Conductivity for Corrugated Carbon Fiber Sandwich

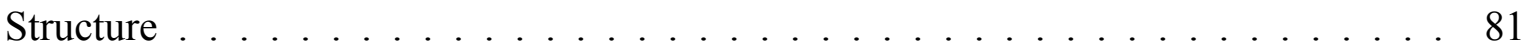




\section{LIST OF FIGURES}

Figure

Page

1.1 Thermal Conductivity vs. Temperature for Pyrogel XT-E Aerogel . . . . . . . . . . 3

2.1 Equivalent Thicknesses and Total Cost of Aerogel and Conventional Insulation . . . . 12

2.2 Equivalent Thicknesses and Total Cost of Aerogel and Conventional Insulation . . . . 13

2.3 General Arrangement of the Guarded Hot Plate Apparatus . . . . . . . . . . . . . 16

3.1 Thermal Resistance Diagram of the Flat Plate Sandwich Structure Sample . . . . . 19

3.2 Boundary Conditions of the Flat Plate Sample . . . . . . . . . . . . . . . . . . . 24

3.3 Nodal Control Volume Analysis . . . . . . . . . . . . . . . . . . . . 25

3.4 Boundary Condition Diagram of Corrugated Carbon Fiber Sample . . . . . . . . . . 32

3.5 Dimensions of the Corrugated Carbon Fiber Structure . . . . . . . . . . . . . . 33

3.6 Straight and Corrugated Computational Paths in the Corrugated Sample Model . . . . 34

4.1 Diagram of Test Setup . . . . . . . . . . . . . . . . 36

4.2 Diagram of Test Enclosure . . . . . . . . . . . . . . . . . 37

4.3 Sample Housing in Test Enclosure . . . . . . . . . . . . . . . . . . . . 38

4.4 FluxDAQ+ Data Acquisition Manufactured by FluxTeq . . . . . . . . . . . . . . . . 41

4.5 Temperature Control Feedback Circuit . . . . . . . . . . . . . . . . . . . 42

4.6 Feedback Control Loop of Temperature Control Circuit . . . . . . . . . . . . . . . . . 42

4.7 Corrugated Carbon Fiber Sandwich Structure with Pyrogel XT-E . . . . . . . . . . . 44

4.8 Plot of Cure Cycle for Flat Plate Carbon Fiber . . . . . . . . . . . . . . . . . . . 45

4.9 Diagram of PHFS-09e Heat Flux Sensor Application on Sample . . . . . . . . . . . 47

4.10 Diagram of Type-T Thermocouple Sensor Application on Sample . . . . . . . . . . . 48 
4.11 Temperature Control Interface $\ldots \ldots \ldots \ldots \ldots \ldots$

4.12 The Effect of Ramping in a Heating System . . . . . . . . . . . . . . 51

4.13 Experimental Test Setup . . . . . . . . . . . . . . . . . . . . 53

5.1 Temperature Along Length for $1 \mathrm{~mm}$ Pyrogel XT-E Flat Plate Sample . . . . . . . . . 57

5.2 Temperature Along Length for $2 \mathrm{~mm}$ Pyrogel XT-E Flat Plate Sample . . . . . . . . . 58

5.3 Temperature Along Length for 3mm Pyrogel XT-E Flat Plate Sample . . . . . . . . . 58

5.4 Temperature Along Length for 5mm Pyrogel XT-E Flat Plate Sample . . . . . . . . . 59

5.5 Steady State Results of Flat Plate Samples vs. Pyrogel XT-E Thickness . . . . . . . . 60

5.6 Straight Path Transient Analysis for Pyrogel XT-E Insulation . . . . . . . . . . . . 62

5.7 Straight Path vs. Corrugated Path Transient Analysis for Pyrogel XT-E Insulation at

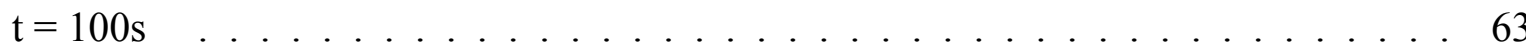

5.8 Thermal Bridging Effect of Corrugated Carbon Fiber Sample with Pyrogel XT-E

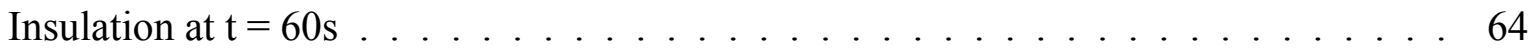

5.9 Flat Plate Sample with $5 \mathrm{~mm}$ Pyrogel XT-E Insulation at $\mathrm{t}=60 \mathrm{~s} \ldots \ldots \ldots \ldots$

5.10 Insulation Comparison for Corrugated Carbon Fiber Sample at $\mathrm{t}=20 \mathrm{~s} \ldots \ldots$

5.11 Insulation Comparison for Corrugated Carbon Fiber Sample at $\mathrm{t}=80 \mathrm{~s} \quad \ldots \ldots \ldots$

5.12 Insulation Comparison for Corrugated Carbon Fiber Sample at $\mathrm{t}=160 \mathrm{~s} \ldots \ldots \ldots \ldots$

5.13 Thermal Conductivity vs. Time for Flat Plate Sandwich Structure . . . . . . . . . 70

5.14 Thermal Conductivity vs. Time for Corrugated Carbon Fiber Sandwich Structure . . . 72

5.15 Average Relative Uncertainty Values for Flat Plate Sandwich Structure . . . . . . . 82

5.16 Average Relative Uncertainty Values for Corrugated Carbon Fiber Sandwich

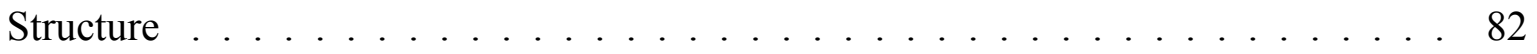




\section{CHAPTER 1}

Introduction

This thesis is a study of how aerogel insulation affects the thermal conductivity of metal and composite structures. Aerogel is a very lightweight material that has a low density and thermal conductivity, making it excellent for insulation applications. It is essentially a gel that has its liquid replaced by a gas. Aerogel can be made from many different materials, even rice husk ash; this type of aerogel would emit less of a carbon fiber footprint in the construction of a building. Designing and building structures that are more energy efficient, while not limiting the structural integrity, is a top priority for any architect. For a building or business owner, maximizing the effectiveness of insulation is the best way to decrease energy costs, and with the light weight and small effective volume of aerogel, will not add much weight to the building. Though using aerogel as insulation in the design of new structures appears to be a popular method, retrofitting aerogel insulation to current structures is more cost-effective in the short term. Overall, using aerogel insulation in structures will maximize interior space. In more extreme environments where high thermal and mechanical stresses are present, such as those experienced in the aerospace industry, the low density and excellent thermal properties of aerogel are highly sought out. Minimizing weight is crucial in spaceflight, as well as protecting spacecraft and cargo from intense forces and heat. Integrating aerogel into a corrugated carbon fiber structure can provide a composite structure that could lessen the impact of these intense forces experienced in spaceflight. Applying aerogel to structures with the goal of improving their resistance to thermal conductivity will help minimize power consumption and total cost. 


\subsection{Statement of Research}

The question first asked is: How does aerogel effect the thermal conductivity of structures, specifically carbon fiber? How "good" does the thermal insulative properties of the structure have to be, i.e. how much aerogel insulation is more than enough? What is the ideal amount of aerogel to significantly limit thermal conductivity of the structure while keeping geometry relatively unchanged? Despite the significant thermal performance of Pyrogel XT-E, there is concern that the materials making up the structure itself will cause thermal bridging and limit the thermal performance of the structure as a whole. This research will help answer these questions and concerns by performing thermal conductivity tests on metal and carbon fiber test samples with various layers of aerogel in between. These studies will give a better idea of how well aerogel regulates the conduction of heat in composite structures.

\subsection{General Approach}

The general approach to performing this research and answering this question is two-fold: to craft a model to understand and predict the thermal behavior of the samples and to perform thermal experiments to obtain thermal conductivity values for the samples. As mentioned in the previous section, the thermal conditions in the intended applications are not expected to reach steady state; however, approaching steady-state conditions in the experiment simplifies analysis and provides a control for a better understanding of the effects that aerogel has on the thermal performance of structures. 


\subsubsection{Pyrogel XT-E}

Pyrogel XT-E is a fiberglass-aerogel composite sheet insulation material manufactured by Aspen Aerogels. The thermal conductivity for the Pyrogel XT-E aerogel is dependent on temperature; a curve from the manufacturer can be seen in Figure 1.1, as well as a list of its composition in Table 1.1 [1]. Though dependent on temperature, the thermal conductivity does not differ by a significant amount in the modeled temperature ranges, so it is assumed to be constant when assigning material and thermal properties in the computer models.

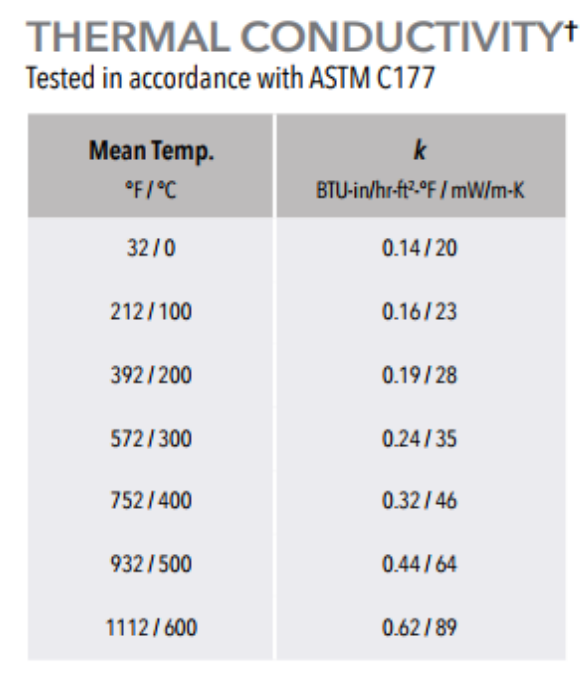

Thermal conductivity measured at a compressive load of $2 \mathrm{psi}$.

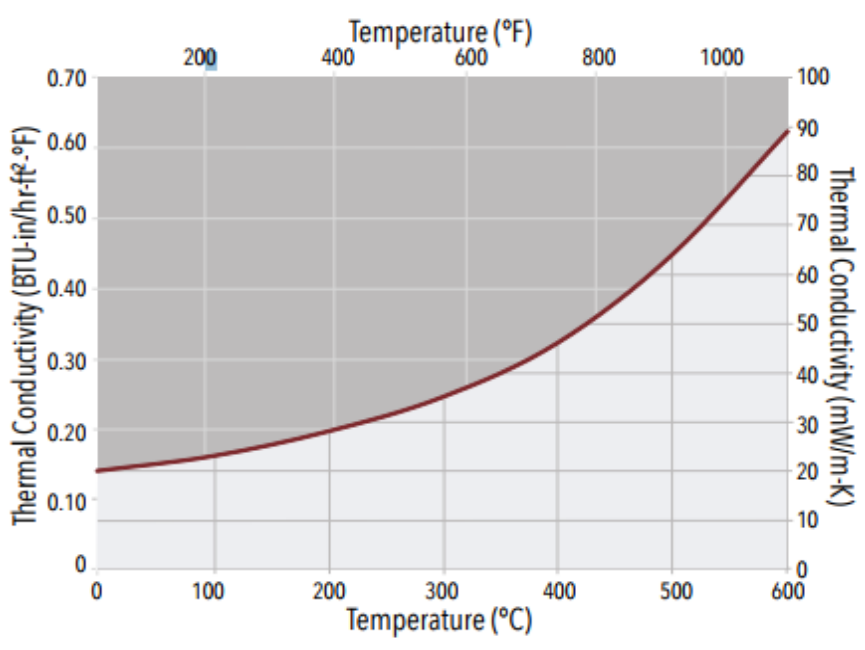

Figure 1.1 - Thermal Conductivity vs. Temperature for Pyrogel XT-E Aerogel [1].

Table 1.1 - Material Composition of Pyrogel XT-E Aerogel [2].

\begin{tabular}{|c|c|c|}
\hline Chemical Name & CAS No. & Percent \\
\hline Synthetic Amorphous Silica & $7631-86-9$ & $30-40 \%$ \\
\hline Methylsilylated Silica & $68909-20-6$ & $10-20 \%$ \\
\hline Fibrous Glass (textile grade) & Not Applicable & $40-50 \%$ \\
\hline Iron Oxide (iron (III) oxide) & $1309-37-1$ & $1-10 \%$ \\
\hline Aluminum Trihydrate (aluminum hydroxide) & $21645-51-2$ & $1-5 \%$ \\
\hline $\begin{array}{c}\text { Other components are either non-hazardous } \\
\text { ingredients or are below the concentration } \\
\text { limit for classification }\end{array}$ & Mixture & Balance \\
\hline
\end{tabular}


Pyrogel XT-E was chosen as the insulation to be studied for a combination of price, ease of use, and accessibility. Pure aerogel can be difficult to work with; having silica aerogel particles woven into a fiberglass sheet allows for simple experimental setup. Pyrogel XT-E was also easy to order in bulk and has necessary thermal and physical properties readily available, which simplified experimental analysis. An initial goal of this thesis was to study the thermal properties of aerogel manufactured from bio-waste (specifically that of rice-husk ash), but that is more difficult to maintain and manufacture working insulation samples from. Additionally, thermal and physical properties may need to be experimentally determined, adding extraneous elements to this thesis. Using Pyrogel XT-E enables a sufficient study of the effects of aerogel on composite structures while being aware that similar performing insulation can be made from bio-waste.

\subsubsection{Theoretical Model}

To begin theoretical analysis, hand calculations were performed on a control volume of the test sample. Energy balance equations was applied on the control volume to theoretically compute the thermal conductivity of the sample. Two different sample orientations were then constructed in ANSYS Workbench. The first model is a layer of Pyrogel XT-E sandwiched in between plates of 6061 Aluminum. This was used to study the effect of Pyrogel XT-E thickness on the thermal conductivity of the sample. The second model is a corrugated carbon fiber sandwich structure, which consists of a corrugated carbon fiber section sandwiched in between two sheets of carbon fiber. This model was run with Pyrogel XT-E filled in the air gaps, as well as multiple types of similar insulation to perform a comparison study. 


\subsubsection{Experimental Method}

The experimental approach consists of a test specimen in the sample housing that is surrounded by insulation on all sides except the back of the sample. This encourages all heat to travel through the sample to obtain accurate and stable results. The first cycle of testing validates the test setup by experimentally determining the thermal conductivity of one layer of Pyrogel XT-E, which is known. The second cycle tests a corrugated carbon fiber sandwich structure; tests were conducted with integration of Pyrogel XT-E in the corrugated air gaps. A flat plate heating element connected

to a temperature control circuit was applied to the front face of the test specimen, with a thermocouple in between the heating element and the front of the sample. A heat flux sensor with an integrated thermocouple was fixed to the back of the test specimen to measure the temperature gradient across it.

\subsubsection{Scope of Thesis}

Chapter 2 discusses previous work with aerogel insulation applications that is included in a literature review. This review covers topics such as the chemical makeup of aerogel and how it is typically made. It then details different manufacturing techniques and how aerogel can be given different characteristics depending on the intended application. General applications of aerogel are discussed, such as various thermal applications; these include residential and commercial building insulation, spacecraft and spacesuit insulation, and outdoor clothing insulation. The literature review concludes with a discussion about the industry ASTM standard for experimentally determining certain thermal properties. This section also highlights what aspects of the ASTM standard were used in the experiments conducted in this thesis. 
Chapter 3 discusses the various theoretical models. The chapter starts by discussing the theory behind the experiment with control volume analysis and hand calculations. It then discusses the construction of a computer model using Microsoft Excel and ANSYS Workbench for both steady state and transient analysis. Using the Microsoft Excel models, a study analyzing the transient heat transfer through the flat plate sample is discussed. The next section reviews the construction and study of the ANSYS Workbench models, which analyzes the corrugated carbon fiber sandwich structure samples.

Chapter 4 covers the entire experimental process, including materials used, test enclosure design, temperature control circuit construction, and experimental execution. The experimental setup lays out each component and its purpose, such as what parameter it measures and how it measures that parameter. Additionally, the type of tests performed and the goal of each test is discussed.

Chapter 5 includes a discussion of experimental results, comparing them to the theoretical models as well as mentioning the uncertainties in the experimental design. Towards the end of this chapter, a review of the computational and experimental design is covered, highlighting where they can be improved. The results of this experiment are compared with current literature, which is followed by a discussion of how the results can improve the understanding of aerogel's role in thermal insulation applications so that it can be used more in the future.

Chapter 6 summarizes the entire paper, discussing the key points and reviewing the results of the theoretical models and experimental data. Future work opportunities on the subject are mentioned, such as further in-depth analysis to be performed if more time was allowed. 


\section{CHAPTER 2}

Literature Review

This chapter will present an overview of literature related to the study of the thermal insulating performance aerogel has when integrated with metal and composite structures. It will extract relevant findings and apply them to the analysis of this study, covering topics ranging from how aerogel is made to aerogel design to current applications of aerogel.

\subsection{Aerogel Manufacturing Techniques}

Aerogels can be made of many different materials and can have certain materials added to them to customize their performance to an intended application. However, the main composition of aerogel is a nanoparticle structured network among a gaseous membrane, which is derived from a polymerization process [3]. The manufacturing process consists of three main steps: gelation from a solution to a gel, aging, and drying [4].

\subsubsection{Sol-gel Process}

The sol-gel synthesis is the most common way to produce aerogels. Its name describes what is happening during this process, which is the process of a solution forming into a gel by the addition of a catalyst. The medium in the solution helps to identify the type of gel to be produced; hydrogel, alcogel, and aerogel refer to gels based in water, alcohol, and air, respectively [4]. The gelation process begins with polymerization, which involves combining a few different monomers to form 
unlimited numbers of larger molecules, or polymers. These larger molecules contain repeating structural units of the original monomer molecules [5]. As the monomers begin to connect and form together, small numbers of oligomers (molecules made of limited numbers of monomers) will form. As the process develops, these oligomers will connect to each other in the solvent to form a 3D structure; this completes the polymerization process. At its core, this gel is formed from chemical reactions of hydrolysis and/or water/alcohol condensations [3].

\subsubsection{Aging}

To apply aerogels to different applications, various aging techniques are used. The main purpose of these techniques is to reinforce the aerogel structurally so that in can be used in higher stress applications [3]. Two phenomena can occur during aging, which are the neck growth of silica particles to the necks between particles due to reprecipitation, and small particles reprecipitating into larger ones [4]. Typically applied after gel formation and before drying, aging techniques use syneresis to modify the silica pores by changing the phase of liquid within them. To initiate an aging process, either water or alkoxysilanes are added to the gel in its mother solution, which encourages condensation and/or reprecipitation. This causes the pore size and density of the aerogel to increase, significantly strengthening the aerogel for structural applications [3].

\subsubsection{Drying}

The most critical part of manufacturing aerogel is the drying process, which involves the formation of a gel into a solid by extracting the liquid from the gel. Taking care to dry the gel properly is important because capillary stresses can form, which causes residual stresses at the interfaces between the liquid solvent and the silica nanoparticles. There are three common drying 
procedures; freeze-drying, evaporation, and supercritical drying. Freeze-drying almost always produces a brittle product not suitable for most applications. Drying through evaporation can result in over-dense aerogels; this is due to condensation of remaining reactive silica in the membrane. During condensation, capillary stresses will cause these particles to form together and decrease the space in between, shrinking the structure and increasing the density of the aerogel. The most common drying method for aerogels is supercritical drying, which aims to rid of capillary stresses. Due to the fact that smaller pore sizes significantly increase capillary stresses, supercritical drying is conducted above the critical temperature and pressure of the pore liquid, thus capillary stresses are basically eliminated [4]. This process is conducted at this temperature and pressure because there is no liquid-vapor interface [6]. The downside to supercritical drying is that it is a timeintensive process that is hard to replicate on a mass production level. To combat this, another drying method, ambient pressure drying (APD), is used. This method aims to reduce capillary stresses along the surface of the aerogel and strengthen the nanoparticle network by introducing Drying Control Chemical Additives (DCCA) to control the size and volume of the pores, as well as distribution [3]. There are two foundations for ambient pressure dried silica aerogels, alkoxysilane and waterglass based aerogels. APD restricts abnormal pore sizing and distribution, which can cause excess capillary stresses and lead to cracks along the surface [4].

\subsection{Aerogel Design}

The manufacturing process of aerogel can be edited to give it certain characteristics to suit its intended application. Being a customizable material allows it to be used across a wide range of applications. 


\subsubsection{Hydrophobic Aerogels}

A popular and impactful characteristic designed into aerogel is hydrophobicity. Due to its impressive thermal insulative performance, aerogel can experience large thermal gradients which can cause moisture buildup due to condensation. This is especially a problem with aerogels made from the common materials of tetramethoxysilane (TMOS) and tetraethoxysilane (TEOS) They can become hydrophilic, meaning that if used as structural insulation in a humid climate, the aerogel could deteriorate and severely limit the structural integrity of the building [3]. Hydrophobic aerogels are made to combat this phenomenon. During the sol-gel process, the inside of the pores are modified by introducing silylating agents to react with the water-free solvent, which prevents adsorption of water in the pores and ensures the aerogel will be hydrophobic [4]. Rao et al. used TMOS as a precursor and thrimethylcholorosilane (TMCS) as a silylating agent, and using the Ambient Pressure Method constructed silica aerogel with very low density and high monolithicity, meaning the nanoparticle structure is more continuous and unbroken [7]. Treating aerogels with this process is extremely beneficial for applications such as space flight and exploration, where the buildup of excess moisture and ice can severely affect the outcome of a mission and the lives involved [8].

\subsubsection{Raw and Organic Material}

Though aerogel exhibits superior insulative qualities than current options, such as fiberglass and other polyurethane-based foams, it is more expensive because of its newer presence in the market. An alternative to make aerogel cheaper to produce, and to lessen its effect on the environment, is to use organic waste material, such as rice husk ash. This organic waste contains between $92 \%$ 
and $97 \%$ amorphous silica, making it a legitimate alternative to common precursor materials, such as TEOS [9].

\subsection{General Applications of Aerogel}

As aerogel manufacturing and research techniques have improved over the last few decades, it has become more common in a wider range of applications. Because of its superior thermal characteristics, low density, and light weight, aerogel has become a leading material for thermal management, sound insulation, and general filter and absorption material. Various applications of aerogel will be covered below.

\subsubsection{Thermal Insulation Applications}

Due to its low thermal conductivity, aerogels are becoming a more common material for insulating buildings and various structures. As mentioned before, there are two main forms of silica aerogel, monolithic and granular. In thermal insulation applications, granular forms are more common because of the fragility of monolithic aerogel formations [10]. To use in this type of application, aerogels granules are woven into a fabric or filled into some sort of containing material. This is seen in Pyrogel XT-E, the aerogel-fiberglass composite used in the experiments performed in this thesis. Aerogels are then combined with other mechanically strong materials for structural reinforcement by interweaving within or sandwiching between them; this method is the primary focus of this thesis. Among the walls of a building, windows are difficult to insulate and exhibit a high amount of thermal energy loss. Depending on their manufacturing techniques, both monolithic and granular aerogels can be made transparent so that when sandwiched between two 
window panes, they improve visible light transmission and light diffusion [10]. This improves lighting in the building or structure, as well as reduces thermal energy losses.

Aerogel is an insulation solution that is ready to be applied and is being explored heavily by retrofitting current buildings. Shukla et al. conducted a cost analysis study to retrofit buildings with new insulation, to which they based their calculations off of a target estimated R-value [10]. In commercial housing, an insulation's thermal resistance is rated in the form of R-value, which is the measure of how well a material resists thermal conduction per unit area. The higher the Rvalue, the greater the thermal resistance of a material is. Conventional insulation was used in the study to compare results to aerogel blanket panels. Figure 2.1 shows a cost-analysis chart for a target R-value of $1.41 \mathrm{~m}^{2}-\mathrm{K} / \mathrm{W}$.

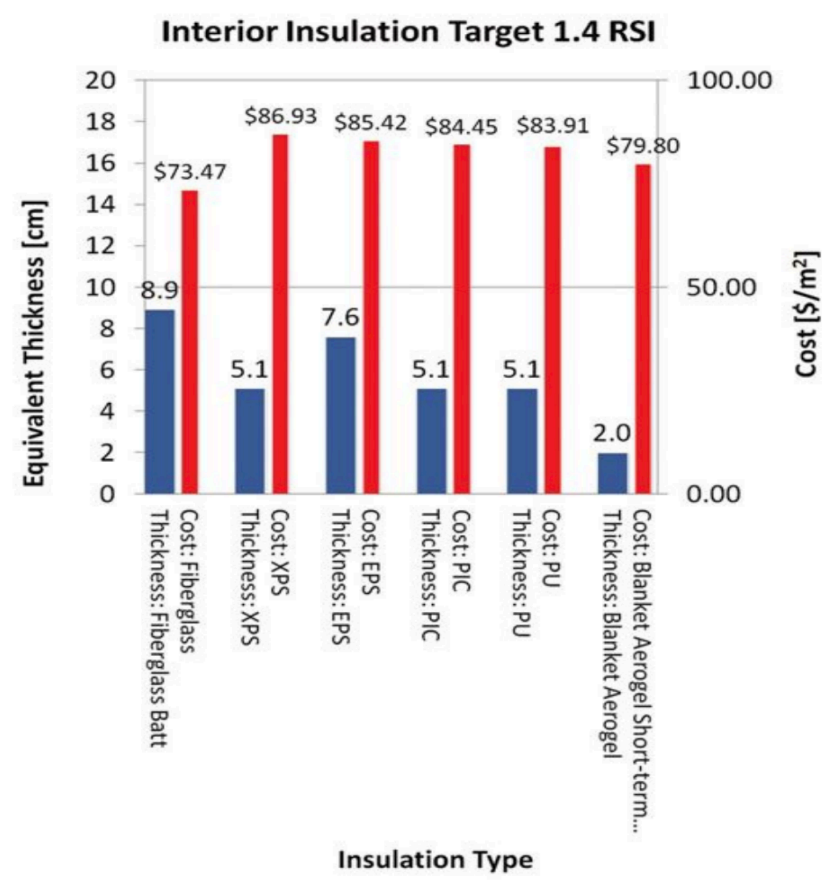

Figure 2.1 - Equivalent Thicknesses and Total Cost of Aerogel and Conventional Insulation. 
It can be seen from this figure that using aerogel for insulation compares well to other options, outperforming most, if only slightly. However, if the desired R-value is increased, using aerogel can become more expensive, as can be seen in Figure 2.2.

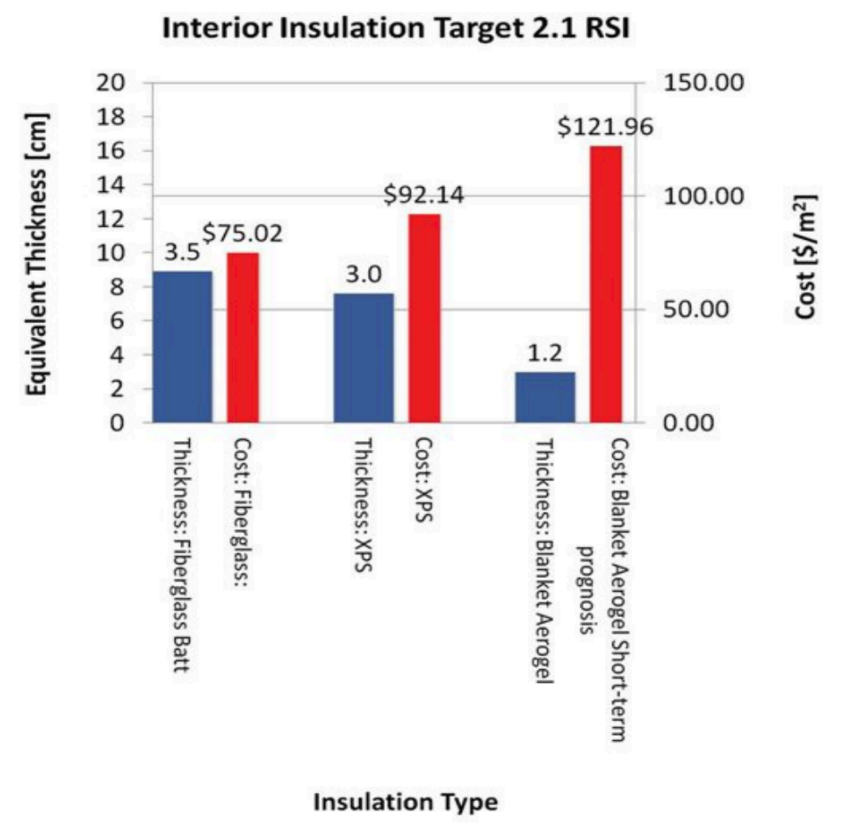

Figure 2.2 - Equivalent Thicknesses and Total Cost of Aerogel and Conventional Insulation.

Based on this study, it is concluded that using aerogel blanket panels is a cost-effective alternative to conventional insulation methods for R-values around $1.41 \mathrm{~m}^{2}-\mathrm{K} / \mathrm{W}$ and lower.

Cuce et al. conducted an experimental analysis of the thermal bridge effect on retrofitted aerogel insulation in a residential building. The heat flux and temperature at four different locations on the internal wall of a test bedroom without insulation and with $20 \mathrm{~mm}$ thick fiber-silica opaque aerogel blanket insulation was measured and validated with a computer model [11]. As can be expected, the aerogel blanket insulation improved thermal energy losses by $88.7 \%$ on average [11]. An interesting problem noted in this study is the effect of thermal bridges concentrated around 
wall junctions. Thermal bridges are the thermal equivalent of short circuits, meaning they are heat's path of least resistance. By installing aerogel panels in interior walls, the increased thermal gradient due to the thermal bridges could cause condensation, leading to bacterial mold growth and other condensation-based problems on the panels.

To combat moisture buildup in sandwiched insulation walls of internal structures, Fort et al. included a vapor tight insulation system within the sandwich structure to limit moisture buildup [12]. During seasons where the internal wall decreases drastically in temperature, temperatures below dew point can cause moisture buildup. Applying this layer to the test sample, along with hydrophobic treatment to the aerogel, improved the moisture resistance of the sandwich structure compared to other similar insulating materials, such as mineral wool. In their study, Fort et al. determined a water absorption coefficient of $0.015 \mathrm{~kg} / \mathrm{m}^{2} \mathrm{~s}^{1 / 2}$ for the aerogel blanket panels [12] while Jerman et al. determined a water absorption coefficient of $5.9 \mathrm{~kg} / \mathrm{m}^{2} \mathrm{~s}^{1 / 2}$ for their best mineral wool sample [13].

Aerogels provide other exciting thermal insulation applications outside of the building industry. NASA and other space programs have conducted research on using aerogel for many different applications including spacesuits and body panels for space aircraft. Fesmire et al. explored how aerogel could help insulate liquid-oxygen feedline bellows on the Space Shuttle External Tank. The advantages of using aerogel insulation would be to minimize ice buildup on the outside of the tank due to cryopumping, a phenomenon where ice and air buildup inside insulation material and limit the performance of spacecraft. The aerogel used in the experiment was hydrophobic and tightly packed, which minimized the effect of cryopumping due to its low thermal conductivity 
and small pore size. These small pore sizes limit the transfer of heat by conduction among the gas molecules, in turn preventing cryopumping in the feedline bellows [8].

Forms of aerogel have already made their way into consumer clothing, as PrimaLoft, a large insulation manufacturer for outdoor apparel, has developed an aerogel-based insulation for jackets, gloves, and boots. It is one of the first companies to provide aerogel-based apparel insulation to a mass market [14]. Implementing aerogel into high-performance apparel has been studied for some time, as NASA has spearheaded this research by studying the use of aerogel in astronaut space suits. Tang et. al. studied the mechanical and thermal performance of fiber-reinforced silica aerogel in a possible future spacesuit for space exploration [15]. A mechanical durability study was performed on five different fiber-reinforced silica aerogel composites (FSACF), which contained different types of aerogel, thicknesses, and additives. Flex testing was performed on the samples, which exhibited bending, shearing, and tension. All samples were relatively intact after 250,000 cycles, although various dusting, or breakdown of the silica aerogel matrix, was present in the samples. The highest-performing sample retained $80 \%$ of its insulation value after all completed test cycles, all samples remained below the $5 \mathrm{~mW} / \mathrm{m}-\mathrm{K}$ target in a $-30^{\circ} \mathrm{C}$ environment, even after 250,000 cycles [15]. Thermal testing involved using a guarded hot-plate, which follows ASTM Method C0177 [16]. It is interesting to note that testing at high vacuum pressures that are observed on the moon's atmosphere (10E-5 Torr), thermal conductivity values remained unchanged after 250,000 cycles, yet at Mars pressure ( 8 Torr), the highest performing sample experienced a $19 \%$ increase in thermal conductivity [15]. 


\subsection{Experimental Methods for Determining Thermal Properties}

As mentioned in the study performed by Tang et. al., the guarded hot-plate method was used, which is covered in ASTM Method C0177 [15] [16]. However, this method uses a test setup with a heat source in the middle and a specimen on either side. A cold plate is placed on the open face of both test specimens, creating a mirrored test setup, which can be seen in Figure 2.3.

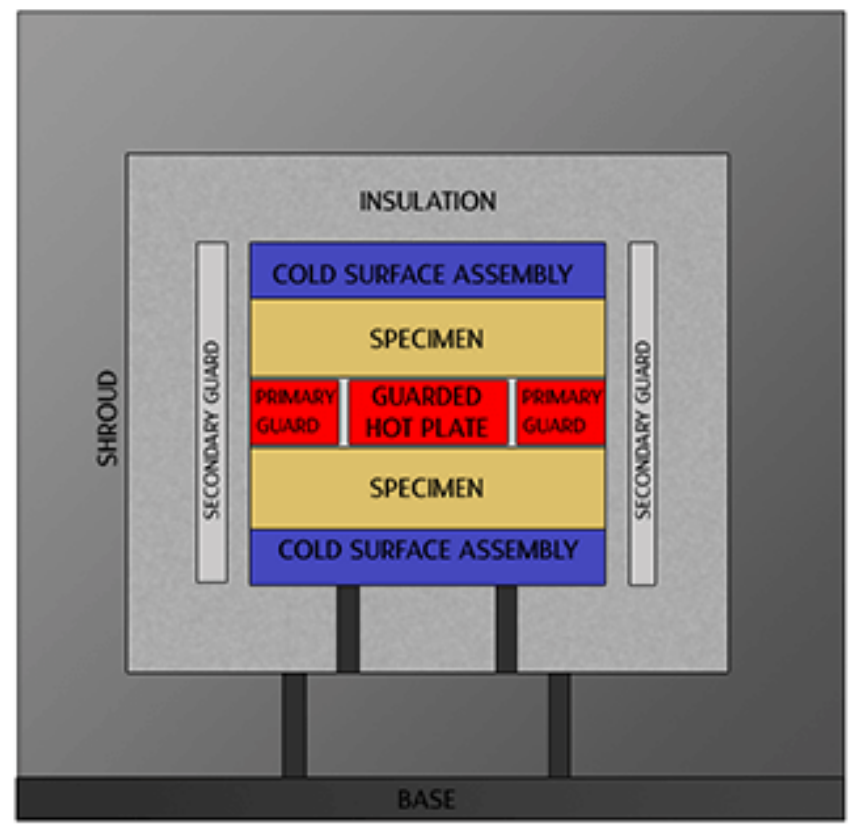

Figure 2.3 - General Arrangement of the Guarded Hot Plate Apparatus [17].

The Guarded Hot Plate method in single-sided mode was used as a rough guide for the tests conducted in this thesis; this is due to simplicity and resource availability. It is noted that guards were not used to prevent heat flow in the lateral direction due to availability; rigid-foam insulation was used instead. The single-sided method is outlined in ASTM Method C1044, which has a test setup almost identical to the one displayed Figure 2.3, but heats only one specimen instead of two [18]. 
The tests performed in this thesis roughly follow the methods highlighted in ASTM Method C1044 and $\mathrm{C} 0177$, but there are some differences. Instead of a cold plate for a heat sink, a jar of cool water was used. While similar, a flat plate silicone heating element was used instead of a guarded hot plate, as designing a test setup around a flat plate heating element with a temperature control circuit was less expensive and better suited for the size of the samples tested.

Sample preparation and test fixture setup for this thesis followed ASTM methods as close as time, resources, and ease of execution would allow. 


\title{
CHAPTER 3
}

\author{
Theoretical Model
}

Steady-state and transient simulations of the flat plate aluminum sample and the corrugated composite sample were modeled in Microsoft Excel and ANSYS Workbench. The purpose is to model experimental cases for comparison purposes as well as model additional cases outside of the bounds of the physical experiment, which will be discussed later.

\subsection{Thermal Resistance Analysis}

Thermal resistance analysis was performed on the flat sandwich structure of area $A$ to develop an expectation as to what the thermal conductivity of the flat plate sample would be. Since the thermal properties of the aerogel and aluminum are known $\left(k_{A l}\right.$ and $\left.k_{\text {aero }}\right)$, as well as the thicknesses of each

component ( $L_{A 1}$ and $L_{a e r o}$ ), this relatively simple calculation could be performed to provide a legitimate performance comparison to the computational model (see Equations 3.1-3.3). Through this process, the total, i.e. effective, thermal conductivity of the sample can be determined, which is the main focus of this thesis. This process was not conducted for the corrugated carbon fiber sandwich structure due to its more complex geometry. We begin with a thermal resistance diagram for each sample layer in Figure 3.1. 


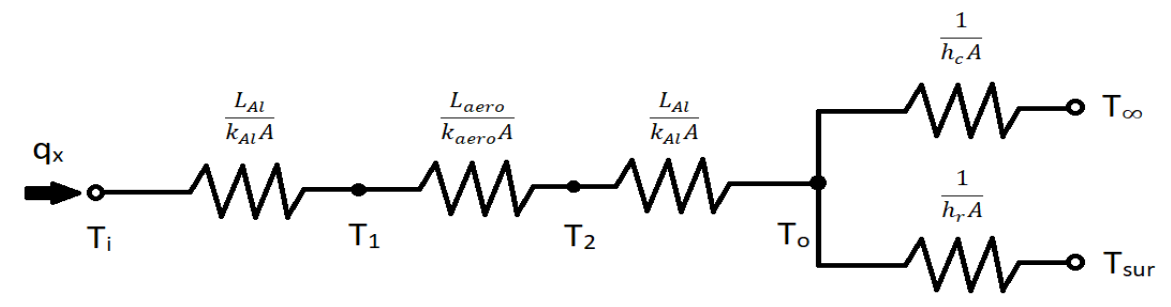

Figure 3.1 - Thermal Resistance Diagram of the Flat Plate Sandwich Structure Sample.

$T_{i}$ and $T_{o}$ are the temperatures at the front and back of the sample. $T_{1}$ and $T_{2}$ are the temperatures at the front and back of the aerogel insulation. The heat into the sample is $q_{x}$. The convective and radiative heat transfer coefficients of the surrounding air are represented as $h_{c}$ and $h_{r}$, respectively. $T_{\infty}$ and $T_{\text {sur }}$ are assumed to be equal and represent the temperature of the surrounding air.

The general equation for the thermal resistance for conduction, convection, and radiation are listed in Equations 3.1, 3.2 and 3.3. These equations can be applied to each section of the sample depending on the type of thermal resistance that section is experiencing.

$$
\begin{aligned}
& R_{\text {cond }}=\frac{L}{k A} \\
& R_{\text {conv }}=\frac{1}{h_{c} A} \\
& R_{\text {rad }}=\frac{1}{h_{r} A}
\end{aligned}
$$


The thermal resistances diagrammed in Figure 3.1 can be written in the relationship seen in Equation 3.4 for heat flux $q_{x}$, as the heat flux at steady state is constant throughout the structure.

$$
q_{x}^{\prime \prime}=\frac{T_{i}-T_{1}}{\frac{L_{A l}}{k_{A l}}}=\frac{T_{1}-T_{2}}{\frac{L_{\text {aero }}}{k_{\text {aero }}}}=\frac{T_{2}-T_{o}}{\frac{L_{A l}}{k_{A l}}}=\frac{T_{o}-T_{\infty}}{\frac{1}{1 / h_{c}}}=\frac{T_{o}-T_{\text {sur }}}{\frac{1}{1 / h_{r}}}
$$

Temperatures $T_{i}, T_{o}, T_{1}, T_{2}$ must be known to calculate temperature differences across sections of the sample. The length and thermal conductivity of each layer of the sample is known, so the effective thermal conductivity $k_{\text {eff }}$ of the sample can be calculated by hand. Equation 3.4 is rearranged to form Equation 3.5 for an expression of the effective thermal conductivity of the sample.

$$
k_{\text {eff }}=k_{\text {aero }} \frac{L_{\text {tot }}}{L_{\text {aero }}}\left(\frac{T_{1}-T_{2}}{T_{i}-T_{o}}\right)
$$

\subsubsection{Heat Diffusion Equation Derivation}

We begin with an energy balance of the control volume in Equation 3.6.

$$
\dot{E}_{\text {in }}+\dot{E}_{g}-\dot{E}_{\text {out }}=\dot{E}_{\text {st }}
$$

The heat diffusion equation in Equation 3.7 is derived from Equation 3.6 and applied toward the control volume.

$$
\left(q_{x}+q_{y}+q_{z}\right)+q-\left(q_{x+d x}+q_{y+d y}+q_{z+d z}\right)=\rho c_{p} \frac{\partial T}{\partial t}
$$

Fourier's Law in Equation 3.8 is applied to the energy balance, Equation 3.6, for the energy in and energy out term. 


$$
q^{\prime \prime}=-k \nabla T
$$

The full heat diffusion equation for the control volume can be seen in Equation 3.9.

$$
\frac{\partial}{\partial x}\left(k \frac{\partial T}{\partial x}\right)+\frac{\partial}{\partial y}\left(k \frac{\partial T}{\partial y}\right)+\frac{\partial}{\partial z}\left(k \frac{\partial T}{\partial z}\right)+\dot{q}=\rho c_{p} \frac{\partial T}{\partial t}
$$

Equation 3.10 simplifies Equation 3.9 for 1-D conduction and constant thermal conductivity $k$ with steady-state conditions.

$$
\frac{\partial^{2} T}{\partial^{2} x}+\frac{\dot{q}}{k}=0
$$

There is no energy generated within the sample or control volume, so Equation 3.10 reduces to this final form in Equation 3.11 to model the thermal gradient.

$$
\frac{\partial^{2} T}{\partial^{2} x}=0
$$

Under these conditions, the heat flux is constant in the direction of heat transfer, which is in the $\mathrm{x}$ direction for the assumption of 1-D flow. Integrating Equation 3.11 twice results in the following linear relationship in Equation 3.12 for the temperature along the length of each section of the sample.

$$
T(x)=C_{1} x+C_{2}
$$


The data from the thermocouples will give two boundary conditions, the temperature at the front face of each section of the sample and the temperature at the back face of each section of the sample. The two constants in Equation 3.12 can be solved using the two boundary conditions in Equations $3.13 \mathrm{a}$ and $3.13 \mathrm{~b}$ to give a true temperature distribution equation for each respective section of the sample.

$$
\begin{gathered}
T(x=0)=T_{i}=C_{2} \\
T(x=L)=T_{o}=C_{1} L+T_{i}
\end{gathered}
$$

Solving these two equations will result in values for the two constants $C_{l}$ and $C_{2}$. Plugging them into Equation 3.12 gives the following linear temperature distribution equation in Equation 3.14.

$$
T(x)=\left(\frac{T_{o}-T_{i}}{L}\right) x+T_{i}
$$

Though the thermal conductivity can easily be calculated by hand for the flat plate sample, it will be essential to experimentally determine the value so that the contact resistance and the effectiveness of the experimental setup can be studied. When comparing the theoretical thermal conductivity to the experimentally determined value, any differences between the two will likely be attributed to error, specifically contact resistance between the various layers of material in the sample. Studying transient finite difference models created in Microsoft Excel will provide insight as to what thickness of aerogel insulation performs best. 


\subsection{Flat Plate Sandwich Structure Sample}

To develop an understanding as to how heat flows through structures implemented with Pyrogel XT-E aerogel, a flat plate sample will be studied where the thickness of Pyrogel XT-E will be varied.

The aluminum flat plate structure will consist of two plates of aluminum with a layer of Pyrogel XT-E aerogel sandwiched in between. The 6061-T6 aluminum plates are modeled as 0.125" $(3.175 \mathrm{~mm})$ thick. Simulations will be run with aerogel insulation thicknesses of $1 \mathrm{~mm}, 2 \mathrm{~mm}, 3 \mathrm{~mm}$, and $5 \mathrm{~mm}$. Although the minimum thickness of the Pyrogel XT-E aerogel is $5 \mathrm{~mm}$, it may be possible that that the sample will have sufficient thermal resistance at an insulation thickness less than $5 \mathrm{~mm}$.

The location of each boundary condition can be seen in the Figure 3.2. There will be an applied temperature of $120^{\circ} \mathrm{C}$ on the front of the sample. The back of the sample will have both convective and radiative boundary conditions. The convective heat transfer coefficient is modeled as 3.51 $\mathrm{W} / \mathrm{m}^{2}-\mathrm{K}$ at an ambient temperature of $25^{\circ} \mathrm{C}$; this was chosen based on two sources. The free convection conditions from Table 1.1 in Introduction to Heat Transfer, $6^{\text {th }}$ Edition provided an estimate as to what the convection coefficient value would be, which was between 2 and $25 \mathrm{~W} / \mathrm{m}^{2}$ $\mathrm{K}$ [19]. With that range in mind, the experimental data from the flat plate structure was used to calculate the convective heat transfer coefficient using Newton's Law of Cooling, where $T$ is the temperature on the back surface of the sample.

$$
q^{\prime \prime}=h_{c}\left(T_{\infty}-T\right)
$$


While performing a convective coefficient analysis for the models would likely have provided a more accurate representation of the heat transfer in the sample, using the experimental data provided sufficient. When comparing the theoretical to the experimental results, this source of error will be noted and left as an assumption in the modeling.

The emissivity for aluminum is modeled as 0.1 at a bulk temperature of $25^{\circ} \mathrm{C}$, which was chosen based on the ambient temperature and literature from Omega Engineering [20]. To minimize the amount of computational power needed to run the computer simulations, symmetrical conditions about two axes was taken advantage of by taking a quarter of the entire sample. Due to this, the faces that border the smaller section to be analyzed are modeled as perfectly insulated.

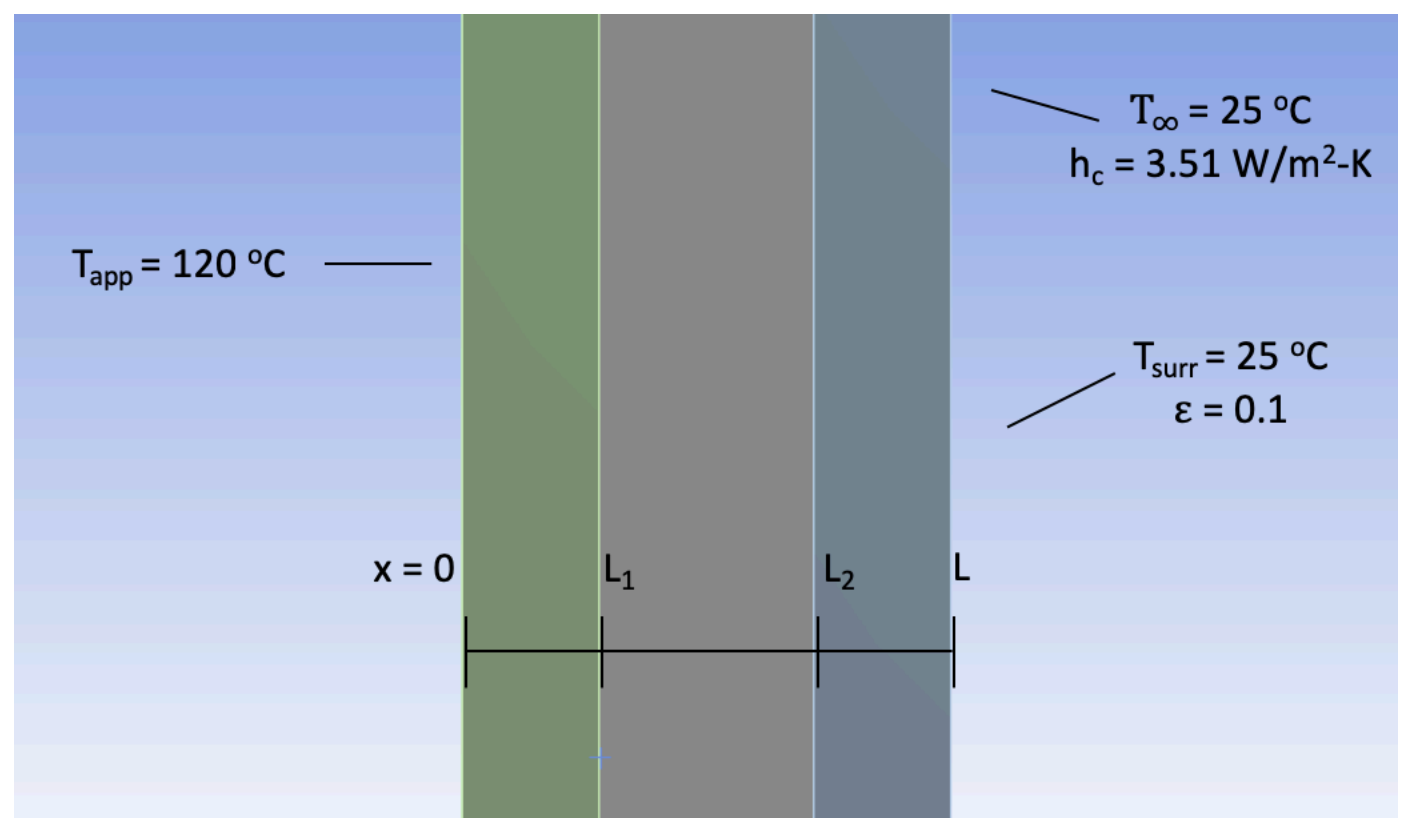

Figure 3.2 - Boundary Conditions of the Flat Plate Sample. 
The goal of designing the thermal models and performing the experiments is to minimize the losses at the outer edges of the sample, as it is difficult to model these heat losses exactly. The differences in temperature and thermal conductivity measurements between the experimental and theoretical data will likely be attributed to these losses, as well as error due to contact resistance.

A steady-state simulation was performed in ANSYS Workbench on all flat plate samples. The results are useful when analyzing the heat flow through each of the samples over time. To save on computational time, and based on the applied boundary conditions, 1-D heat transfer through the sample thickness was assumed for the flat plate transient models. Therefore, the transient models for the flat plate sample were computed in Microsoft Excel using the explicit form of the finite difference method. Equations were derived using the control volume approach around nodes at each respective boundary. Figure 3.3 depicts this nodal control volume approach.

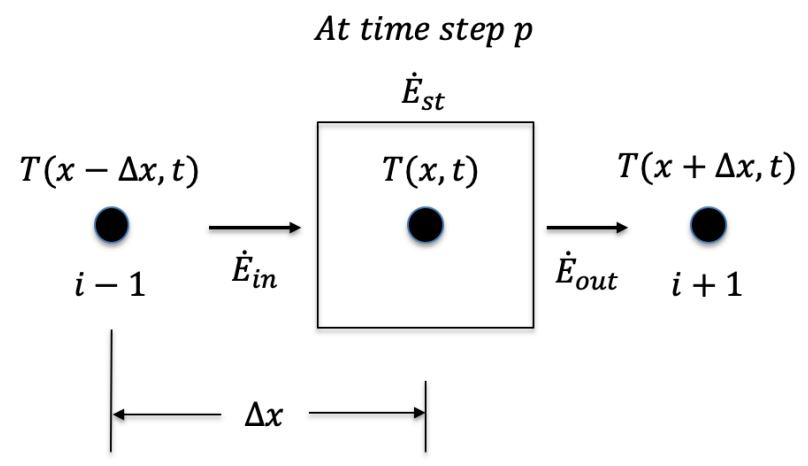

Figure 3.3 - Nodal Control Volume Analysis.

The equation for nodes along the boundary condition at $\mathrm{x}=0$, i.e. the face of the applied temperature, is the boundary condition in Equation 3.16. 


$$
T(0, t)=120^{\circ} \mathrm{C}
$$

The initial condition for the initial temperature in the sample is based off of the assigned ambient temperature in Equation 3.17.

$$
T(x, 0)=25^{\circ} \mathrm{C}
$$

The finite difference equations were split into three groups, one for each layer of the flat plate sample. For the front plate of aluminum, the equation for nodes at the first boundary $(x=0)$ can be seen in Equation 3.15. The temperature for the interior nodes are represented by Equation 3.18, which is the explicit form of the finite difference method. The explicit form takes advantage of a prescribed initial condition; it allows computation of the temperature at the next time step using the temperatures at the current time step for a certain location. The equations are simply "marching forward" in time.

$$
T_{i}^{p+1}=(1-2 F o) * T_{i}^{p}+F o *\left(T_{i-1}^{p}+T_{i+1}^{p}\right)
$$

The $T_{i}^{p+1}$ represents the temperature at the current x-location $(i)$ at the next time step $(p+1)$. The Fourier number is the dimensionless time step and is defined by Equation 3.19, which contains a grouped material constant term in Equation 3.20.

$$
F o=\frac{\alpha \Delta t}{\Delta x^{2}}
$$

Where

$$
\alpha=\frac{k}{\rho c_{p}}
$$


The temperature for the nodes at the second boundary, which is the boundary between the front aluminum plate and the Pyrogel XT-E aerogel $\left(\mathrm{x}=\mathrm{L}_{1}\right)$, is represented by the following boundary condition in Equation 3.21.

$$
\frac{d}{d x} T\left(L_{1}, t\right)=0
$$

This relationship is true because the nodes along the boundary at $\mathrm{x}=\mathrm{L}_{1}$ are shared by the front aluminum plate section and the middle Pyrogel XT-E aerogel section. The temperature between these two samples cannot change at this location because two different temperatures cannot be defined at the same node instantaneously. This boundary condition leads to Equation 3.22, the temperatures at the boundary of $\mathrm{x}=\mathrm{L}_{1}$.

$$
T_{L_{1}}^{p+1}=\left(1-2 F_{O}\right) * T_{L_{1}}^{p}+2 F_{o} * T_{L_{1}-1}^{p}
$$

The equation for nodes on the second boundary $\left(\mathrm{x}=\mathrm{L}_{1}\right)$, which is in the second section (the middle layer of Pyrogel XT-E), can be seen above in Equation 3.22. The temperature at the interior nodes is represented by the general explicit finite difference equation, Equation 3.18. The temperature for the nodes at the third boundary, which is the boundary between the Pyrogel XT-E aerogel and the back aluminum plate $\left(x=L_{2}\right)$ is represented by the boundary condition in Equation 3.23.

$$
\frac{d}{d x} T\left(L_{2}, t\right)=0
$$


This relationship is true for the same reason the boundary condition at $\mathrm{x}=\mathrm{L}_{1}$, Equation 3.21 , is true. This boundary condition leads to Equation 3.24, the temperatures at the boundary of $x=\mathrm{L}_{2}$.

$$
T_{L_{2}}^{p+1}=(1-2 F o) * T_{L_{2}}^{p}+2 F o * T_{L_{2}-1}^{p}
$$

The equation for nodes on the third boundary $\left(\mathrm{x}=\mathrm{L}_{2}\right)$, which is in the third section (the back plate of aluminum), can be seen above in Equation 3.24. The temperature at the interior nodes is represented by the general explicit finite difference equation, Equation 3.18. The temperature for the nodes at the fourth boundary, which is the boundary between the back aluminum plate and the ambient $(x=L)$, is represented by the following energy balance boundary condition, Equation 3.25. This boundary experiences conduction, convection, and radiation.

$$
\rho c_{p} \frac{\partial T}{\partial t}=k \frac{\partial T}{\partial x}+h\left(T_{\infty}-T_{L}^{p}\right)+\varepsilon \sigma\left(\left(T_{L}^{p}\right)^{4}-T_{\text {sur }}^{4}\right)
$$

Where $\varepsilon$ and $\sigma$ are the emissivity of aluminum and Stefan-Boltzmann constant, respectively. $\mathrm{T}_{\text {sur }}$ is the temperature of the surroundings, which in this model is assumed equal to $T_{\infty}$. This boundary condition leads to Equation 3.26, the temperatures at the boundary of $\mathrm{x}=\mathrm{L}$.

$$
T_{L}^{p+1}=T_{L}^{p}+F o *\left[T_{L-1}^{p}-T_{L}^{p}+B i *\left(T_{\infty}-T_{L}^{p}\right)+\frac{\varepsilon \sigma \Delta x}{k}\left(\left(T_{L}^{p}\right)^{4}-T_{\text {sur }}^{4}\right)\right]
$$

The Biot number, which is a ratio that compares the effect, or influence, of conductive and convective heat transfer, is defined in Equation 3.27. 


$$
B i=\frac{h \Delta x}{\mathrm{k}}
$$

Selecting a proper Fourier number will ensure stability and convergence for the solution to the transient model. The criteria for selecting a stable Fourier number is represented in the following relationship in Equation 3.28, which is true for 1-D heat transfer. This relationship is derived from the interior node equation in Equation 3.17.

$$
(1-2 F o) \geq 0
$$

The prescribed boundary condition equations in Equations 3.16, 3.17, 3.21, 3.23, and 3.25 can be seen in Table 3.1 for their respective boundary conditions.

Table 3.1 - Finite Difference Method Boundary Conditions for Flat Plate Sample.

\begin{tabular}{|c|c|}
\hline Boundary & Boundary Condition \\
\hline $\mathrm{t}=0 \mathrm{~s}$ & $\mathrm{~T}(\mathrm{x}, 0)=25^{\circ} \mathrm{C}$ \\
\hline $\mathrm{x}=0$ & $\mathrm{~T}(0, \mathrm{t})=120^{\circ} \mathrm{C}$ \\
\hline $\mathrm{x}=\mathrm{L}_{1}$ & $\frac{\mathrm{d}}{\mathrm{dx}} \mathrm{T}\left(\mathrm{L}_{1}, \mathrm{t}\right)=0$ \\
\hline $\mathrm{x}=\mathrm{L}_{2}$ & $\frac{\mathrm{d}}{\mathrm{dx}} \mathrm{T}\left(\mathrm{L}_{2}, \mathrm{t}\right)=0$ \\
\hline $\mathrm{x}=\mathrm{L}$ & $\rho \mathrm{c}_{\mathrm{p}} \frac{\partial \mathrm{T}}{\partial \mathrm{t}}=\mathrm{k} \frac{\partial \mathrm{T}}{\partial \mathrm{x}}+\mathrm{h}\left(\mathrm{T}_{\infty}-\mathrm{T}_{\mathrm{L}}^{\mathrm{p}}\right)+\varepsilon \sigma\left(\left(\mathrm{T}_{\mathrm{L}}^{\mathrm{p}}\right)^{4}-\mathrm{T}_{\text {sur }}^{4}\right)$ \\
\hline
\end{tabular}


The temperatures for the boundaries $\mathrm{x}=\mathrm{L}_{1}$ and $\mathrm{x}=\mathrm{L}_{2}$ are at nodes shared between two different material sections of the flat plate sample. To develop a relationship at these nodes, it is noted that two different temperatures cannot be defined at the same node location instantaneously. Therefore, this differential relationship is true. The boundary condition at the exposed face of the sample, at $\mathrm{x}=\mathrm{L}$, includes conduction, convection, and radiation. The material properties and analysis settings for the models can be seen in Table 3.2 and Tables 3.3 through 3.6.

Table 3.2 - Material Properties for Flat Plate Models.

\begin{tabular}{|c|c|c|c|c|}
\hline & $\mathrm{k}(\mathrm{W} / \mathrm{m}-\mathrm{K})$ & $\mathrm{c}_{\mathrm{p}}(\mathrm{J} / \mathrm{kg}-\mathrm{K})$ & $\rho\left(\mathrm{kg} / \mathrm{m}^{3}\right)$ & $\varepsilon$ \\
\hline Aluminum 6061-T6 & 167 & 896 & 2700 & 0.1 \\
\hline Pyrogel XT-E (Aerogel) & 0.022 & 840 & 200 & - \\
\hline
\end{tabular}

Table 3.3 - Analysis Settings for Flat Plate Model with 1mm-thick Pyrogel XT-E.

\begin{tabular}{|c|c|c|c|c|c|}
\hline & $\mathrm{t}(\mathrm{mm})$ & $\mathrm{n}$ (\# of nodes) & $\mathrm{dx}(\mathrm{mm})$ & Fo & $\mathrm{Bi}$ \\
\hline Front (Aluminum) & 3.175 & 25 & 0.127 & 0.428 & - \\
\hline Middle (Pyrogel XT-E) & 1 & 75 & 0.013 & 0.074 & - \\
\hline Back (Aluminum) & 3.175 & 25 & 0.127 & 0.428 & $7.60 \mathrm{E}-06$ \\
\hline
\end{tabular}

Table 3.4 - Analysis Settings for Flat Plate Model with 2mm-thick Pyrogel XT-E.

\begin{tabular}{|c|c|c|c|c|c|}
\hline & $\mathrm{t}(\mathrm{mm})$ & $\mathrm{n}$ (\# of nodes) & $\mathrm{dx}(\mathrm{mm})$ & Fo & $\mathrm{Bi}$ \\
\hline Front (Aluminum) & 3.175 & 25 & 0.127 & 0.428 & - \\
\hline Middle (Pyrogel XT-E) & 2 & 75 & 0.0267 & 0.018 & - \\
\hline Back (Aluminum) & 3.175 & 25 & 0.127 & 0.428 & $7.60 \mathrm{E}-06$ \\
\hline
\end{tabular}

Table 3.5 - Analysis Settings for Flat Plate Model with 3mm-thick Pyrogel XT-E.

\begin{tabular}{|c|c|c|c|c|c|}
\hline & $\mathrm{t}(\mathrm{mm})$ & $\mathrm{n}$ (\# of nodes) & $\mathrm{dx}(\mathrm{mm})$ & Fo & $\mathrm{Bi}$ \\
\hline Front (Aluminum) & 3.175 & 25 & 0.127 & 0.428 & - \\
\hline Middle (Pyrogel XT-E) & 3 & 75 & 0.04 & 0.008 & - \\
\hline Back (Aluminum) & 3.175 & 25 & 0.127 & 0.428 & $7.60 \mathrm{E}-06$ \\
\hline
\end{tabular}


Table 3.6 - Analysis Settings for Flat Plate Model with 5mm-thick Pyrogel XT-E.

\begin{tabular}{|c|c|c|c|c|c|}
\hline & $\mathrm{t}(\mathrm{mm})$ & $\mathrm{n}$ (\# of nodes) & $\mathrm{dx}(\mathrm{mm})$ & Fo & Bi \\
\hline Front (Aluminum) & 3.175 & 25 & 0.127 & 0.428 & - \\
\hline Middle (Pyrogel XT-E) & 5 & 75 & 0.067 & 0.003 & - \\
\hline Back (Aluminum) & 3.175 & 25 & 0.127 & 0.428 & $7.60 \mathrm{E}-06$ \\
\hline
\end{tabular}

\subsection{Corrugated Composite Sandwich Structure Sample}

This sample consists of a corrugated carbon fiber composite section sandwiched between two carbon fiber flat plate sections. In the experimental tests, strips cut from the sheets of Pyrogel XTE are placed in the air gaps created by the corrugated section. It would be unavoidable to completely rid of small pockets of air between strips of aerogel; however, modeling the smallscale heat transfer inside the air gaps is outside the scope of this thesis. Convection would be observed between the aerogel and the small pockets of air, and radiation would be observed between the tightly-packed strips of aerogel. To simplify the model, the aerogel insulation in the air gaps of the corrugated sample were modeled as a solid. After discussing the Pyrogel XT-E insulated model, other insulation types will be analyzed and compared to Pyrogel XT-E.

There is an applied temperature of $120^{\circ} \mathrm{C}$ on the front of the sample. The back of the sample has both convective and radiative boundary conditions. The convective heat transfer coefficient is modeled as $3.08 \mathrm{~W} / \mathrm{m}^{2}-\mathrm{K}$ at an ambient temperature of $25^{\circ} \mathrm{C}$; this was chosen based on two sources. The free convection conditions from Table 1.1 in Introduction to Heat Transfer, $6^{\text {th }}$ Edition provided an estimate as to what the convection coefficient value would be, which was between 2 and $25 \mathrm{~W} / \mathrm{m}^{2}-\mathrm{K}[19]$. With that range in mind, the experimental data from the corrugated composite sandwich structure was used to calculate the convective heat transfer coefficient using Newton's Law of Cooling, which can be seen in Equation 15. While performing 
a convective coefficient analysis for the models would likely have provided a more accurate representation of the heat transfer in the sample, using the experimental data provided sufficient. When comparing the theoretical to the experimental results, this source of error will be noted and left as an assumption in the modeling. The emissivity for carbon fiber is modeled as 0.85 at a bulk temperature of $25^{\circ} \mathrm{C}$, which was chosen based on the ambient temperature and Table 2 data from Hubbard, et. al. [21]. To minimize the amount of computational power needed to run the computer simulations, symmetry was taken advantage of by taking a slice of the entire sample and only analyzing one piece of the corrugation. Due to this, the faces exposed due to the slice were modeled as perfectly insulated. This can be seen in Figure 3.4.

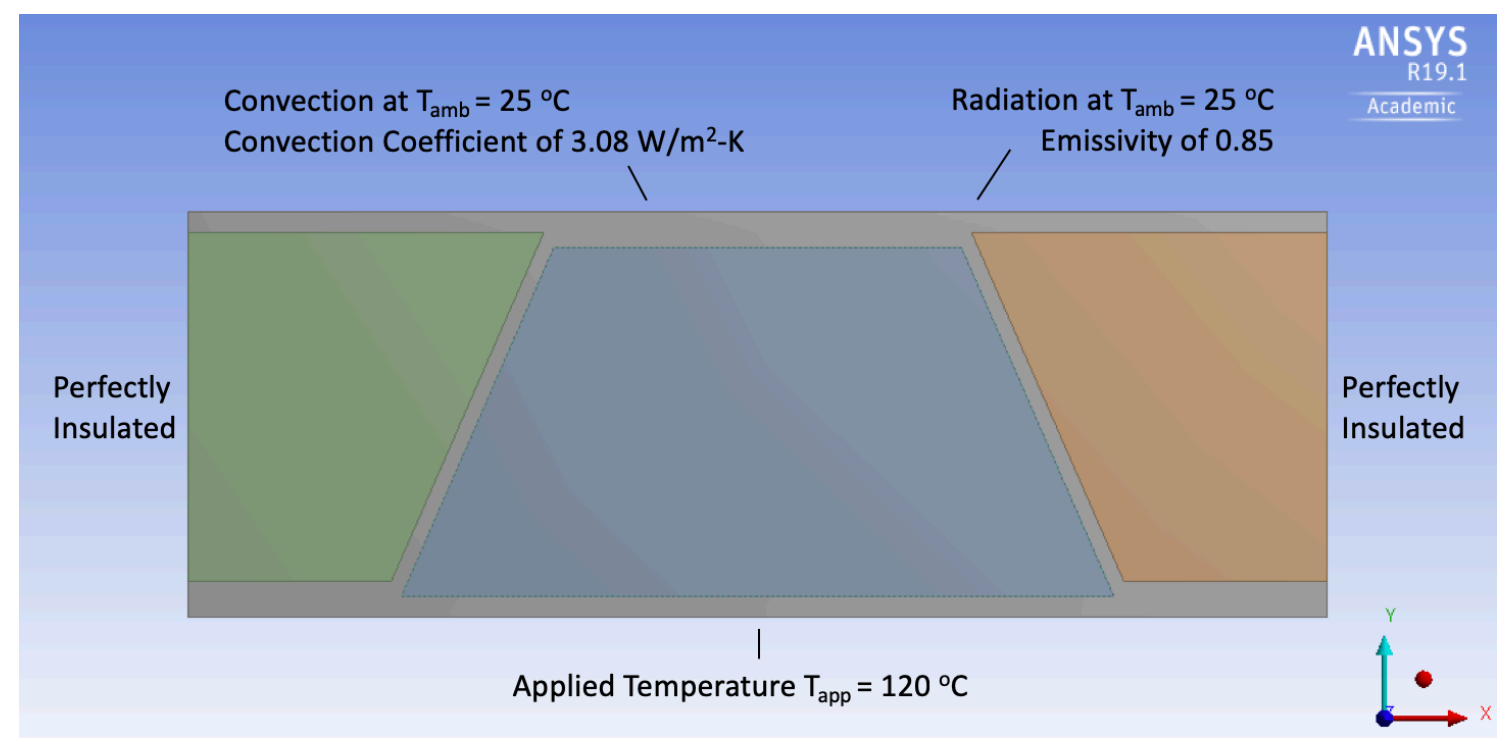

Figure 3.4 - Boundary Condition Diagram of Corrugated Carbon Fiber Sample.

The dimensions of the corrugated carbon fiber sandwich structure can be seen in Figure 3.5. 


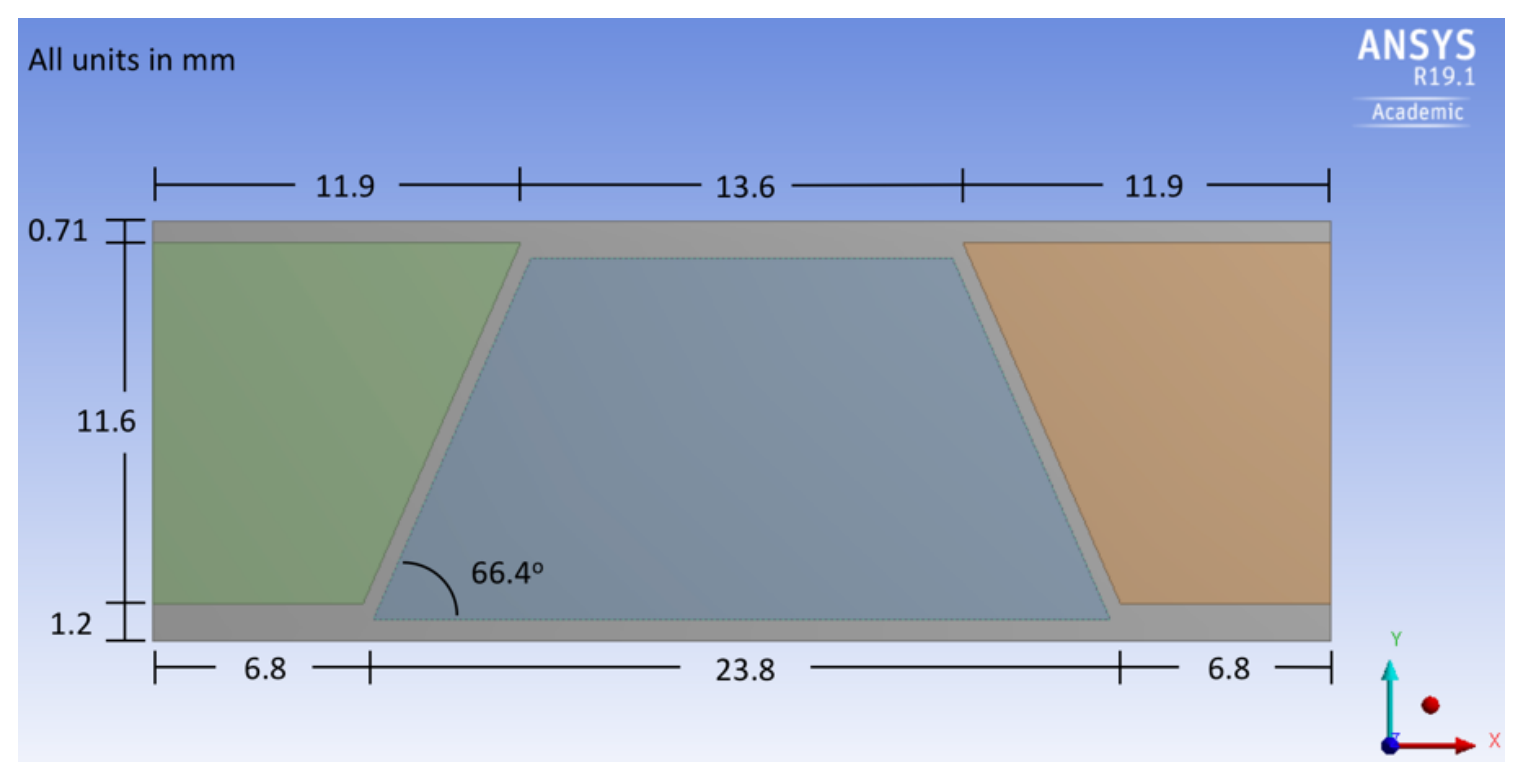

Figure 3.5 - Dimensions of the Corrugated Carbon Fiber Structure.

Analysis settings for the corrugated model can be seen in Table 3.7.

Table 3.7 - Material Properties for Corrugated Carbon Fiber Sample.

\begin{tabular}{|c|c|c|c|c|}
\hline & $\mathrm{k}(\mathrm{W} / \mathrm{m}-\mathrm{K})$ & $\mathrm{c}_{\mathrm{p}}(\mathrm{J} / \mathrm{kg}-\mathrm{K})$ & $\rho\left(\mathrm{kg} / \mathrm{m}^{3}\right)$ & $\varepsilon$ \\
\hline Carbon Fiber & 0.61 & 1000 & 1400 & 0.85 \\
\hline Pyrogel XT-E (Aerogel) & 0.024 & 840 & 200 & - \\
\hline
\end{tabular}

Thermal properties for carbon fiber vary greatly depending on a multitude of characteristics, such as the fiber and matrix material, fiber orientation, number of plies, weight and volume fraction, etc. The material constant values above were obtained from literature and were assumed to be constant based on observed temperature ranges [1] [19] [21].

For each sample, temperatures were taken from two different paths on the sample: through the middle of the corrugated section and along the carbon fiber in the corrugated section. The purpose 
of this is to obtain an understanding of the heat transfer through the part of the sample consisting primarily of the insulation and through the path of carbon fiber corrugation. The latter path is interesting because the thermal properties of the different types of insulation will influence the conduction of heat through the corrugated carbon fiber section. Note that on the plot for the corrugated path, the $\mathrm{x}$-axis displays the thickness location through the sample and not the location moving laterally along the width of the sample. Figure 3.6 displays the two computational paths used in the ANSYS Workbench model of the corrugated sample.

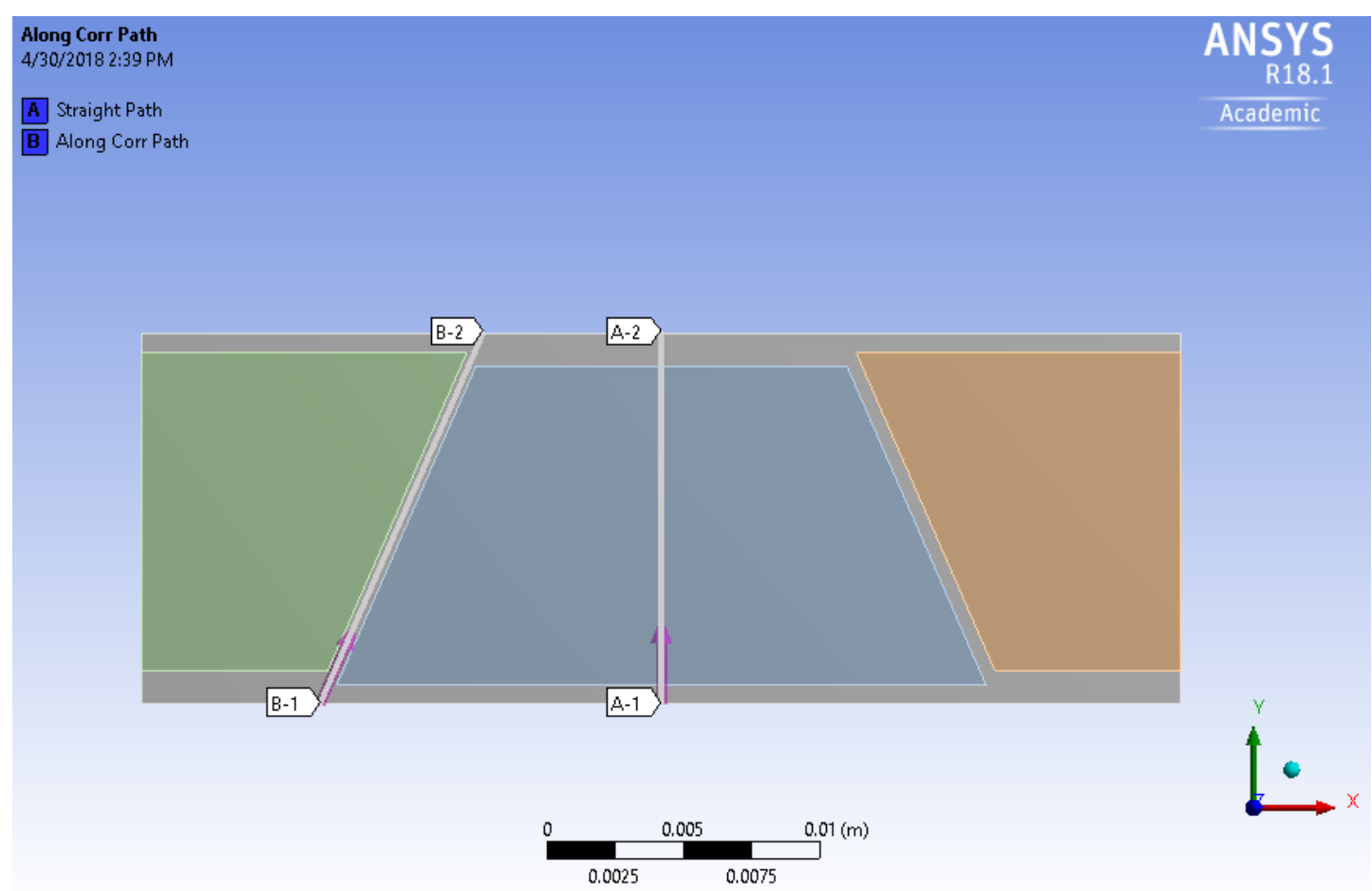

Figure 3.6 - Straight and Corrugated Computational Paths in the Corrugated Sample Model.

A comparison study using the corrugated carbon fiber model was performed with various types of common insulation materials to determine if Pyrogel XT-E, and aerogel in general, outperform traditional insulation materials by improving the structure's effective thermal conductivity. The 
insulation materials analyzed and their respective material constants are described in Table 3.8 [22].

Table 3.8 - Material and Thermal Properties of Comparison Insulation Types.

\begin{tabular}{|c|c|c|c|}
\hline Insulation & $\mathrm{k}(\mathrm{W} / \mathrm{m}-\mathrm{K})$ & $\mathrm{c}_{\mathrm{p}}(\mathrm{J} / \mathrm{kg}-\mathrm{K})$ & $\rho\left(\mathrm{kg} / \mathrm{m}^{3}\right)$ \\
\hline Pyrogel XT-E & 0.024 & 840 & 200 \\
\hline Air & 0.028 & 1009 & 1 \\
\hline Cellulose & 0.040 & 2020 & 40 \\
\hline Expanded Polystyrene (EPS) & 0.036 & 1300 & 22 \\
\hline Polyurethane & 0.025 & 1450 & 35 \\
\hline Aerogel Particles (Cabot P100) & 0.014 & 1000 & 150 \\
\hline
\end{tabular}




\section{CHAPTER 4}

\section{Experimental Setup \& Method}

Now that the flow of heat through the flat plate sample and the corrugated carbon fiber sample has been modeled, an experiment is set up and conducted to understand the actual heat flow through the samples and ultimately determine each sample's thermal conductivity. This chapter begins with an overview of the test setup, which goes into depth about the test enclosure, heat source and temperature control, data acquisition and sensors, samples and sample construction, and experimental method.

\subsection{Experimental Setup}

The test system contains the following main components: test enclosure, sample, temperature control and heat source, and data acquisition. A basic diagram of the components of the test setup can be seen in Figure 4.1.

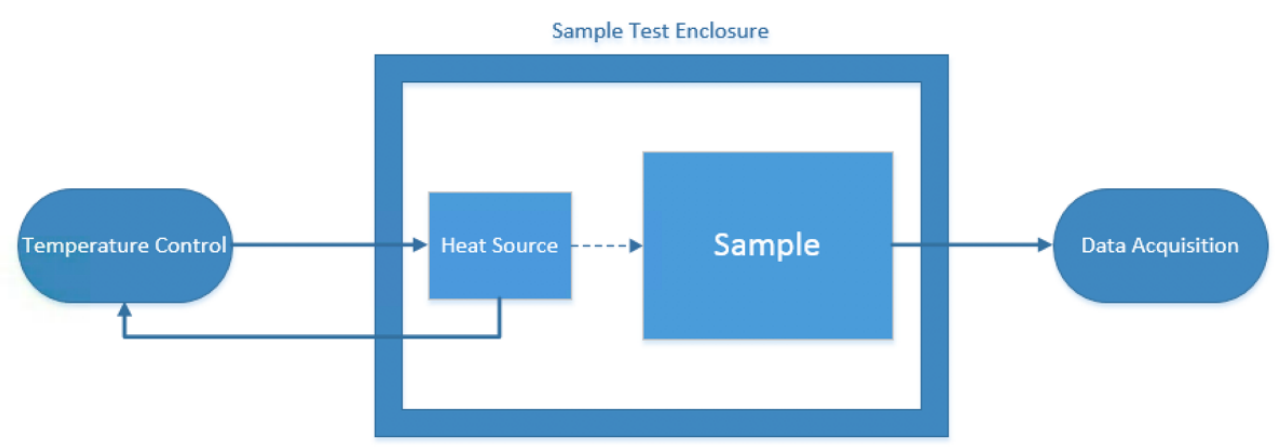

Figure 4.1 - Diagram of Test Setup. 


\subsubsection{Test Enclosure}

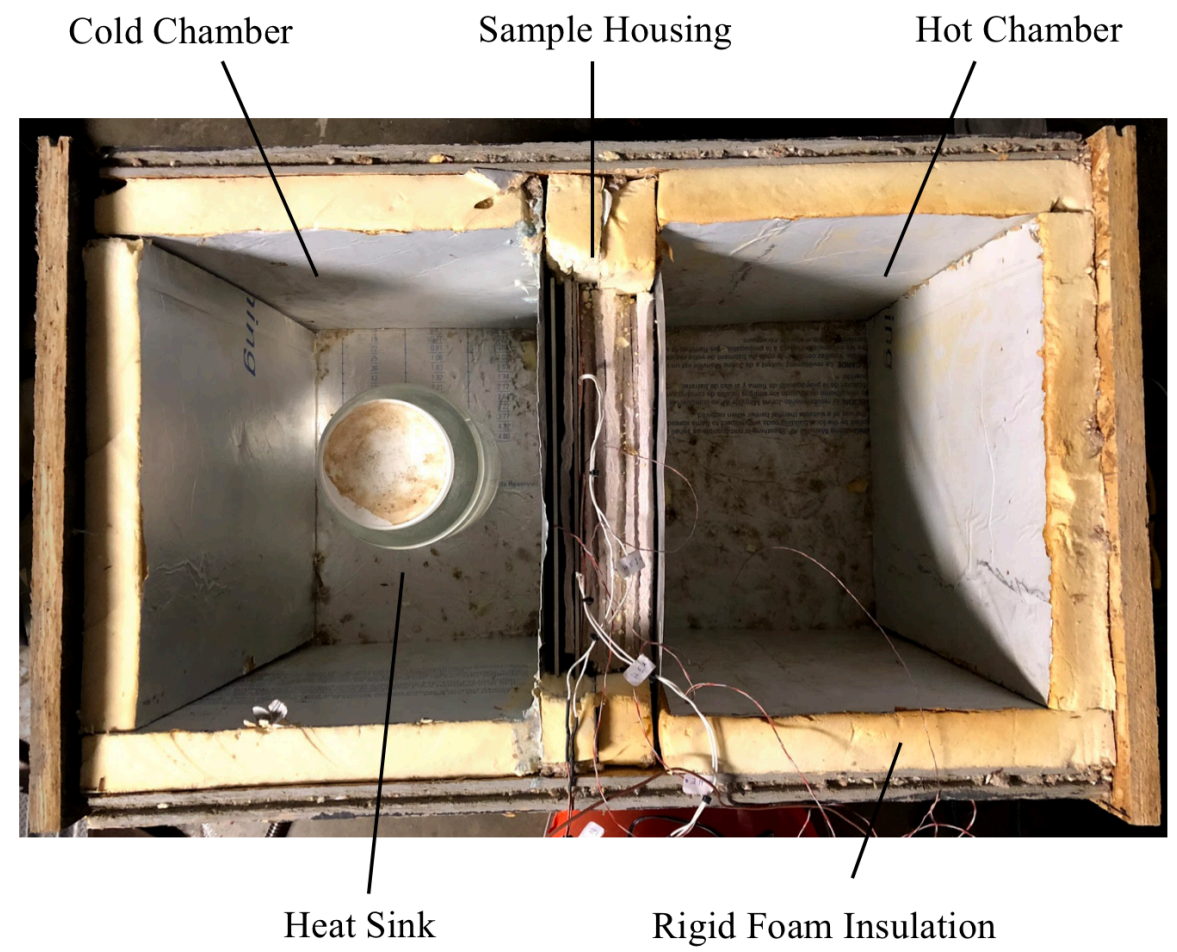

Figure 4.2 - Diagram of Test Enclosure.

The test enclosure is constructed of 0.75 -inch thick plywood and is internally lined on all surfaces with Johns Manville AP Foil-Faced Polyisocyanurate Continuous Foam Insulation, which is 0.75 inches thick and has an R-Value of $1.63 \mathrm{~K}-\mathrm{m}^{2} / \mathrm{W}[23]$. This minimizes heat loss from the bottom and sides of the sample. The top of the test enclosure is a piece of the Johns Manville insulation; it is removeable so that the sample housing can be accessed to change samples and position the heating element and sensors. The sample housing sits in the middle of the test enclosure; on either side of the sample housing is a 10.5 " $\mathrm{x} 13.5$ " $\mathrm{x} 17$ " area for a heat sink and a heat source. The cold chamber houses the heat sink, which is a glass jar with approximately 5 liters of cool water that pulls the heat through the sample housing. This test enclosure was initially built for a different project with the same intentions, testing the thermal performance of insulation materials, but the 
heat source was a heat lamp that was placed in the hot chamber of the test enclosure. In the past, using the heat lamp was an issue because of the lack of control over the temperature, which is why a temperature control circuit using flat plate silicone heating elements was designed and implemented for this thesis. Therefore, the hot chamber was vacant during these tests.

\subsubsection{Sample Housing}

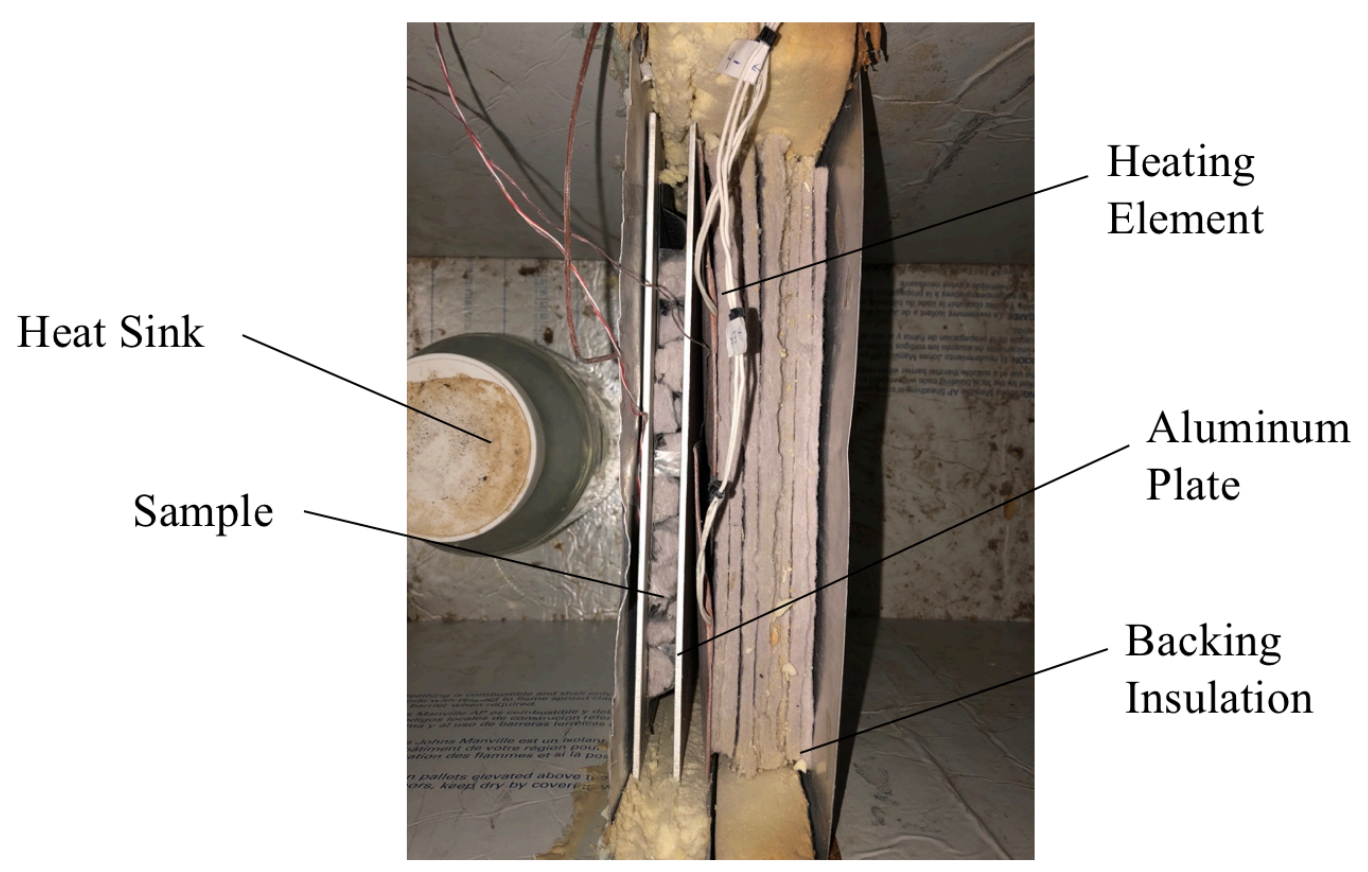

Figure 4.3 - Sample Housing in Test Enclosure.

The sample housing sits inside the test enclosure, which can be seen in Figure 4.3 (for this photo, top insulation is absent, and components are not compressed together so that each component is displayed effectively). The sample housing is $82 \mathrm{~mm}$ thick and contains the heating element and sensors, the sample, and the backing insulation. It is supported on either side by a 1/32-inch thick sheet of aluminum. The extra space in the sample housing is filled with backing Pyrogel XT-E insulation for two purposes - to maximize the amount of heat going through the sample and to 
provide enough compression to ensure the heat supply, sample, and sensors have sufficient surface contact between them. During testing, the space on top of the sample and the backing insulation is filled with extra Johns Manville insulation to minimize heat escaping out the top.

\subsubsection{Heat Source}

Two silicon rubber flexible flat plate heaters apply heat to the front face of the samples during testing. They are manufactured by Tempco and are 12" $\mathrm{x} 6$ ", together forming a heating area of 1 $\mathrm{ft}^{2}$. Equation 4.1 was used to determine the required power of this application in watts,

$$
P=1.25 \frac{m c_{p} \Delta T}{\Delta t}
$$

Where $m$ is the mass of the aluminum plate to be heated to and maintained at $120{ }^{\circ} \mathrm{C}, c_{p}$ is the specific heat of 6061-T6 aluminum, $T$ is the change in temperature from room temperature to 120 ${ }^{\circ} \mathrm{C}$, and $t$ is the desired time for the heater to reach the set temperature of $120^{\circ} \mathrm{C}$. It will be discussed later, but the applied temperature of $120^{\circ} \mathrm{C}$ was selected based on the limits of the sensors. The time to heat up was arbitrarily set at 10 minutes. It is recommended by the manufacturer, Tempco, that a factor of safety of $25 \%$ of the calculated power be added to the total required power to account for unknown anomalies [24]. The required power output of the heater was calculated to be $151 \mathrm{~W}$. Equation 4.2 was used to calculate the required watt density of the heater,

$$
\text { Watt Density }=\frac{P}{A_{\text {heater }}}
$$


Where $A$ is the area of the heater $\left(1 \mathrm{ft}^{2}\right)$. The required watt density of the heater was calculated as $1.05 \mathrm{~W} / \mathrm{in}^{2}$, yet the heaters selected have a power output of $360 \mathrm{~W}$ and a watt density of $5 \mathrm{~W} / \mathrm{in}^{2}$. This is so that these heating elements and its integrated temperature control circuit can be used in future research projects that may have higher power requirements. The two heating elements are wired in parallel so that equal power is applied to both. The heating elements are clamped, not adhered, to the front of the samples during testing; adhesive was not used because the heating elements were used for multiple tests on different samples.

\subsubsection{Data Acquisition}

The FluxDAQ+ data acquisition system, manufactured by FluxTeq, was used for data acquisition during testing, which can be seen in Figure 4.4. Long-term SD card logging is possible so that temperature, heat flux, and R-value data can be recorded in a .csv file during testing. The maximum sampling rate of the FluxDAQ+ is $2.5 \mathrm{~Hz}$, which is more than enough for this application. The sensors used with the FluxDAQ+ data acquisition system are a thermocouple and a heat flux sensor. The thermocouple used is a Type-T thermocouple and the heat flux sensor used is a differential-temperature thermopile Large Surface Area Heat Flux Sensor, which is manufactured by FluxTeq. It measures temperature (via an integrated Type-T thermocouple), heat flux, and in-situ R-values. The heat flux sensor is capable of covering a sensing area of 3.45 " $\mathrm{x}$ 3.75", which accounts for a sufficient percentage of the $12 " \times 12$ " sample area. The sensor attains a heat flux resolution of approximately $0.1-0.2 \mathrm{~W} / \mathrm{m}^{2}$ and has a sensitivity of $70-90 \mathrm{mV} / \mathrm{W} / \mathrm{cm}^{2}$. The measurable temperature range of the heat flux sensor reaches its maximum at $120^{\circ} \mathrm{C}$, but it is noted in the data sheet that further testing on the maximum temperature is being conducted and that higher temperatures may be possible [25]. 


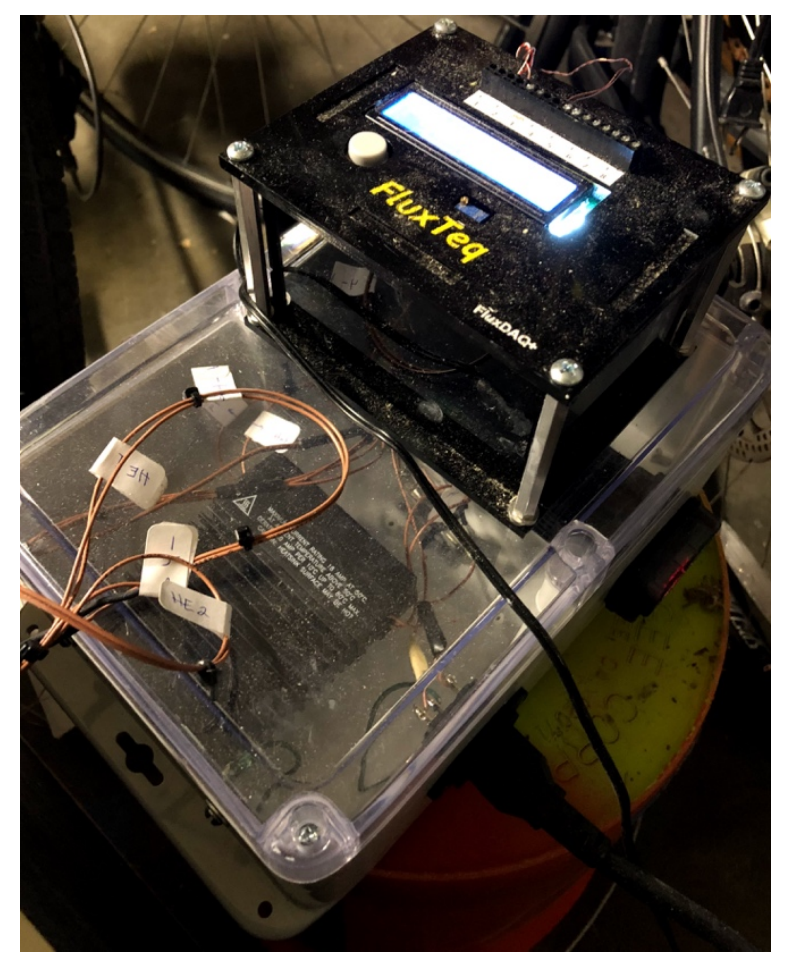

Figure 4.4 - FluxDAQ+ Data Acquisition Manufactured by FluxTeq.

\subsubsection{Temperature Control}

A temperature control circuit, which can be seen in Figure 4.5, was designed and assembled specifically for this thesis. It was implemented with the flat plate heating element to effectively control the applied temperature, establishing a control variable. It also prevented damage to the test enclosure due to excessive heat, as the enclosure is well-insulated and is exposed to heat until steady state conditions are reached. The components used in this temperature control circuit, along with the flat plate heating element, are a Proportional Integral Derivative (PID) controller and a solid-state relay. A reference Type-K thermocouple forms a feedback loop with the PID controller. A 7.5 A fuse will be used to protect the main components of the circuit. 


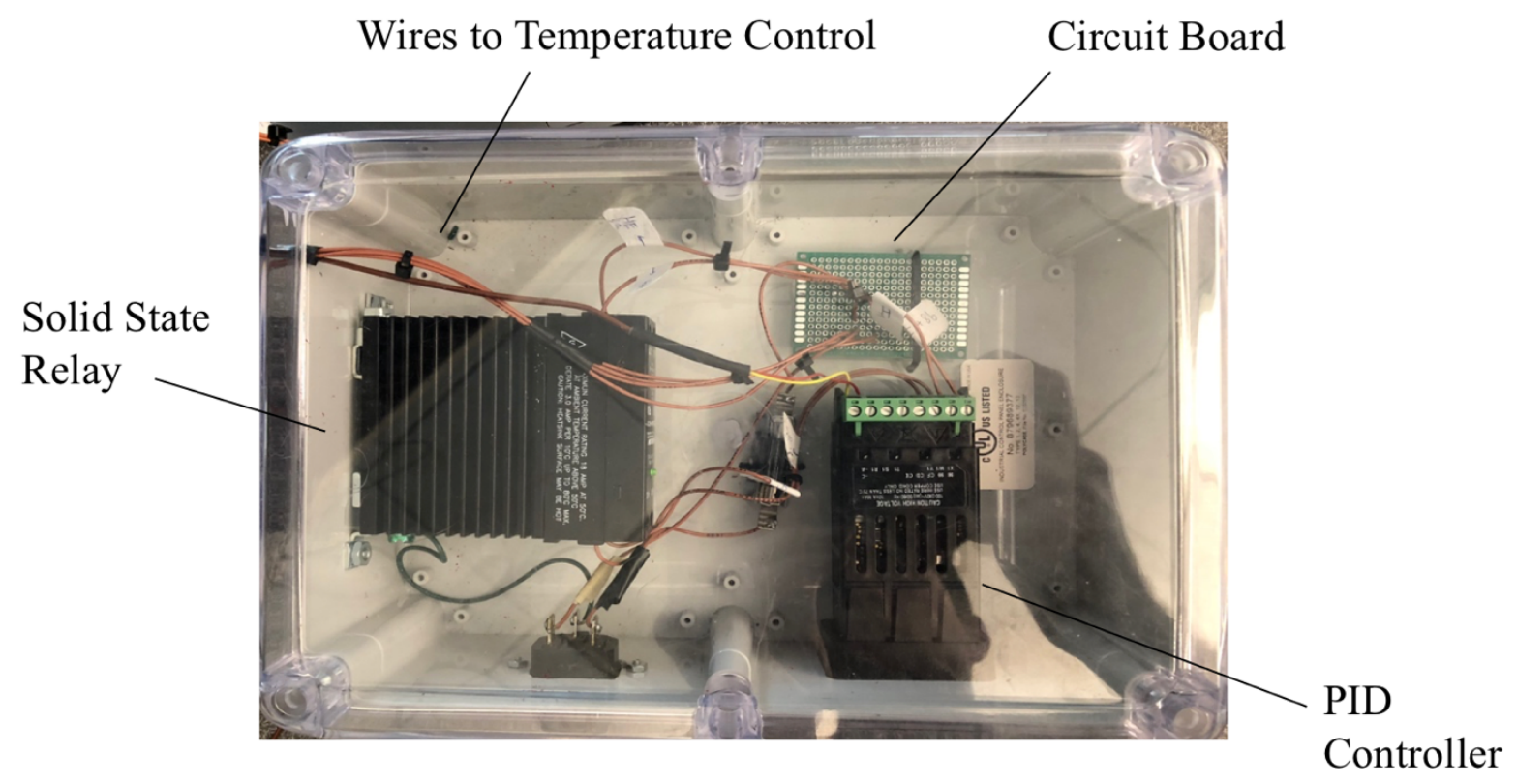

Figure 4.5 - Temperature Control Feedback Circuit.

The temperature control circuit will be laid out as follows in Figure 4.6.

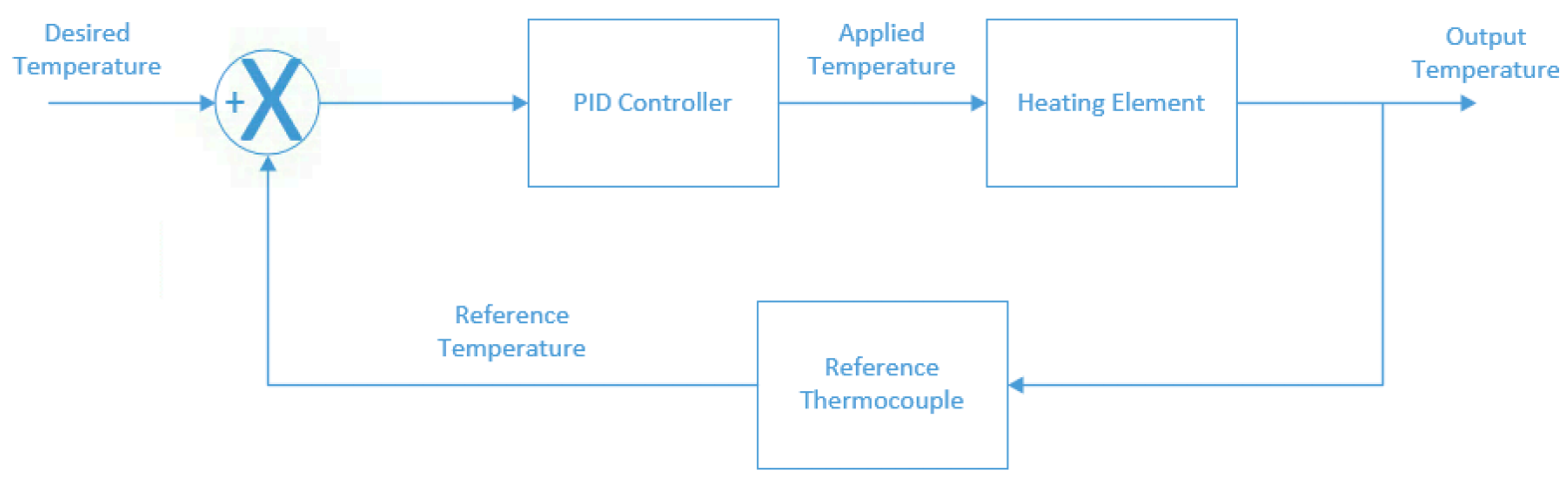

Figure 4.6 - Feedback Control Loop of Temperature Control Circuit.

\subsection{Sample Preparation}

The two main samples tested are the flat plate sample with $5 \mathrm{~mm}$ of Pyrogel XT-E and the corrugated carbon fiber sandwich structure with Pyrogel XT-E in the corrugation gaps. Both 
samples are sandwiched by aluminum plates to ensure a consistent temperature distribution is applied to the sample. The area chosen for the sample is $1 \mathrm{ft}^{2}$ because it is large enough in size compared to the exposed areas of the sensors.

\subsubsection{Pyrogel XT-E Flat Plate Sample}

The flat plate sample consists of two plates of 6061 aluminum, $3.175 \mathrm{~mm}$ thick, with a sheet of 5 mm Pyrogel XT-E aerogel sandwiched in between. The downside to using flat plate silicone heaters that use electric coils is that they can have an inconsistent temperature distribution across their area. To get as close to 1-D heat transfer as possible, an aluminum plate was placed on either side of the $5 \mathrm{~mm}$ layer of Pyrogel XT-E. This ensures that the sensors measuring the heat are working with as consistent of a temperature distribution as possible. Due to its very high thermal conductivity, the aluminum plate approaches a relatively uniform temperature distribution, which it then applies to the sample. The other plate of aluminum was placed on the back of the $5 \mathrm{~mm}$ layer of Pyrogel XT-E for the same reason, as the heat flux sensor is most accurate when the heat transfer is as close to 1-D as possible. Testing this sample will validate the experimental setup by comparing the experimentally determined thermal conductivity to the published value.

\subsubsection{Corrugated Composite Sandwich Structure Sample}

This sample consists of a corrugated carbon fiber section sandwiched between two flat carbon fiber plates, the geometry of which can be seen in Figure 4.7. Like the flat plate sample, this sample is sandwiched between the same two plates of aluminum to ensure consistent 1-D heat transfer through the sample (see Section 4.2.1). Sheets of Pyrogel XT-E were cut into thin strips 
and layered into the air gaps created by the flat plate section against the corrugated section. As noted before, the effect of thermal bridging in the carbon fiber corrugation will be interesting to consider, as it could negate some of the insulative effect of the Pyrogel XT-E. However, this sample is expected to insulate very well, which with its superior structural characteristics shall make a strong, heat resistant structure.

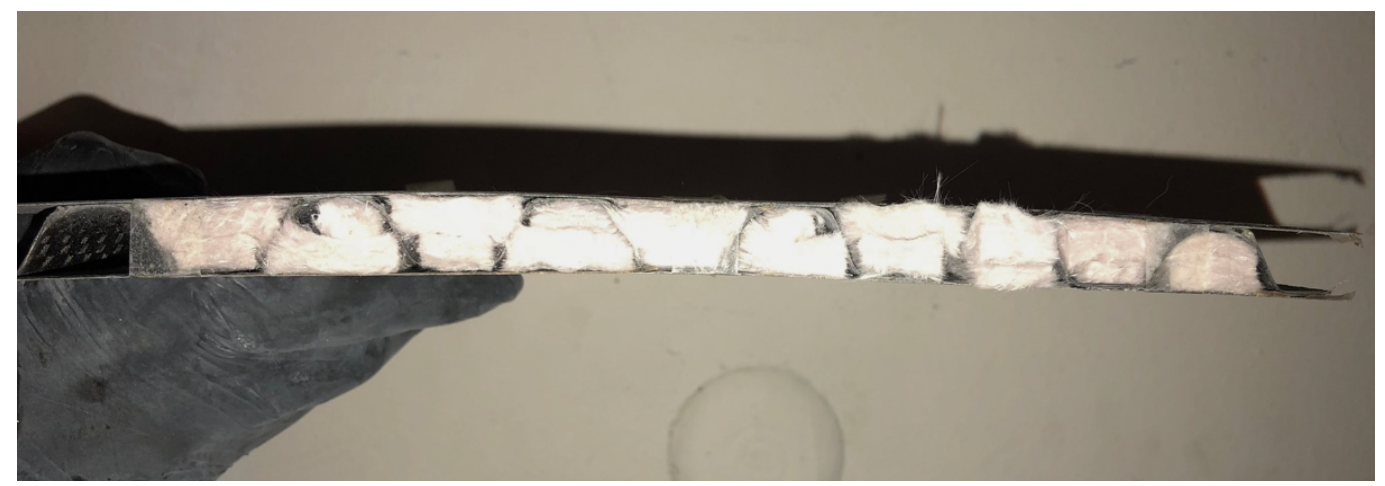

Figure 4.7 - Corrugated Carbon Fiber Sandwich Structure with Pyrogel XT-E.

The two flat plate sections and the corrugated section are taped together using 3M Polyester 8911 heat resistant tape, which can withstand temperatures up to $204^{\circ} \mathrm{C}$ [26]. The compression supplied by the back insulation in the sample housing and a metal clamp around the sample housing provide sufficient contact area amongst the test components.

The corrugated carbon fiber section consists of three layers of a $2 \times 2$ patterned weave of $230 \mathrm{GPa}$ prepreg. The cross-sectional geometry of the corrugated section was based off of the geometry determined by Mano et. al. [27]. The layers for the corrugated section were prepared in a corrugated aluminum mold. The corrugated section remained in the mold for the duration of the 
curing process so that it would hold its shape. The corrugated section was not made specifically for this thesis, as it was leftover as an extra sample from a previous project.

The flat carbon fiber plates consist of three plies of Cytec MTM 49LT resin and CF0302 fibers. They were vacuum sealed and cured according to the cure cycle displayed in Table 4.1 and Figure 4.8.

Table 4.1 - Cure Cycle for Flat Carbon Fiber Plate.

\begin{tabular}{|c|c|c|c|}
\hline Segment & Type & Set Temperature $\left({ }^{\circ} \mathrm{C}\right)$ & Duration (min) \\
\hline 1 & Soak & 25 & 1 \\
\hline 2 & Ramp & 25 & 60 \\
\hline 3 & Soak & 120 & 240 \\
\hline 4 & Soak & 50 & 36 \\
\hline 5 & Soak & 50 & 1 \\
\hline
\end{tabular}

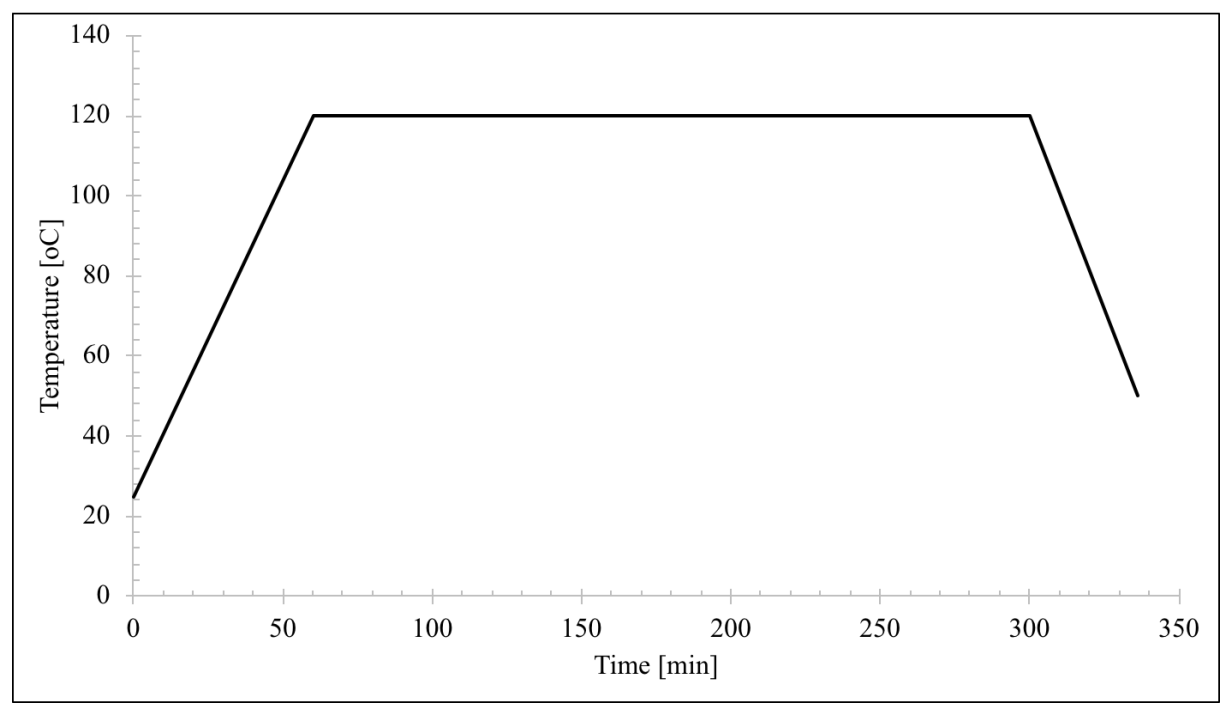

Figure 4.8 - Plot of Cure Cycle for Flat Plate Carbon Fiber.

The resin and matrix combination used was the best readily available material to use; however, the data sheet of MTM 49LT could not be found. The data sheet of a very similar composite, MTM 49-3, was used as a guide for designing the cure cycle [28]. 


\subsection{Experimental Method}

This section will discuss everything that was done to setup and perform a test. It starts with preparing the sample, then moves on to setting up the FluxDAQ+ data acquisition system and applying the sensors. Following this is a step-by-step process to configure the temperature control circuit. Once that is set up, it will outline how to insert and arrange all components into the sample housing.

\subsubsection{Sample Geometry}

The test procedure begins by preparing the sample. Each sample is approximately 12 " x 12 " and is prepared in similar ways, so both samples will be referred to as "the sample". The only difference between the two sample geometries is the way the insulation is inserted into the sample. The flat plate sample consists simply of a $5 \mathrm{~mm}$ layer of Pyrogel XT-E, while the corrugated carbon fiber sample consists of Pyrogel XT-E strips, which are cut from the bulk roll, in the corrugated air gaps. Each corrugated air gap houses two Pyrogel XT-E strips stacked on top of each other; the approximately $10 \mathrm{~mm}$ of insulation created by this method fits well inside the roughly $11.6 \mathrm{~mm}$-thick corrugated air gap. This stacking scheme can be seen in Figure 4.7. As noted before (see Section 4.2.1), both samples are sandwiched by aluminum plates to ensure 1-D heat transfer through the sample.

\subsubsection{FluxDAQ+ Data Acquisition System Configuration}

The sensors to input data to the FluxDAQ+ are the Type-T thermocouple attached to the front of the sample and the heat flux sensor attached to the back of the sample. The leads for these two 
sensors are hooked up to Channel 1 and 2 on the FluxDAQ+. Before plugging in to power, an SD card must be inserted to the card reader slot. If this is not inserted before plugging in, an error will display on the menu screen stating, "Failed Initialization". Once the SD card is inserted, the FluxDAQ+ is plugged in to power. A message saying "Press button to start test" will display, to which the grey button is pressed to begin recording data. However, this is not pressed until all other components are set up and ready for testing.

\subsubsection{Sensor Application}

Sensors are then applied to the sample, which is sandwiched by aluminum plates. Diagrams displaying the sensor application can be seen in Figures 4.9 and 4.10.

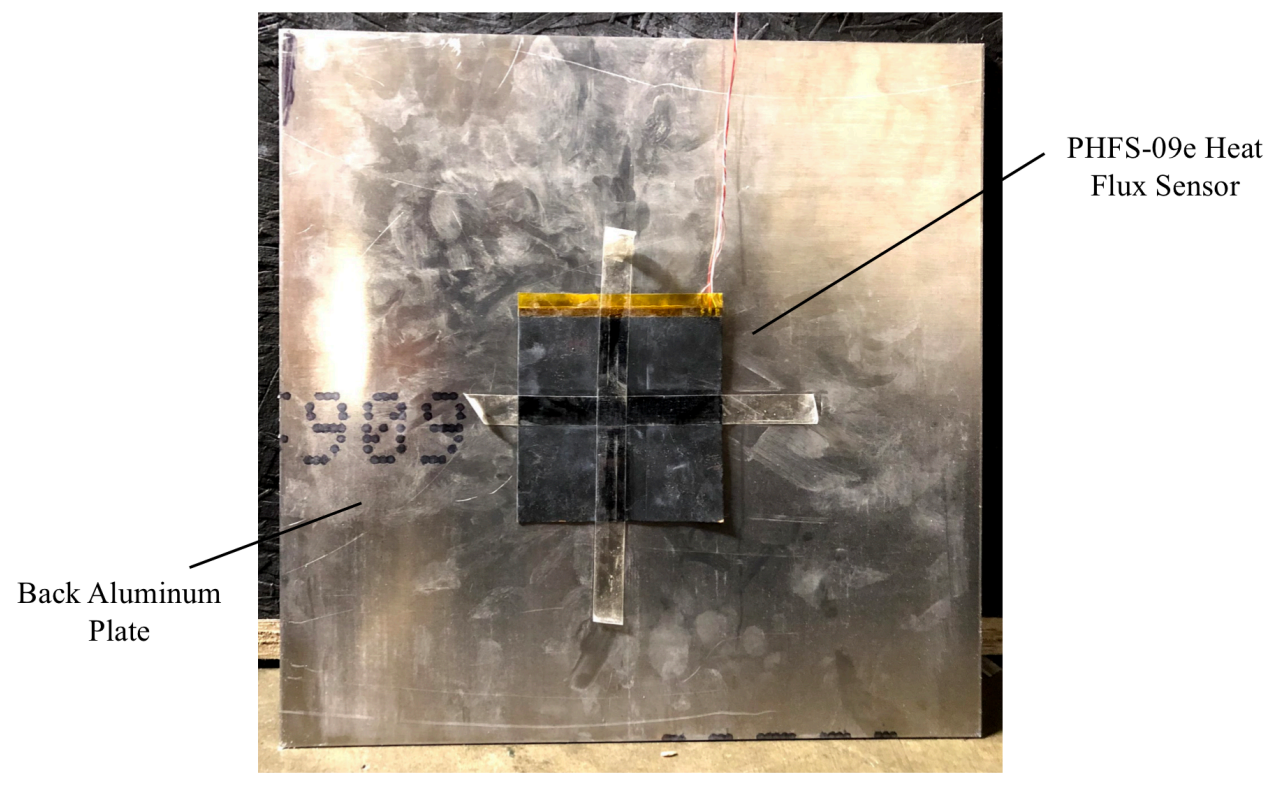

Figure 4.9 - Diagram of PHFS-09e Heat Flux Sensor Application on Sample. 


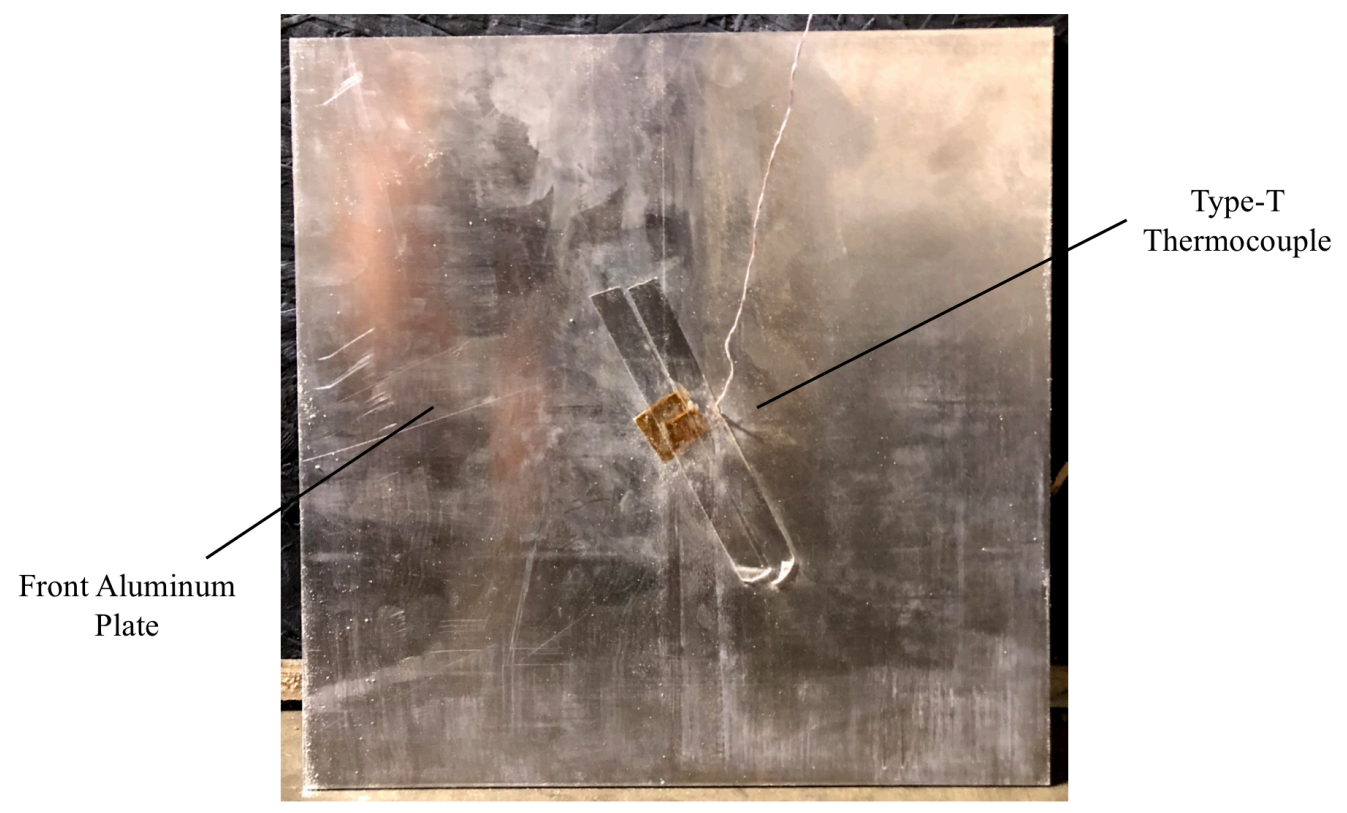

Figure 4.10 - Diagram of Type-T Thermocouple Sensor Application on Sample.

The Type-T thermocouple, which sends data to the FluxDAQ+, is attached to the front face of the front aluminum plate with 3M Polyester 8911 heat resistant tape. The PHFS-09e heat flux sensor, which includes a Type-T thermocouple, is attached to the outside face of the back aluminum plate with the same heat resistant tape. Both sensors are attached in line with each other in the middle of the samples to further ensure 1-D heat transfer is measured. Once sensors are attached to the aluminum plates, the sample is inserted into the sample housing.

According to ASTM Method C0177, the thermocouples and other temperature sensors are to be inserted into the sample material somehow, such as cutting grooves into the material for the sensors to reside [16]. Grooves were not cut into the sample material because this was not feasible with the carbon fiber samples. Doing so with the Pyrogel XT-E was considered, but preliminary experiments with temperature sensors mounted directly against the Pyrogel XT-E resulted in 
inconsistent and fluctuating temperature data. As noted before, this is why the temperature sensors are mounted to flat aluminum plates that sandwich the test samples. This method ensures uniform heat transfer through the samples.

The recommended number of thermocouples on the surface of a sample is recommended by ASTM Method $\mathrm{C} 0177$ to be dependent on area $A$. The number of thermocouples should not be less than $10 \times \sqrt{A}$, or 2 , whichever is greater [16]. In the test setup for this thesis, only one thermocouple was placed on each face of the sample in line with each other. A more robust distribution of thermocouples was desired to ensure 1-D heat transfer was present, but limitations with equipment surfaced. The FluxDAQ+ data acquisition system is only configured for two inputs, so adding sensors in addition to the heat flux sensor and thermocouple would not have been read. This is worth noting during data analysis.

\subsubsection{Temperature Control Configuration}

Before placing all components in the sample housing and beginning a test, the PID controller must be configured to the appropriate settings for the type of test. First, plug in the temperature control circuit. A menu will appear which can be seen in Figure 4.11. 


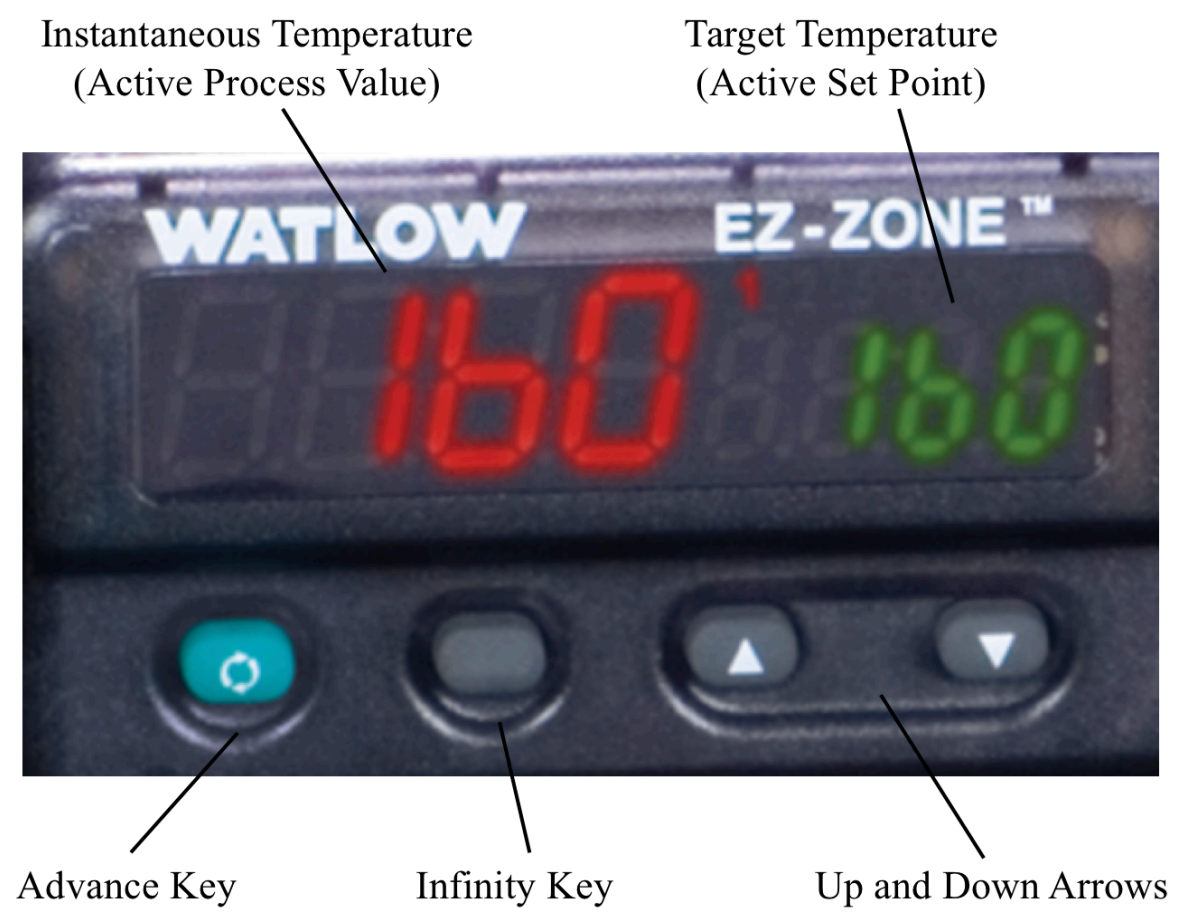

Figure 4.11 - Temperature Control Interface.

The first menu to walk through is the Operations Menu. The green "Advance Key" is used to scroll through each prompt, while the "Up and Down" arrows are used to change each prompt. The infinity key can be pressed to go back one menu function or pressed and held for two seconds to return to the Operations Menu. The following settings that are discussed are changed from their default setting and have an actual impact on the operation of the temperature controller for this application. All other settings that are left at default or that do not apply to this application are not discussed. The labels in the parentheses are what is displayed on the temperature controller readout.

The only setting to be changed in the Operations Menu is the heat proportional band (h.Pb), which is set to $120^{\circ} \mathrm{C}$. The other menu to configure is the Setup Menu. To access this menu, the "Up and Down" arrows are held together for approximately 3 seconds. Scrolling through prompts in 
this menu is done the same as in the Operations Menu. Sensor type (SEn) is left at the default of thermocouple (t.C). The next prompt, linearization (Lin), sets the type of thermocouple, which in this case is Type-K. The setting for Type-K is "H", which can be seen in Table 4.2.

Table 4.2 - Thermocouple Type Key for PID Controller.

\begin{tabular}{|l|l|l|l|l|l|l|l|l|l|l|l|}
\hline Thermocouple Type & B & C & D & E & F & J & K & N & R & S & T \\
\hline PID Controller Setting & b & c & d & E & F & J & H & n & r & S & t \\
\hline
\end{tabular}

The precision of the temperature display ( $\mathrm{dEC})$ is then set in tenths as " 0.0 ". Following that, the display units setting (C_F) is set as ${ }^{\circ} \mathrm{C}$. The ramp action (rP) is left at default, but it is worth mentioning. Default for this setting is "Off", or no ramping; Figure 4.12 displays the effect of ramping in a heating system.
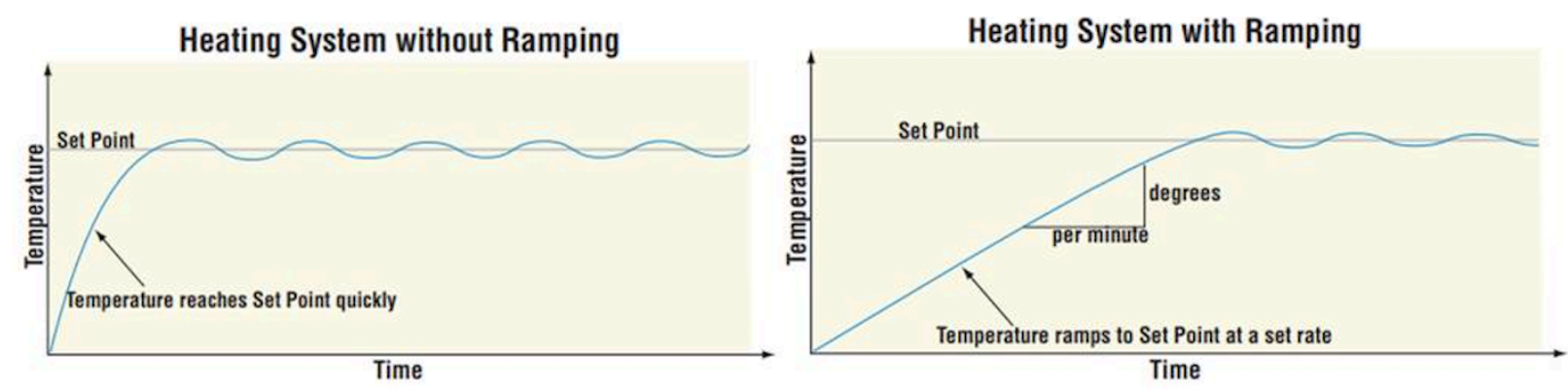

Figure 4.12 - The Effect of Ramping in a Heating System [29].

Once the Infinity Key is pressed to return to the main display menu, the temperature controller is set up for testing. Unplug the temperature control circuit until testing is ready to start. 


\subsubsection{Sample Housing Configuration}

Once inserted into the sample housing, the sample and its attached sensors are placed against the side of the sample housing closest to the heat sink. The two 12 " 6 " flat plate heating elements are then placed in the sample housing against the front face of the front aluminum sample plate. The input Type-K thermocouple, which is a reference thermocouple that forms a feedback loop with the PID temperature controller, is then inserted in between the flat plate heating elements and the front face of the front aluminum plate. It is placed as close to the thermocouple that is attached to the front face of the front aluminum plate as possible so that they both read the same temperature. The remaining space in the sample housing is filled with layers of backing Pyrogel XT-E insulation, which prevents escaping heat and ensures as much heat as possible is pushed through the sample. Layers of Pyrogel XT-E are inserted in the sample housing until the components in the sample housing are sufficiently compressed against each other. This aims to minimize contact resistance and hold all components together so that there is no extraneous internal movement. Additionally, a metal clamp is tightened about the sample housing to ensure the components are sufficiently compressed together. This preparation of the samples follows the method highlighted in 6.8.2.2 and Note 14 of ASTM Method C0177 [16]. See Figure 4.2 for a photo illustrating this setup. 


\subsubsection{Running a Test}

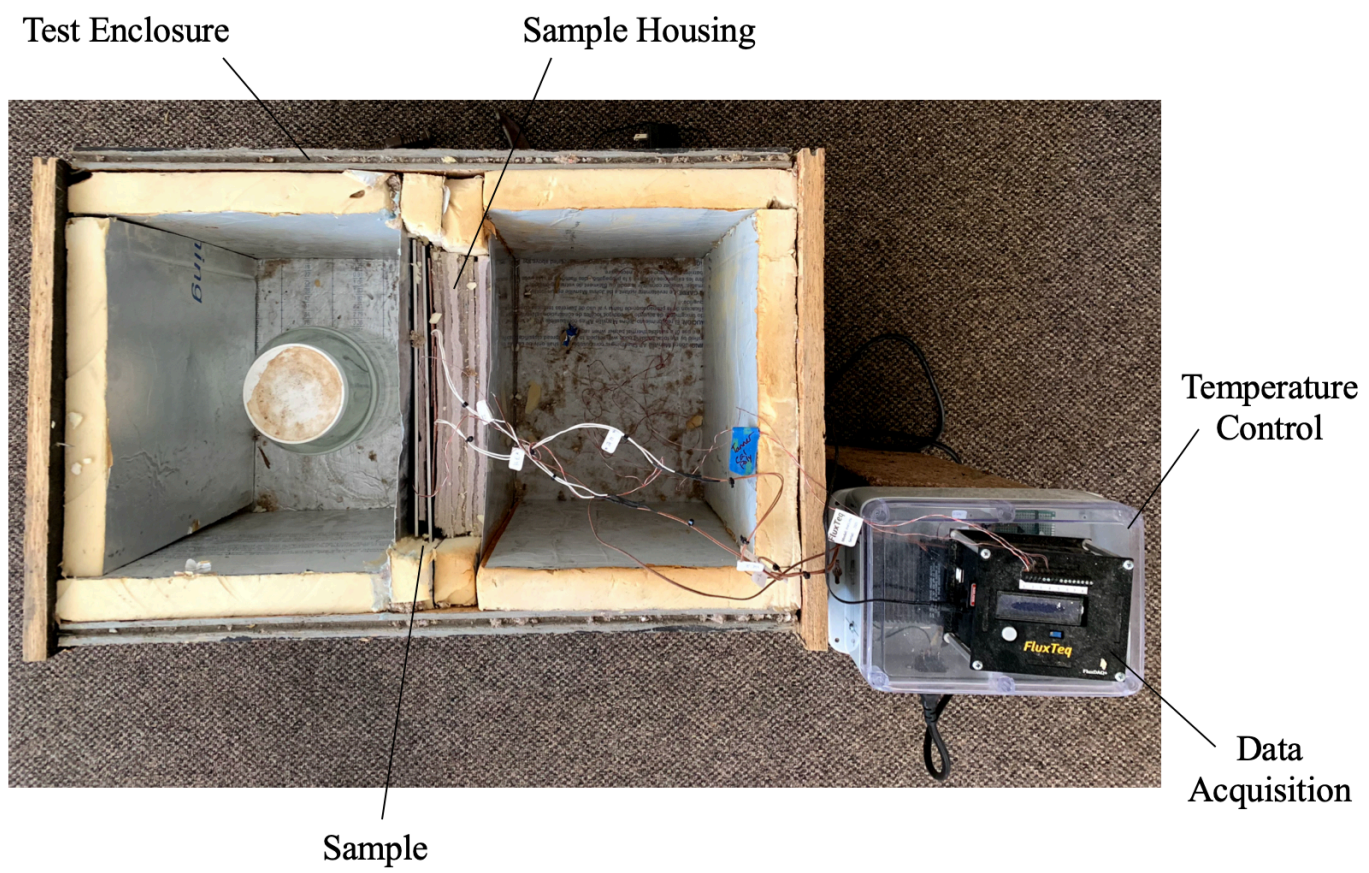

Figure 4.13 - Experimental Test Setup.

Once the FluxDAQ+ and PID Controller are configured, the sensors are attached to the sample, the sample, heating elements, and backing insulation are placed in the sample housing, and the top insulation is placed in the sample housing and on top of the test enclosure, testing is ready to start. Plug in the FluxDAQ+ and the temperature control circuit, press the grey test button on the FluxDAQ+, and wait the appropriate amount of time for the test to complete. Selecting a test duration was based off of the computer models and then shortened as needed from there. The longest tests were run for just over three hours, but for other tests, it was evident based on the plots that the curves reached steady state after only an hour. It is noted in ASTM Method C0177 that duration to steady state is measured on the order of hours, and after testing, it was evident that testing for more than three hours was a substantial amount of time to reach and remain at steady state conditions [16]. Once the test is complete, unplug the FluxDAQ+ and temperature control 
circuit, then remove the top insulation and allow the test enclosure to cool before removing the sample. Before beginning the next test, ample time must be allowed to pass for the sample and the rest of the sample housing to cool down. This should be one to two hours, or until the sample is cool to the touch. Having the sample sufficiently cool before the next test allows uniformity across all thermal conductivity calculations. 


\section{CHAPTER 5}

Theoretical, Numerical, and Experimental Results \& Discussion

This section will highlight the analysis from the Theoretical Model and Experimental Setup \& Method sections and discuss the results from each, starting with the theoretical model results and then moving toward the experimental results. These will then be compared and discussed, followed by thoughts for future work and research.

\subsection{Theoretical \& Numerical Analysis Results}

Two models were created for thermal conductivity, the flat plate structure and the corrugated carbon fiber structure. The flat plate structure model was developed to understand the flow of heat through various thicknesses of Pyrogel XT-E, while the corrugated carbon fiber structure model was developed to get an idea as to how heat would transfer through the sample to compare to the experimental data.

\subsubsection{Finite Difference Model of Flat Plate Sandwich Structure}

Pyrogel XT-E thicknesses of $1 \mathrm{~mm}, 2 \mathrm{~mm}, 3 \mathrm{~mm}$, and $5 \mathrm{~mm}$ were analyzed for the flat plate sandwich structure sample. ANSYS Workbench was used to create a steady-state model to understand the long-term thermal performance of this sample and analyze its effective thermal conductivity. The change in temperature across the sample, heat flux, and effective thermal conductivity for each Pyrogel XT-E thickness can be seen in Table 5.1. 
Table 5.1 - Steady-State Results of the Flat Plate Sample.

\begin{tabular}{|c|c|c|c|}
\hline $\begin{array}{c}\text { Pyrogel XT-E } \\
\text { Thickness }(\mathrm{mm})\end{array}$ & $\Delta \mathrm{T}\left({ }^{\circ} \mathrm{C}\right)$ & $\begin{array}{c}\text { Heat Flux } q \\
\left(\mathrm{~W} / \mathrm{m}^{2}\right)\end{array}$ & $\begin{array}{c}\text { Effective Thermal } \\
\text { Conductivity } k_{\text {eff }} \\
(\mathrm{W} / \mathrm{m}-\mathrm{K})\end{array}$ \\
\hline 1 & 15.8 & 348.0 & 0.162 \\
\hline 2 & 26.9 & 296.1 & 0.092 \\
\hline 3 & 35.2 & 258.1 & 0.069 \\
\hline 5 & 46.8 & 205.9 & 0.050 \\
\hline
\end{tabular}

Microsoft Excel was then used to create a finite difference transient model (see Section 3.2) for each of the Pyrogel XT-E thicknesses. Microsoft Excel was used rather than ANSYS Workbench due to computation time and computer memory. The time step used for each flat plate model was different for certain time blocks during the simulations. For times just greater than zero (around 1 $\mathrm{ms}$ ), the temperatures calculated by the finite difference approximations were inaccurate because of instability. Contributing to this problem is the small length step through the sample for the finite difference equations. Note from the discussion of the Fourier number (see Equations 3.18 and 3.27) that its value depends heavily on the length step. As the length step gets smaller, the Fourier number becomes unstable and causes large inaccuracies in the temperature data. To combat this and ensure stability, each simulation was broken up into time step sections, which can be seen in Table 5.2.

Table 5.2 - Time Step Sections for Transient Flat Plate Simulations.

\begin{tabular}{|c|c|}
\hline Duration & dt $(\mathrm{s})$ \\
\hline 0 to $0.05 \mathrm{~s}$ & $1 \mathrm{E}-04$ \\
\hline $0.05 \mathrm{~s}$ to $30 \mathrm{~min}$ & 0.1 \\
\hline 30 min onward & 1 \\
\hline
\end{tabular}

For each flat plate sample, a plot of temperature vs. sample thickness was computed. Each curve on the plots represents the temperature distribution through the sample at a certain time step. The 
vertical black lines represent the boundaries where the aluminum plates meet the Pyrogel XT-E; in between the vertical black lines is the Pyrogel XT-E. The steady-state results are plotted on the same graph to understand the thermal performance of the sample and to gain perspective as to how the heat transfers through the sample over time. These plots can be seen in Figures 5.1 - 5.4.

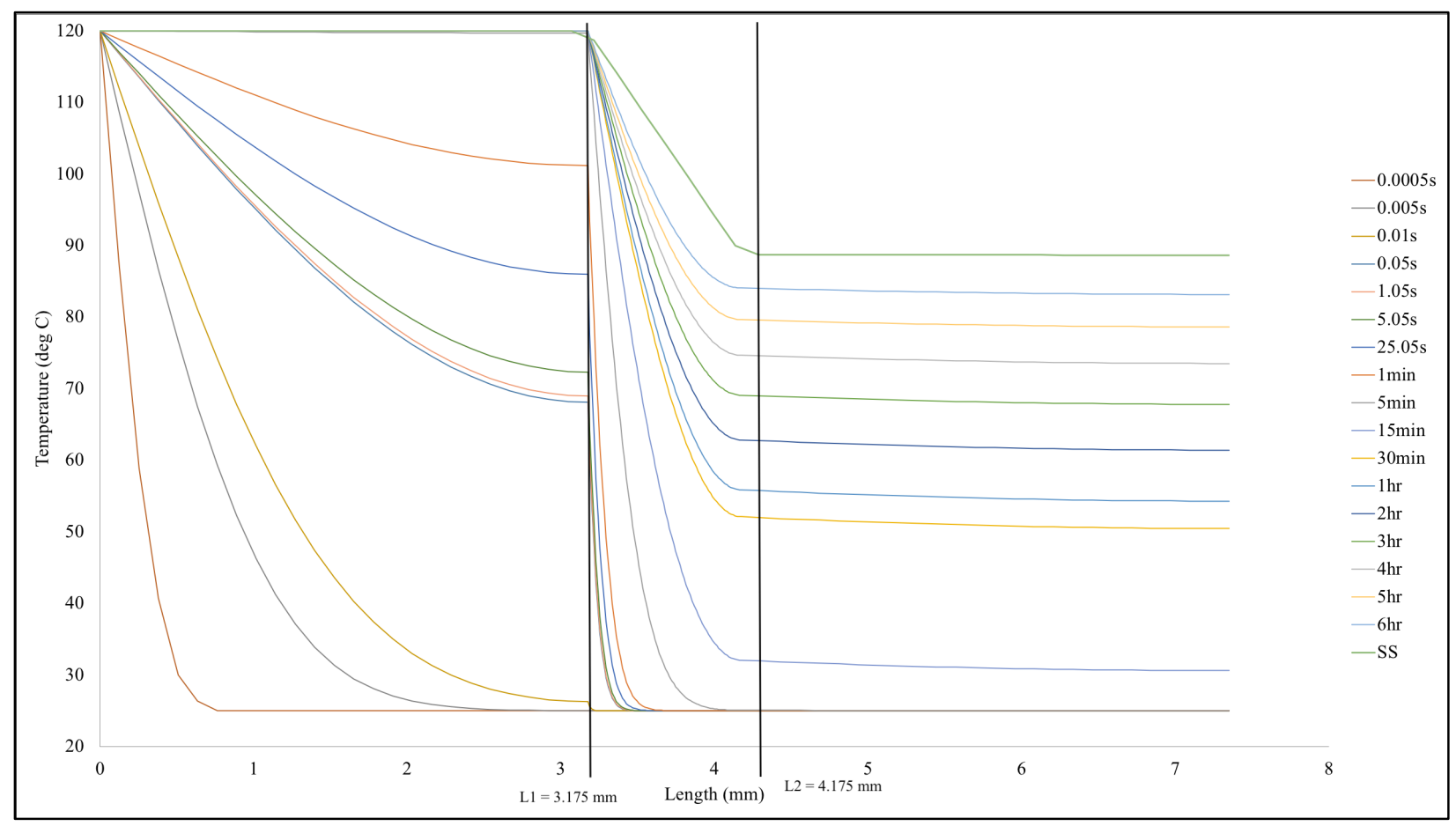

Figure 5.1 - Temperature Along Length for 1mm Pyrogel XT-E Flat Plate Sample. 


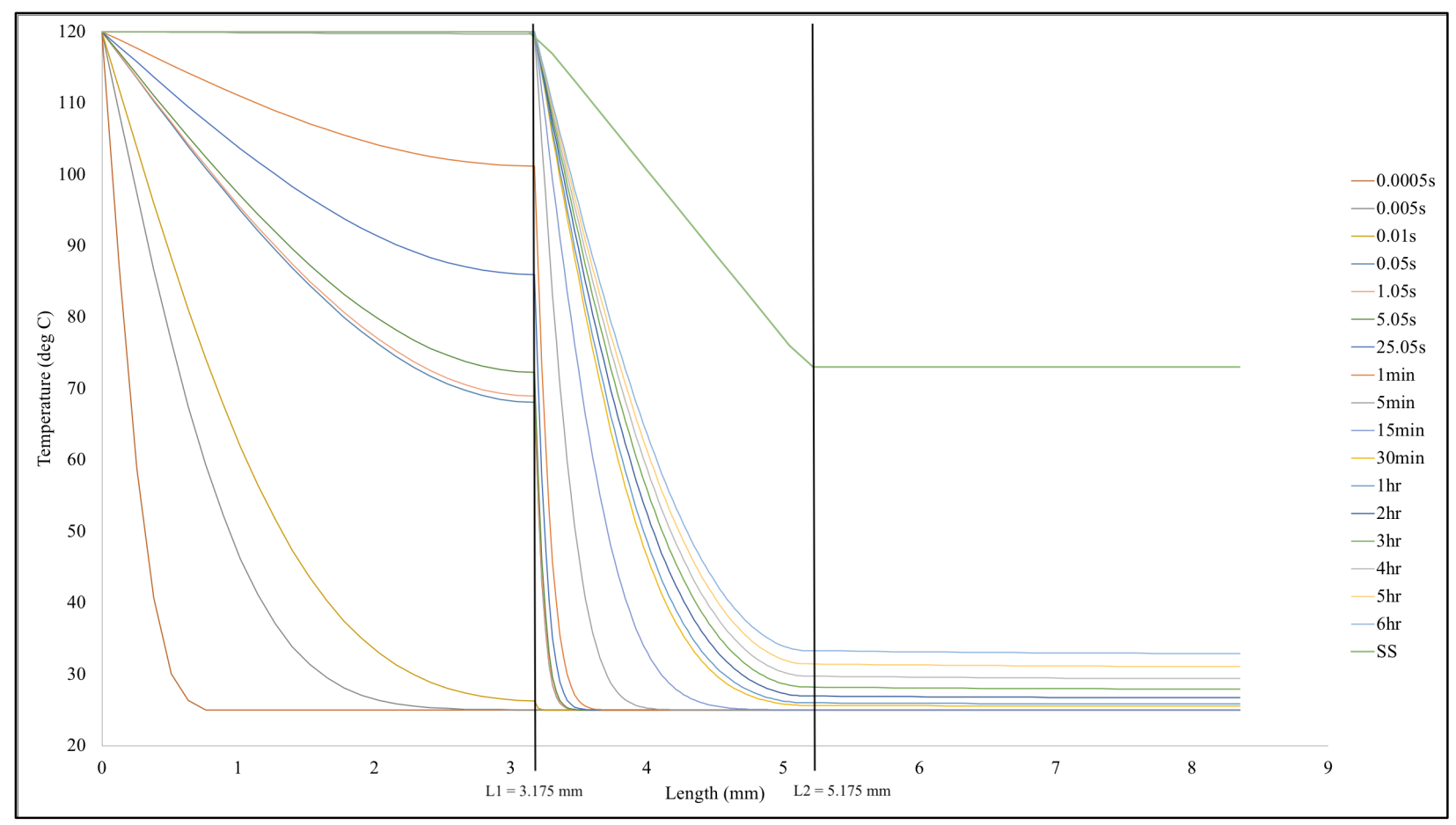

Figure 5.2 - Temperature Along Length for 2mm Pyrogel XT-E Flat Plate Sample.

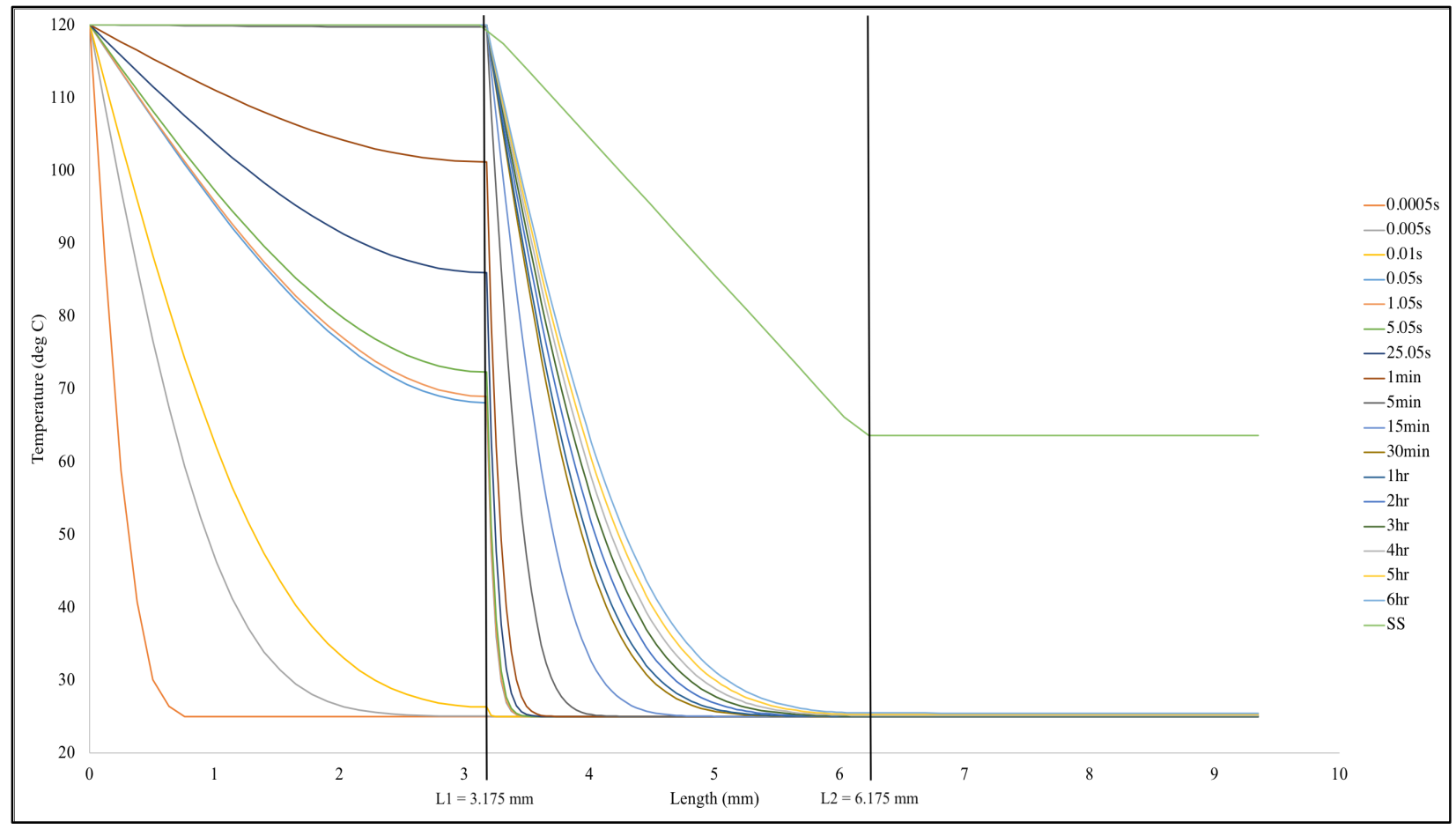

Figure 5.3 - Temperature Along Length for 3mm Pyrogel XT-E Flat Plate Sample. 


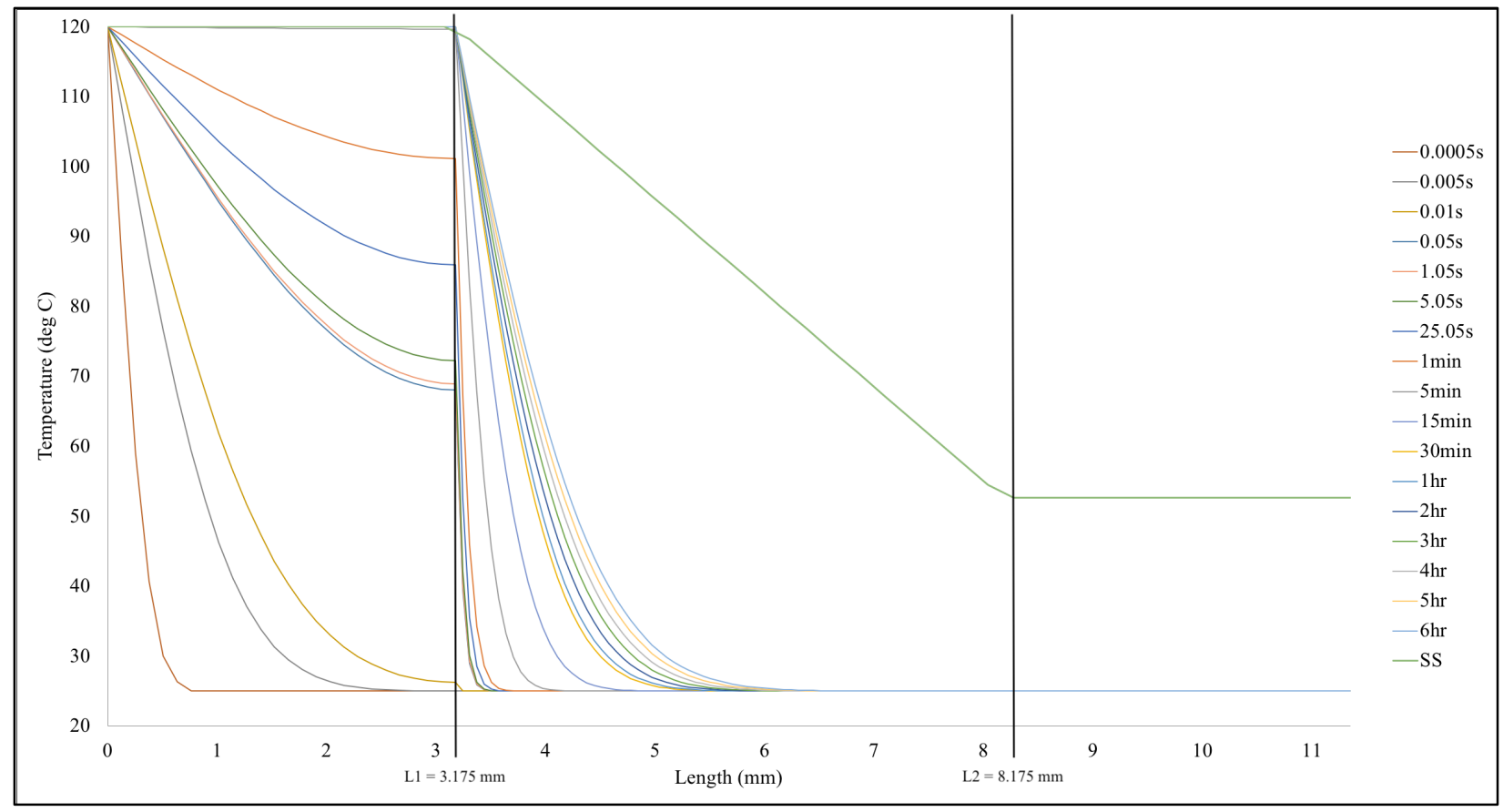

Figure 5.4 - Temperature Along Length for 5mm Pyrogel XT-E Flat Plate Sample.

It can be seen in Figure 5.1 that that the sample with $1 \mathrm{~mm}$ of Pyrogel XT-E almost reaches steadystate conditions after 6 hours. When considering the intended applications of these samples, the sample reaches more than $50 \%$ of its steady-state back-face temperature value at a smaller time window of only 30 minutes. The $2 \mathrm{~mm}$ Pyrogel XT-E sample sees only a slight increase in temperature from ambient after 6 hours and is drastically lower than its steady-state value at that time. It can be seen in Figure 5.2 that after a long amount of time the exposed face of the sample increases only slightly in temperature from ambient, making it a substantial upgrade over the $1 \mathrm{~mm}$ sample for an application of severe temperature exposure over long amounts of time. The $3 \mathrm{~mm}$ Pyrogel XT-E sample improves substantially over the $2 \mathrm{~mm}$ sample, allowing only a marginal amount of heat to escape to the exposed face of the sample after 6 hours. Like the $2 \mathrm{~mm}$ sample, its minimum temperature value after that amount of time is drastically less than the steady-state 
value; it can be seen in Figure 5.3 that the minimum temperature in the sample does not appear to increase over the ambient value. The $5 \mathrm{~mm}$ Pyrogel XT-E sample improves over the $3 \mathrm{~mm}$ sample, but not by a significant enough amount to warrant using it over the $3 \mathrm{~mm}$ sample for the modeled time window. As expected, the effective thermal conductivity of the various flat plate samples decreases as the Pyrogel XT-E layer, and therefore the sample itself, becomes thicker; these results are seen in Table 5.1 and Figure 5.5. Although useful in displaying this trend, the effective thermal conductivity results from the experimental data should carry more weight, as the flat plate theoretical models appear unrealistic in that they take much longer to approach steady state conditions than expected. Due to this, it is likely this data would not replicate itself in real world testing. Figure 5.5 displays the effective thermal conductivity, change in temperature, and heat flux across the flat plate samples for varying Pyrogel XT-E.

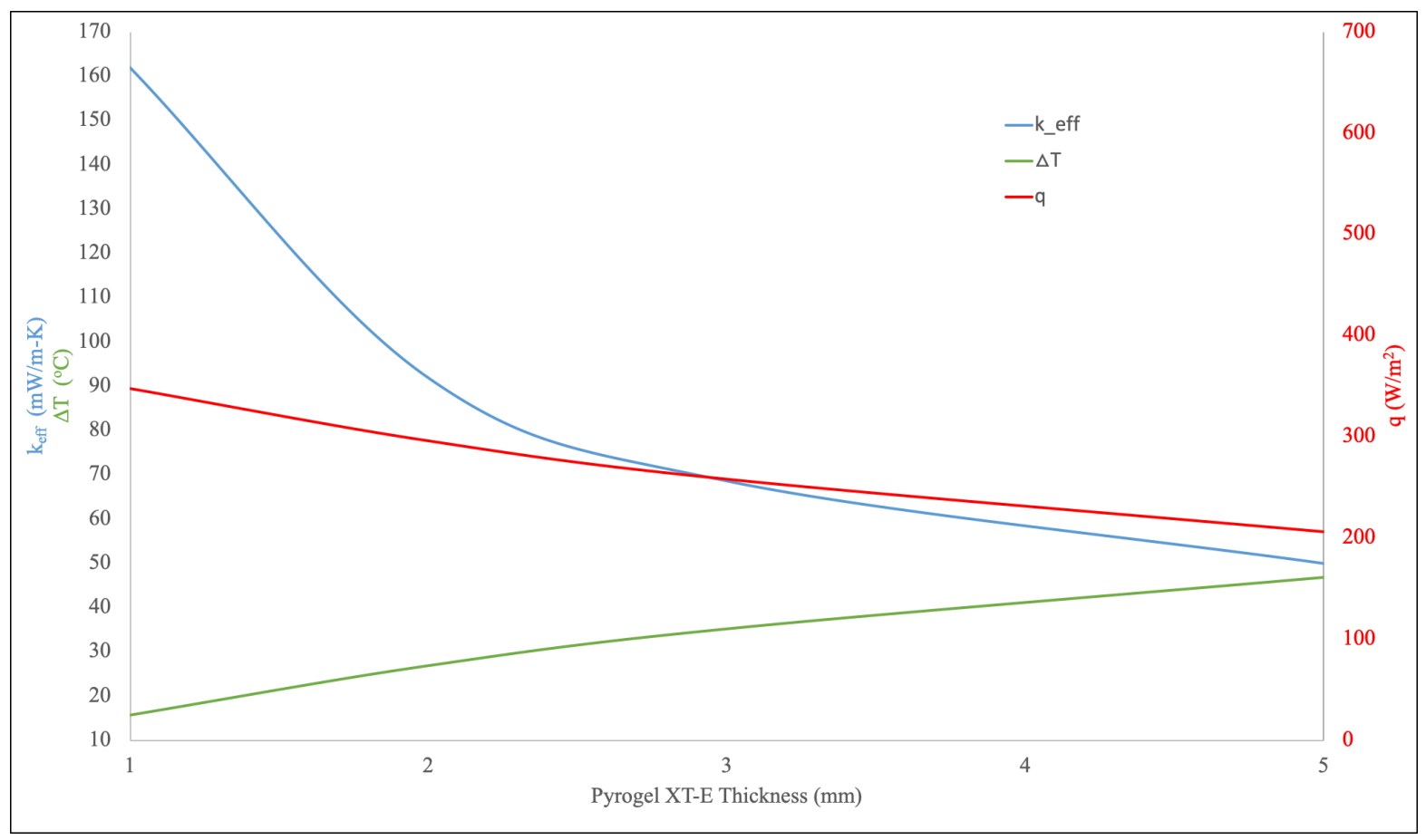

Figure 5.5 - Steady State Results of Flat Plate Samples vs. Pyrogel XT-E Thickness. 
In looking at Figure 5.1 and Figure 5.5, it can be seen that for applications with small durations of high-temperature exposure (i.e. between 0 and 20 to 30 minutes), the sample with a $1 \mathrm{~mm}$ layer of Pyrogel XT-E would perform well. For applications with exposure to high temperatures for longer than 30 minutes, increasing the Pyrogel XT-E thickness to only $2 \mathrm{~mm}$ thick would provide more than enough insulation; this is observed in Figure 5.2 and Figure 5.5. For significant durations of high-temperature exposure, Figures 5.3, 5.4, and 5.5 show that either the $3 \mathrm{~mm}$ or $5 \mathrm{~mm}$ sample will suffice. It is interesting to note in Figure 5.5 that increasing the Pyrogel XT-E thickness from $1 \mathrm{~mm}$ to $2 \mathrm{~mm}$ roughly halves the effective thermal conductivity of the sample. Increasing that to $3 \mathrm{~mm}$ further improves the effective thermal conductivity, but not to the same degree. Increasing beyond $3 \mathrm{~mm}$ appears to produce a linear relationship between effective thermal conductivity and Pyrogel XT-E thickness; this linear relationship is evident in the change in temperature and heat flux curves as well. If budget is a concern and significantly long durations of high-temperature exposure are not imminent, the $2 \mathrm{~mm}$, or even $3 \mathrm{~mm}$, sample appears to be a better option over the $5 \mathrm{~mm}$ sample, which went against expectations.

\subsubsection{ANSYS Model of Corrugated Carbon Fiber Sandwich Structure}

Transient plots for the corrugated carbon fiber sandwich structure were created in ANSYS Workbench. As mentioned in the Section 3.3, the area in the corrugation air gaps was modeled as a solid (except for when modeling air). Temperature vs. sample thickness for the corrugated composite samples were plotted for various time steps. Each curve on the plot represents the temperature distribution through the sample at a certain time step. The steady-state results are plotted on the same graph to show the trend of the temperature distribution through the thickness

of the sample as time increases. For each sample, temperatures were taken from two different 
paths on the sample: through the middle of the corrugated section and along the carbon fiber in the corrugated section; these paths can be seen in Figure 3.6 in Section 3. The purpose of this is to obtain an understanding of the heat transfer through the part of the sample made primarily of the insulation and through the path of carbon fiber corrugation.

Figures 5.6 displays plots of the corrugated carbon fiber sandwich structure along the straight path for Pyrogel XT-E insulation at various time steps. Figure 5.7 compares the temperature distribution through the straight path and corrugated path along the thickness of the corrugated carbon fiber sandwich structure at a time of 100 seconds.

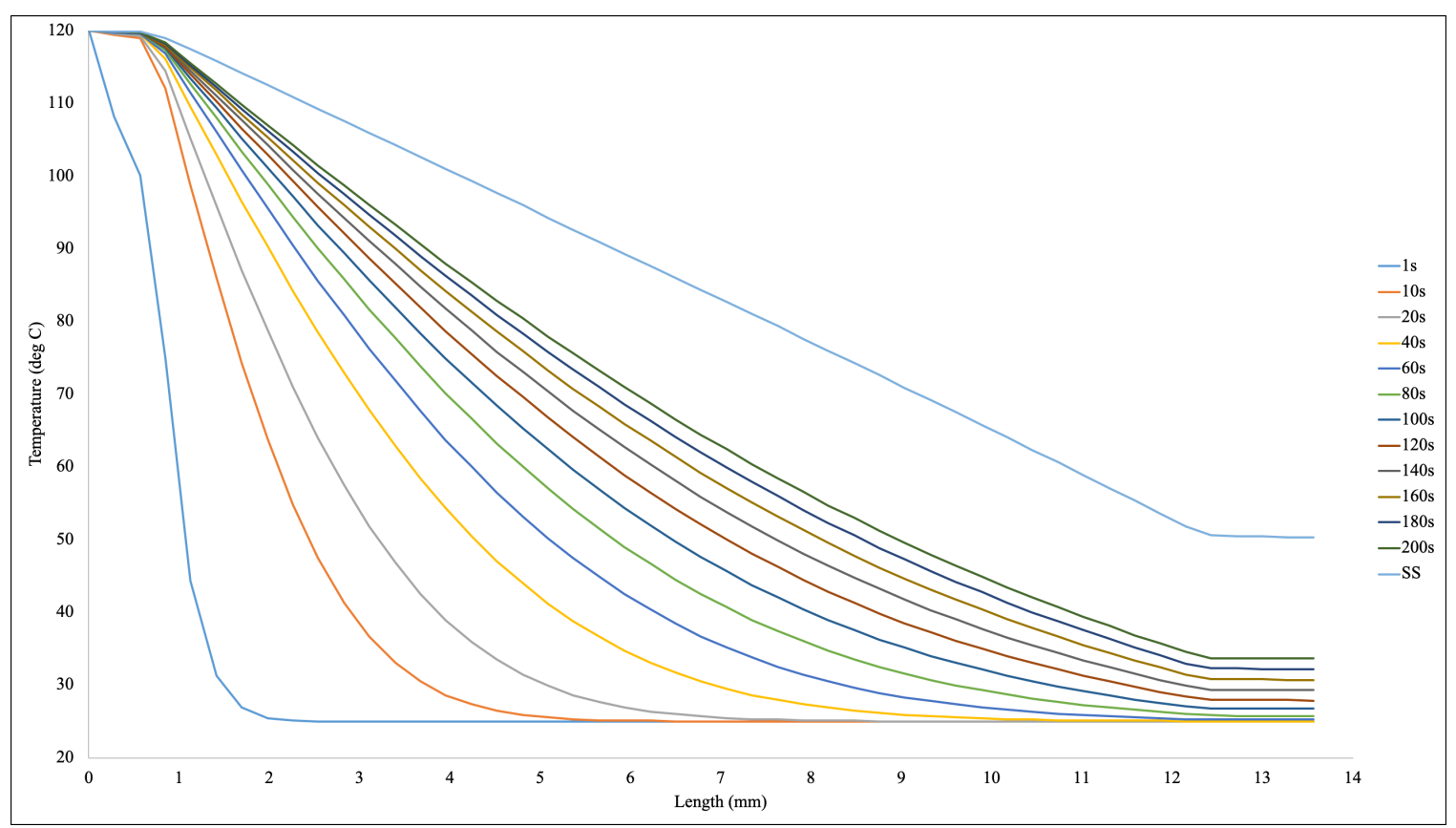

Figure 5.6 - Straight Path Transient Analysis for Pyrogel XT-E Insulation. 


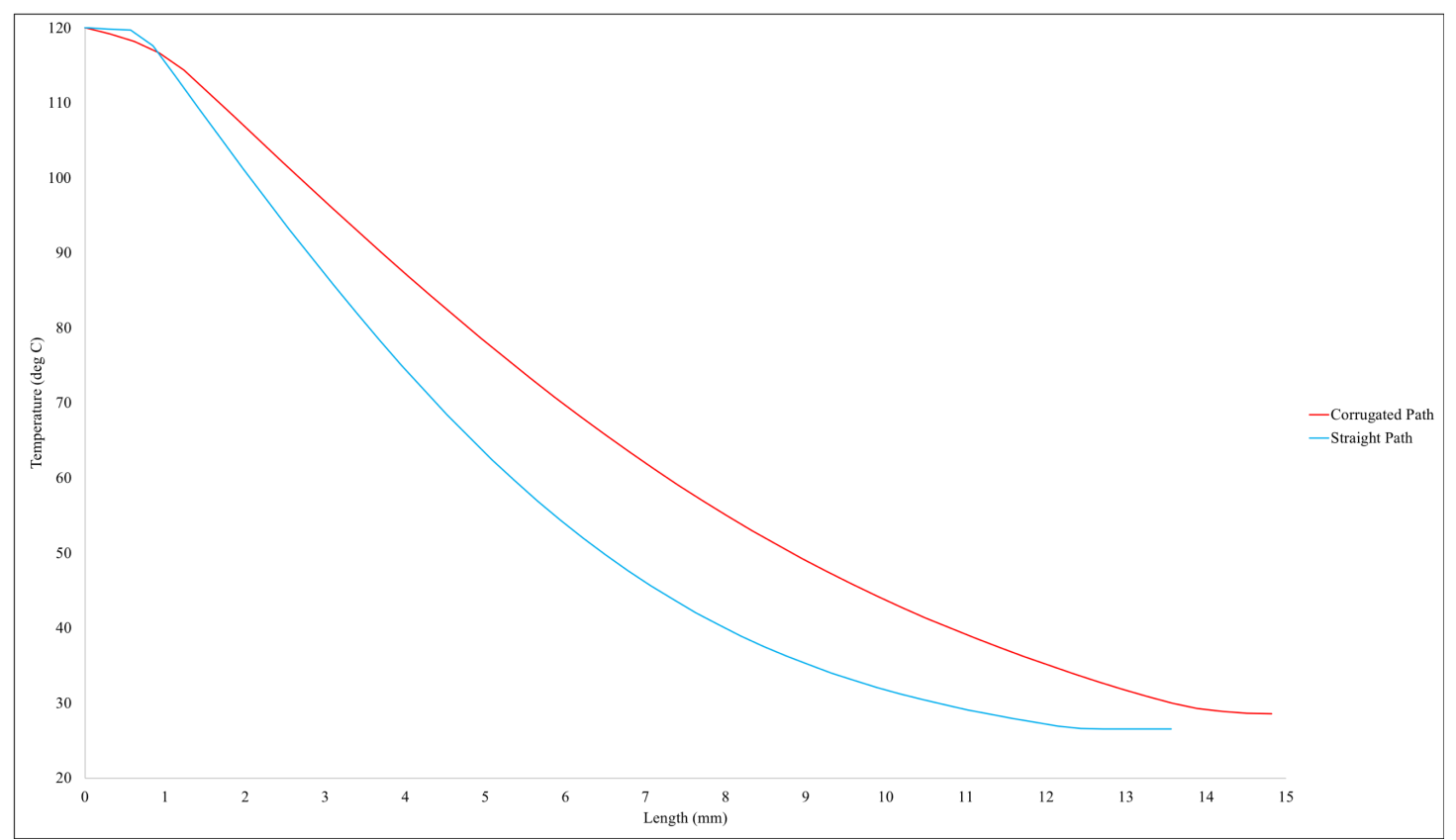

Figure 5.7 - Straight Path vs. Corrugated Path Transient Analysis for Pyrogel XT-E Insulation at $\mathrm{t}=100 \mathrm{~s}$.

It can be seen from Figures 5.6 and 5.7 that, as expected, the straight path through the corrugated carbon fiber sandwich structure sample has lower temperature readings than the corrugated path. Heat looks for the path of least resistance, so heat wants to travel along the carbon fiber corrugation due to the high insulative performance of the Pyrogel XT-E insulation. This thermal bridging effect is evident in Figure 5.8, which is a thermal gradient plot from ANSYS Workbench. 


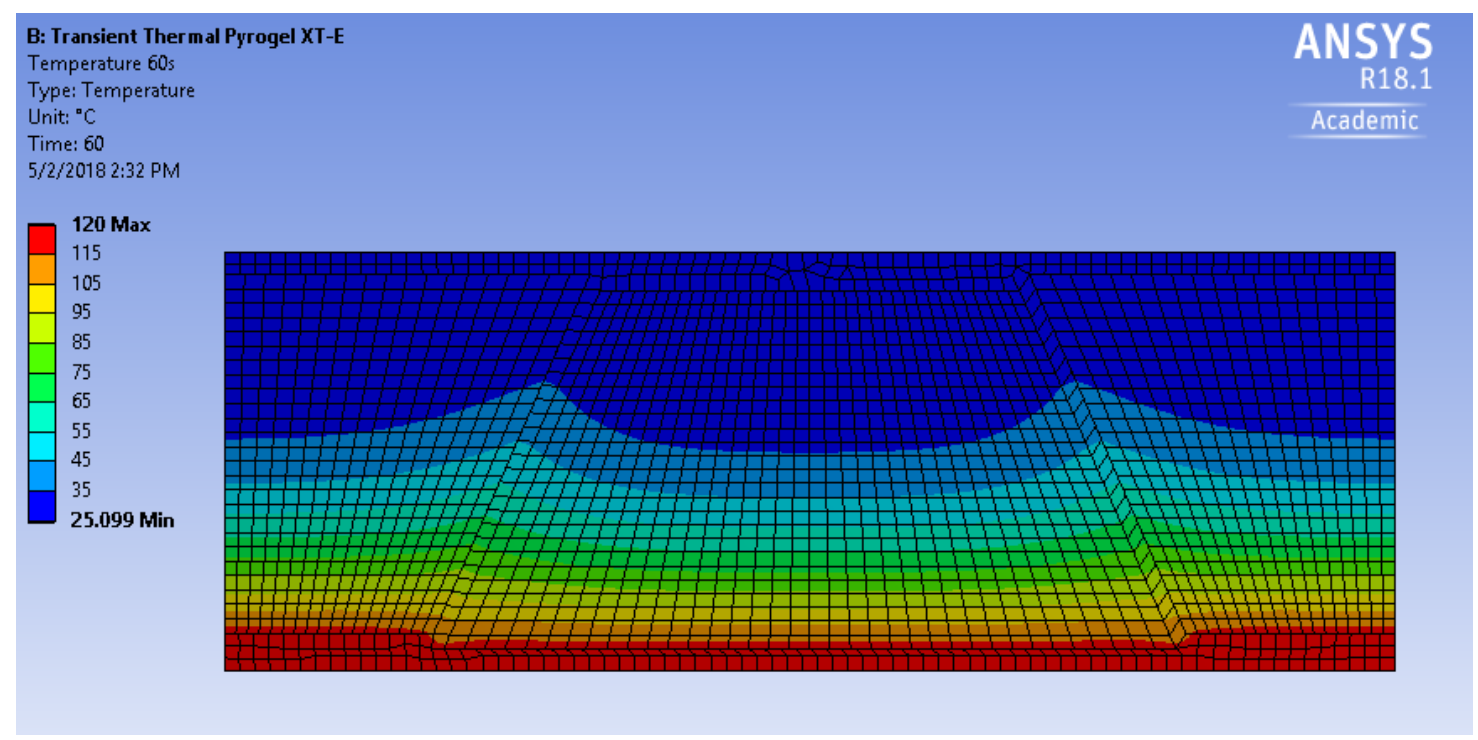

Figure 5.8 - Thermal Bridging Effect of Corrugated Carbon Fiber Sample with Pyrogel XT-E Insulation at $\mathrm{t}=60 \mathrm{~s}$.

The flow of heat through the sample is attracted to the carbon fiber section, which is a primary issue to consider with the corrugated carbon fiber sandwich structure. It is speculated that this phenomenon would be more severe as the applied temperature increases. The flat plate sandwich structure sample model does not experience this thermal bridging, which could explain why it performs substantially better than the corrugated carbon fiber sandwich structure. A thermal gradient plot of the flat plate structure sample with a 5mm layer of Pyrogel XT-E can be seen in Figure 5.9. 


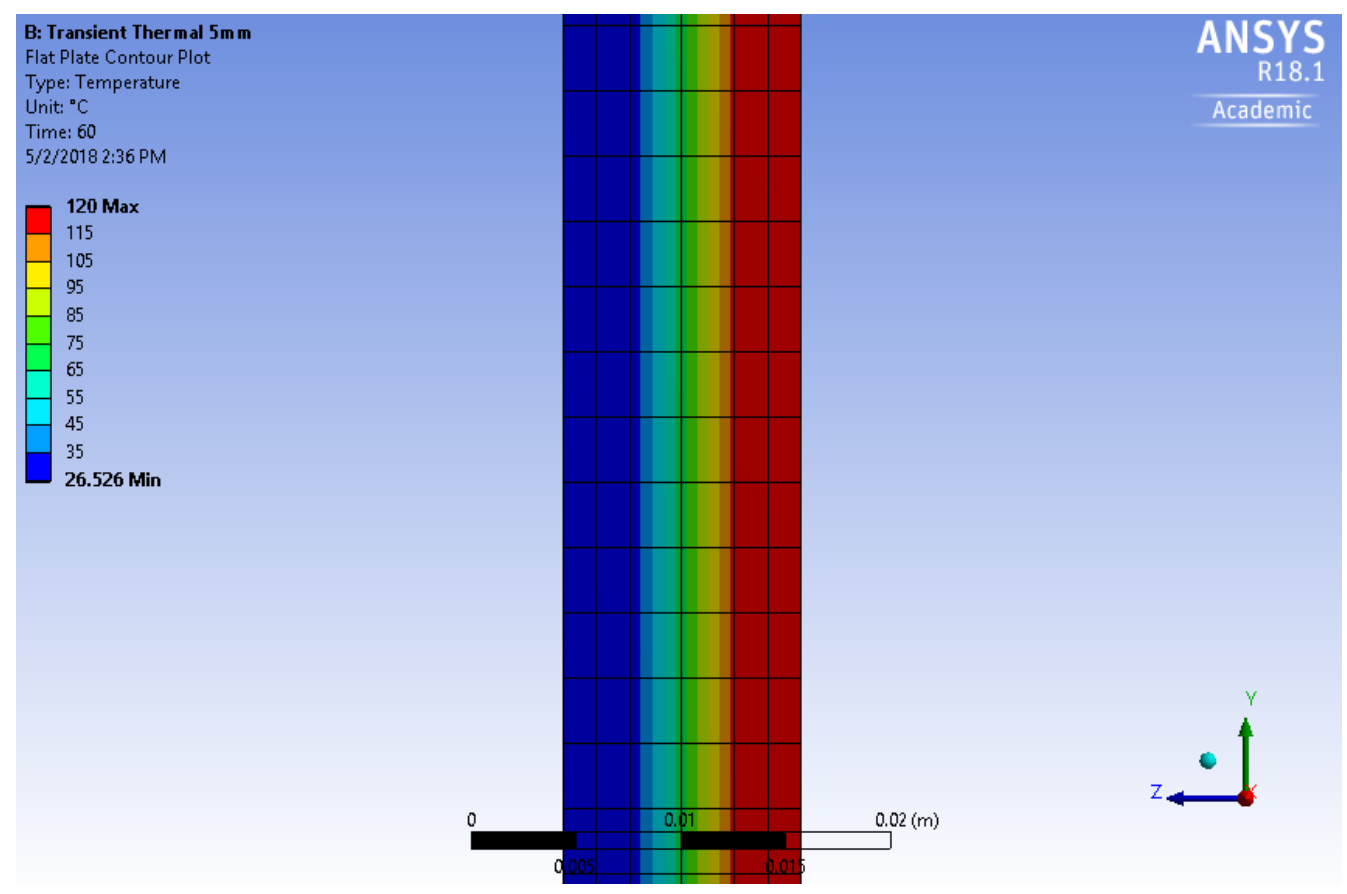

Figure 5.9 - Flat Plate Sample with 5mm Pyrogel XT-E Insulation at t $=60 \mathrm{~s}$.

\subsubsection{Transient Insulation Study on Corrugated Carbon Fiber Sample}

To show how Pyrogel XT-E aerogel (and aerogel in general) performs relative to the competition, other common insulation types were compared to Pyrogel XT-E using the corrugated carbon fiber sample. This sample was run with various insulation types in place of Pyrogel XT-E. Material and thermal properties for the insulations tested can be seen in Table 5.3.

Table 5.3 - Material and Thermal Properties of Insulation Types [8].

\begin{tabular}{|c|c|c|c|}
\hline Insulation & $\mathrm{k}(\mathrm{W} / \mathrm{m}-\mathrm{K})$ & $\mathrm{c}_{\mathrm{p}}(\mathrm{J} / \mathrm{kg}-\mathrm{K})$ & $\rho\left(\mathrm{kg} / \mathrm{m}^{3}\right)$ \\
\hline Pyrogel XT-E & 0.024 & 840 & 200 \\
\hline Air & 0.028 & 1009 & 1 \\
\hline Cellulose & 0.040 & 2020 & 40 \\
\hline Expanded Polystyrene (EPS) & 0.036 & 1300 & 22 \\
\hline Polyurethane & 0.025 & 1450 & 35 \\
\hline Aerogel Particles (Cabot P100) & 0.014 & 1000 & 150 \\
\hline
\end{tabular}


Temperature along the straight path vs. sample thickness was plotted for each insulation type at time instances of 20, 80, and 160 seconds. Those plots can be seen in Figures 5.10, 5.11, and 5.12.

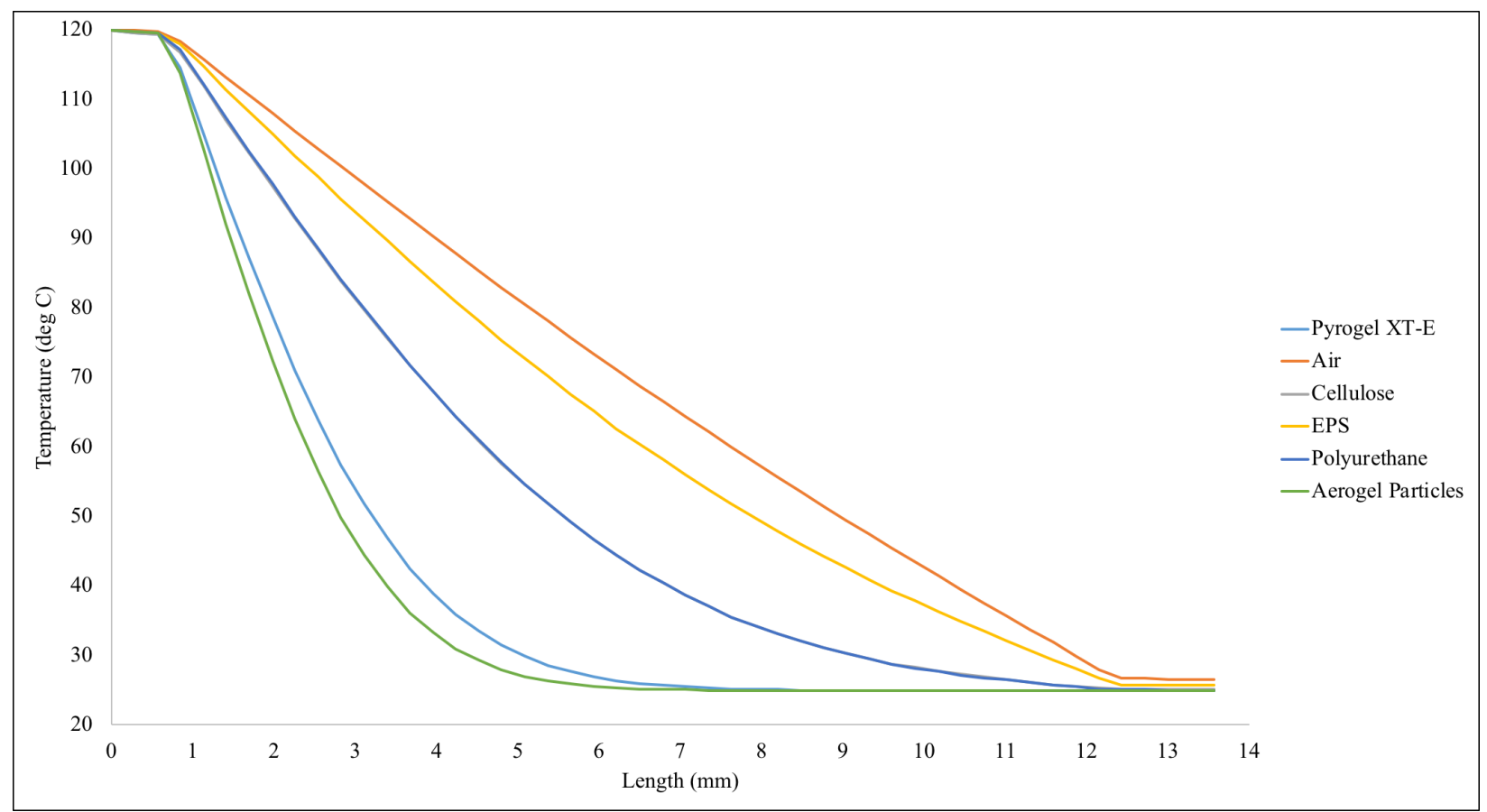

Figure 5.10 - Insulation Comparison for Corrugated Carbon Fiber Sample at $\mathrm{t}=20 \mathrm{~s}$. 


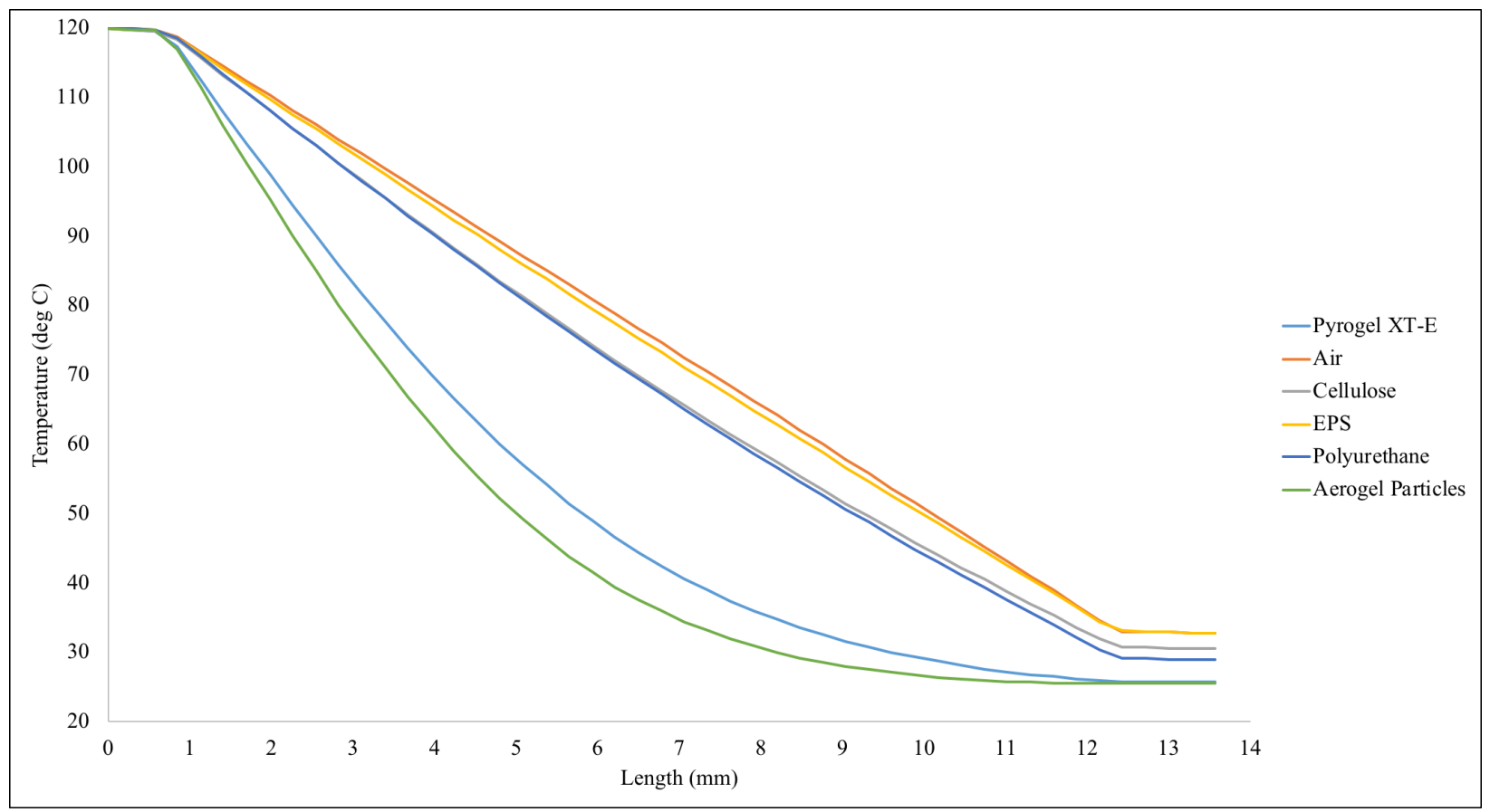

Figure 5.11 - Insulation Comparison for Corrugated Carbon Fiber Sample at $\mathrm{t}=80 \mathrm{~s}$.

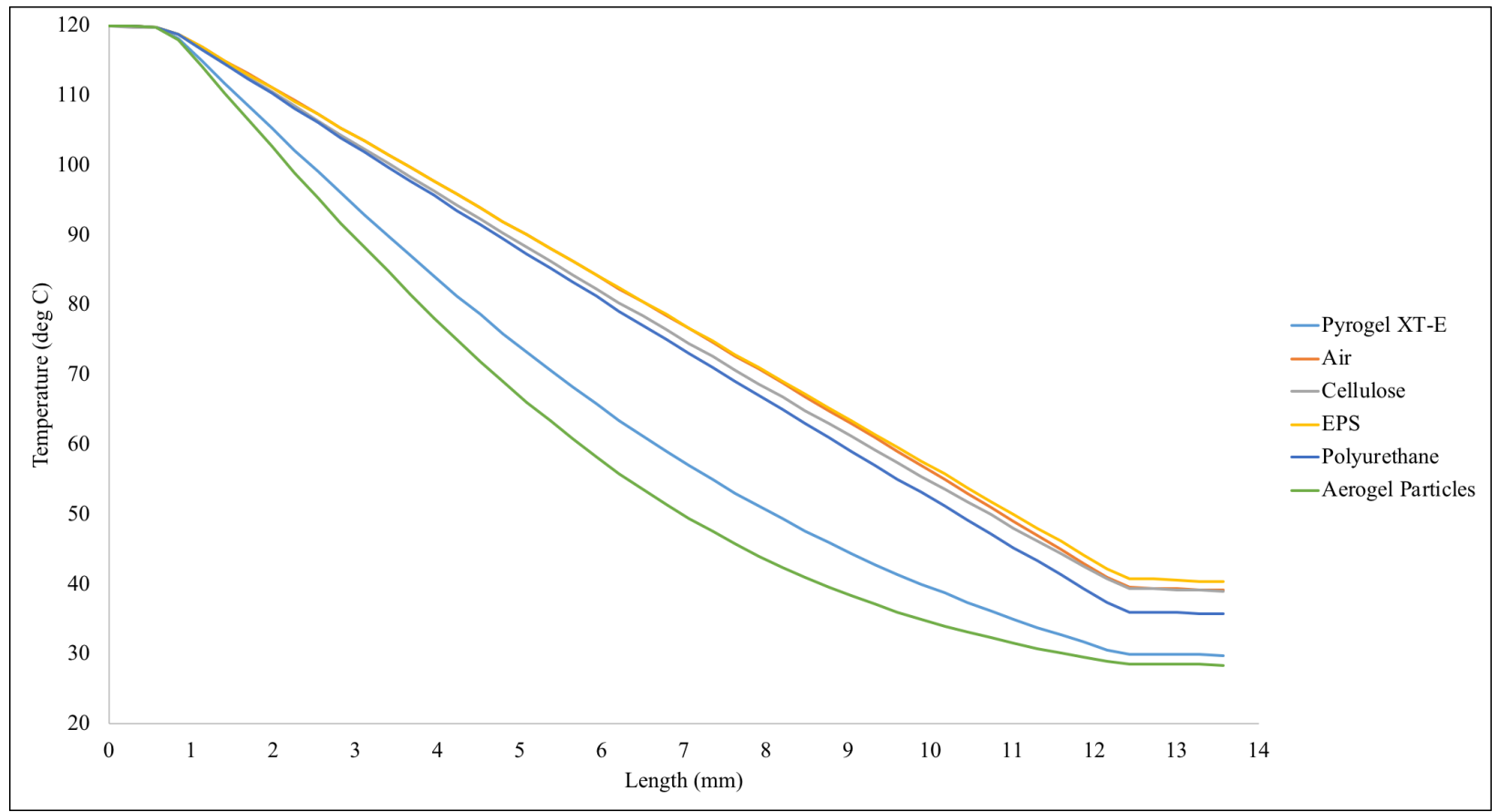

Figure 5.12 - Insulation Comparison for Corrugated Carbon Fiber Sample at $\mathrm{t}=160 \mathrm{~s}$. 
As expected, air insulation allowed the sample to approach steady state the fastest out of all the insulation types. Let it be noted that all insulation materials were modeled as a solid in ANSYS Workbench, while air was modeled as a fluid, which takes into account the bulk fluid motion of heating. Expanded polystyrene (EPS) did not perform much better, especially as time increased beyond 20 seconds. It is difficult to see from the first plot at 20 seconds, but cellulose and polyurethane perform almost identically. As time increases, polyurethane performs only slightly better than cellulose, as cellulose approaches steady-state faster. Pyrogel XT-E and the pure aerogel particles performed the best, with aerogel particles edging out Pyrogel XT-E slightly at each displayed time step. This is possibly due to the fact that Pyrogel XT-E is not pure aerogel; it is composed of a fiberglass base ingrained with silica aerogel (See Table 1.1). Another thing to note is that although polyurethane has a slightly higher thermal conductivity than Pyrogel XT-E, Pyrogel XT-E significantly outperforms it. This reminds us that other thermal and mechanical properties can have a significant effect on the transfer of heat through a sample. Table 5.4 displays the thermal conductivity of the corrugated carbon fiber sample with the various insulation materials.

Table 5.4 - Thermal Conductivity of Insulation Materials.

\begin{tabular}{|c|c|c|}
\hline Insulation & $\mathrm{k}_{\text {eff }}(\mathrm{W} / \mathrm{m}-\mathrm{K})$ & $\mathrm{k}(\mathrm{W} / \mathrm{m}-\mathrm{K})$ \\
\hline Pyrogel XT-E & 0.044 & 0.024 \\
\hline Air & 0.050 & 0.028 \\
\hline Cellulose & 0.063 & 0.040 \\
\hline Expanded Polystyrene (EPS) & 0.059 & 0.036 \\
\hline Polyurethane & 0.047 & 0.025 \\
\hline Aerogel Particles (Cabot P100) & 0.035 & 0.014 \\
\hline
\end{tabular}

As can be seen from Table 5.4, the difference between the effective thermal conductivity of the sample, $k_{\text {eff }}$, and the thermal conductivity of the insulation material alone, $k$, is about the same for each insulation material. As mentioned before, the observation of how the different insulation 
materials would affect the thermal bridging in the corrugated carbon fiber sample was a key point of this study. It was speculated that the materials with the higher thermal conductivities would cause more severe thermal bridging, it can be seen that the effect of thermal bridging in the corrugated carbon fiber sample was relatively the same throughout all insulation materials. This is made certain by the differences between the effective thermal conductivities of the samples and the thermal conductivities of the insulation materials themselves.

\subsection{Experimental Results \& Discussion}

As with the theoretical computer models, experimental analysis was performed on two sample geometries. The samples tested were the flat plate sandwich structure with a $5 \mathrm{~mm}$ layer of Pyrogel XT-E and the corrugated carbon fiber sandwich structure with Pyrogel XT-E in the corrugation gaps. The flat plate sandwich structure was used to validate the testing setup by comparing the experimentally determined thermal conductivity value of Pyrogel XT-E to the published value by its manufacturer, Aspen Aerogels. Each sample orientation was tested 5 times to confirm accuracy of measurement. The effective thermal conductivity was calculated using Equation 5.1.

$$
k_{e f f}=\frac{q L}{\Delta T}
$$

\subsubsection{Flat Plate Sandwich Structure}

The published thermal conductivity for Pyrogel XT-E is about $0.024-0.026 \mathrm{~W} / \mathrm{m}-\mathrm{K}$ for the temperature range experienced during these tests [1]. Figure 5.13 displays the experimentally determined thermal conductivity curves vs. time. 


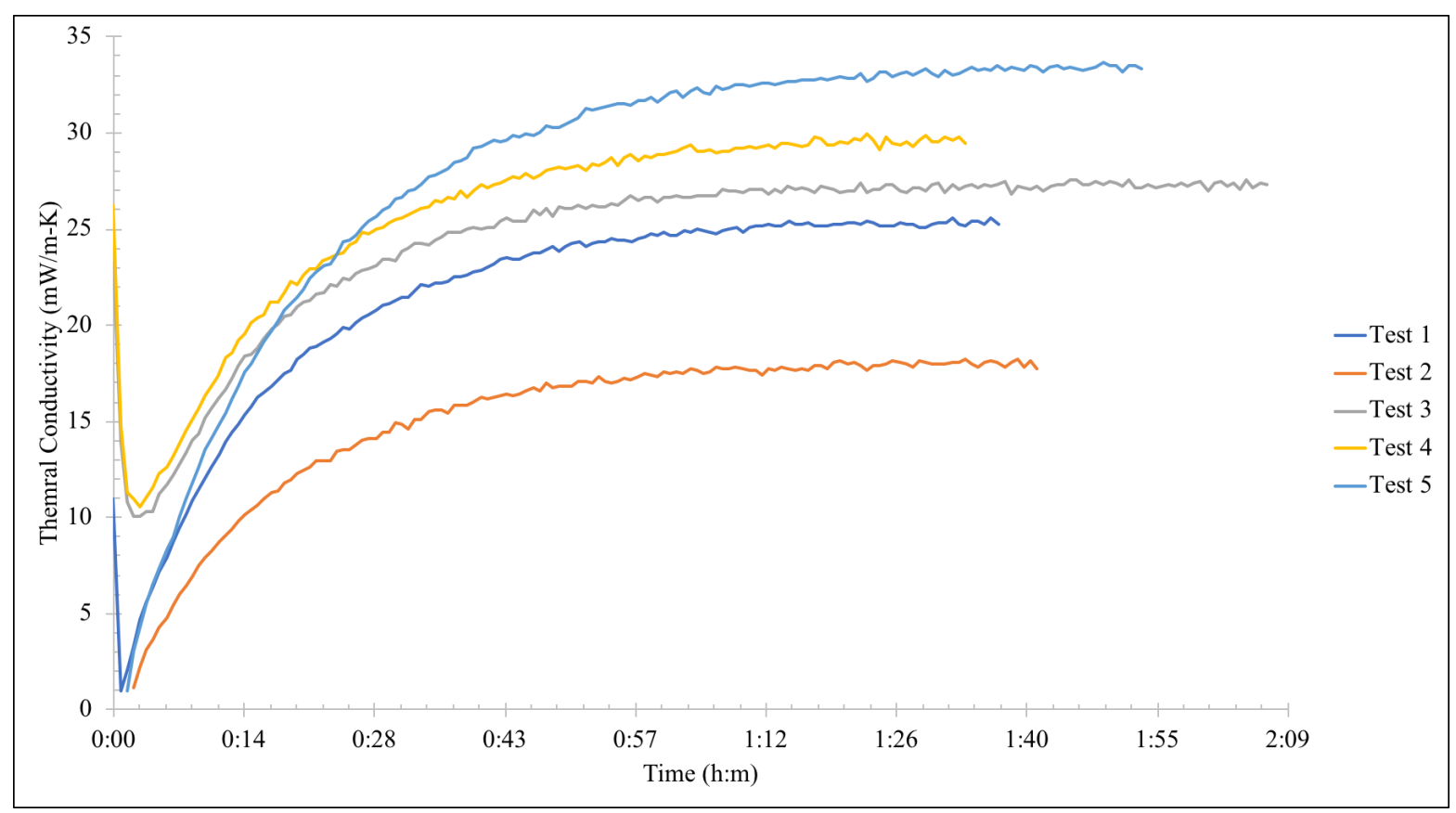

Figure 5.13 - Thermal Conductivity vs. Time for Flat Plate Sandwich Structure.

Table 5.5 displays the average thermal conductivity and standard deviation for the steady state portion of each curve, which was defined as the region of less than or equal to a $1 \%$ change in thermal conductivity across data points. Test 2 was included in Figure 5.13 to show its projection, but it was not included in further analysis due to being well outside of the results spectrum by over three standard deviations. There could be many reasons why Test 2 performed so poorly, but it is likely due to improper contact among the applied heat source and the sensors to the sample or an internal error with the heat flux sensor, as it recorded a value much lower than usual.

Table 5.5 - Thermal Conductivity for Flat Plate Sandwich Structure.

\begin{tabular}{|c|c|c|}
\hline Test & $\mathrm{k}(\mathrm{W} / \mathrm{m}-\mathrm{K})$ & Standard Deviation \\
\hline 1 & 0.025 & 0.11 \\
\hline 3 & 0.027 & 0.16 \\
\hline 4 & 0.029 & 0.30 \\
\hline 5 & 0.033 & 0.35 \\
\hline Average & 0.029 & 3.33 \\
\hline
\end{tabular}


This average thermal conductivity value taken from tests $1,3,4$, and 5 has a percent difference of $11.5 \%$ from the published thermal conductivity value [1]. However, as mentioned before, the published value is the thermal conductivity of Pyrogel XT-E, while this experimentally determined value is the effective thermal conductivity of the flat plate structure. Regardless, this result does a good job of validating the designed test setup and temperature control circuit. It is noted that the temperature at the front of the sample is a few degrees higher than the applied $120^{\circ} \mathrm{C}$; this is likely attributed to a few things. One possible source of this error is due to contact resistance between the heating element, the front aluminum plate, and the front of the sample. The high thermal conductivity of aluminum can potentially cause high thermal contact resistance that contributes to errors in temperature readings. Another theory is that this error is due to the inconsistent temperature distribution applied by the flat plate heating element, as heat is provided through an

electric coil that is not completely uniform; placing a thermally conductive aluminum plate at the front and back of the sample is an attempt to negate the effect of this error.

\subsubsection{Corrugated Carbon Fiber Sandwich Structure}

Figure 5.14 displays the experimentally determined thermal conductivity curves vs. time for the corrugated carbon fiber sandwich structure with Pyrogel XT-E in the corrugation gaps. 


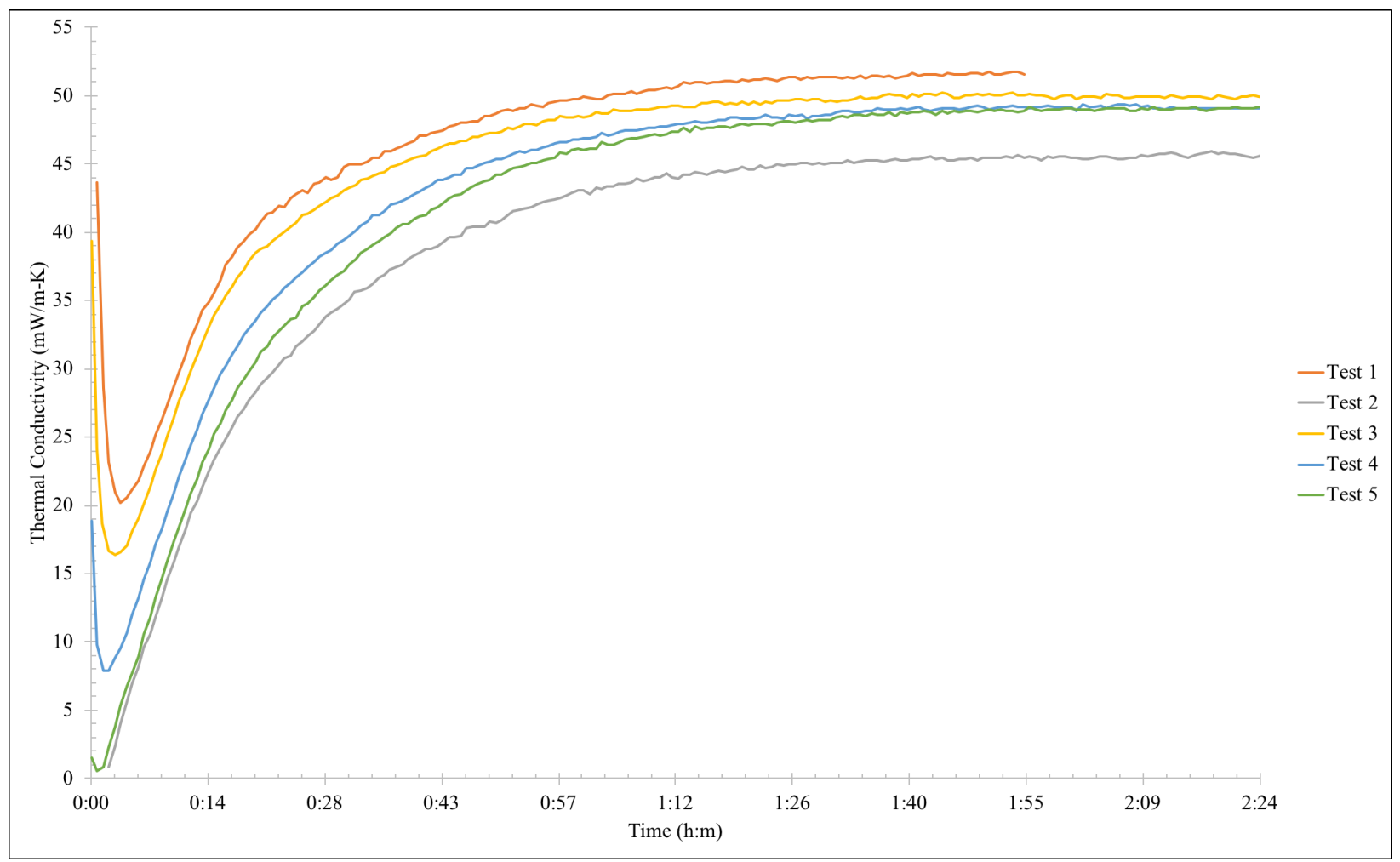

Figure 5.14 - Thermal Conductivity vs. Time for Corrugated Carbon Fiber Sandwich Structure.

Table 5.6 displays the average thermal conductivity and standard deviation for the steady state portion of each curve, which was defined as less than or equal to a $0.5 \%$ change in value.

Table 5.6 - Thermal Conductivity for Corrugated Carbon Fiber Sandwich Structure.

\begin{tabular}{|c|c|c|}
\hline Test & $\mathrm{k}(\mathrm{W} / \mathrm{m}-\mathrm{K})$ & Standard Deviation \\
\hline 1 & 0.051 & 0.69 \\
\hline 2 & 0.045 & 0.26 \\
\hline 3 & 0.050 & 0.43 \\
\hline 4 & 0.049 & 0.18 \\
\hline 5 & 0.049 & 0.14 \\
\hline Average & 0.049 & 2.06 \\
\hline
\end{tabular}


Though the thickness of the Pyrogel XT-E in the corrugation is just over twice as thick as the 5 mm Pyrogel XT-E layer in the flat plate structure, the higher average thermal conductivity of the corrugated carbon fiber sandwich structure is likely due to the thermal bridging along the corrugated carbon fiber. Despite this, adding Pyrogel XT-E in the corrugation gaps provides a significant improvement in the thermal conductivity of this high-strength structure.

Note that the average test duration differs from testing the corrugated carbon fiber structure to the flat plate sandwich structure. This is because the corrugated carbon fiber structure has thicker Pyrogel XT-E insulation (the effects of thermal bridging had not been realized), so it was anticipated that the time to reach steady state would be shorter for the flat plate sandwich structure. Longer test times were then reserved for the corrugated carbon fiber structure. This, however, was not the case, as the flat plate sandwich structure was given just enough time to reach steady state, yet it was enough time to achieve sufficient results.

\subsection{Discussion of Results and Uncertainty}

The flat plate sandwich structure with Pyrogel XT-E was determined to have a thermal conductivity value very close to the published value for that temperature range, which is around $0.024-0.026 \mathrm{~W} / \mathrm{m}-\mathrm{K}$. This was expected and validates the designed test setup and temperature control circuit. Discrepancies are likely due to reasons mentioned previously, especially the thermal contact resistance and heat leakage through poorly insulated spots throughout the test enclosure. As expected, the flat plate sandwich structure with Pyrogel XT-E performed better than 
the corrugated carbon fiber sandwich structure, which can be seen in Table 5.7. This is likely due to the thermal bridging present in the corrugation section of the carbon fiber sandwich structure, as this phenomenon is not present in the flat plate sandwich structure. However, for applications where weight is critical yet high strength and insulative performance are necessary, the corrugated carbon fiber sandwich structure is the better choice.

Table 5.7 - Thermal Conductivity Test Results with Pyrogel XT-E.

\begin{tabular}{|c|c|c|}
\hline Sample & $\begin{array}{c}\text { Experimental } k_{\text {eff }} \\
(\mathrm{W} / \mathrm{m}-\mathrm{K})\end{array}$ & $\begin{array}{c}\text { Thermal Model } k_{\text {eff }} \\
(\mathrm{W} / \mathrm{m}-\mathrm{K})\end{array}$ \\
\hline Flat Plate Sandwich Structure & 0.029 & 0.050 \\
\hline $\begin{array}{c}\text { Corrugated Carbon Fiber } \\
\text { Sandwich Structure }\end{array}$ & 0.049 & 0.044 \\
\hline
\end{tabular}

\subsubsection{Experimental Uncertainty Analysis}

The experiments conducted in this thesis are susceptible to two forms of error, systematic and random error. Systematic error is a fixed offset that can be quantified over repeated measurements at fixed operating conditions, such as calibration error. Random error is more common and is due to unknown sources, such as sensor placement, repeatability of measurement, resolution of the measurement instrument, small changes in environmental conditions, and measurement procedure and technique, among others. There is not necessarily a correct value for the uncertainty of a measurement; it is simply calculated from as many known sources as possible.

There is uncertainty in every aspect of a measurement, and the uncertainty in thermal conductivity will depend on the uncertainty in the values that are used to calculate it. This method is referred 
to as error propagation [stat textbook]. These uncertainties are represented in the form $u_{i}$ where $i$ is any sort of measured value. The relative uncertainty of thermal conductivity, $u_{k}$, is calculated according to ASTM Method 0177, which can be seen in Equations 5.2 and 5.3 [16]. The basic form of the relative uncertainty can be seen in Equation 5.2, which contains the partial derivatives of Equation 5.1. It uses the root-sum-square (RSS) method, which is the square root of the sum of the squares of all uncertainties.

$$
u_{k}=\sqrt{\left(\frac{\partial k}{\partial q} u_{q}\right)^{2}+\left(\frac{\partial k}{\partial L} u_{L}\right)^{2}+\left(\frac{\partial k}{\partial \Delta T} u_{\Delta T}\right)^{2}}
$$

After inserting the partial derivatives of Equation 5.1 and dividing through by Equation 5.1, Equation 5.2 reduces to the relative uncertainty of thermal conductivity, which is seen in Equation 5.3 and is in the form of a percentage.

$$
\frac{u_{k}}{k}=\sqrt{\left(\frac{u_{q}}{q}\right)^{2}+\left(\frac{u_{L}}{L}\right)^{2}+\left(\frac{u_{\Delta T}}{\Delta T}\right)^{2}}
$$

The three uncertainties in Equation 5.3, $u_{q}, u_{L}$, and $u_{\Delta T}$, will be discussed in the proceeding sections.

\subsubsection{Uncertainty Due to Heat Flux Measurement}

Errors in the measurement of heat flux include sensor placement, repeatability or random error, sensor thickness, and the sensitivity of the sensor itself. Some of the errors, such as the error due 
to the sensor thickness, are difficult to quantify, but other errors are easier to attach a numerical value to, such as the sensitivity of the sensor.

The two errors analyzed for the heat flux sensor are the uncertainty due to the sensor sensitivity and the random error associated with repeatability of measurement. The sensitivity of the sensor is dependent on the operating temperature of the sensor; the sensitivity at the calibrated temperature, $25{ }^{\circ} \mathrm{C}$, is $10.35 \pm 0.29 \mu \mathrm{V} /\left(\mathrm{W} / \mathrm{m}^{2}\right)$. For operating temperatures other than $25{ }^{\circ} \mathrm{C}$, a calibration curve is used, which is supplied by the manufacturer, FluxTeq. This can be seen in Equation 5.4 [30].

$$
S_{T^{0} C}=S_{c a l i b} *\left(0.00334 T^{0}{ }_{C}+0.917\right)
$$

Where $S_{\text {calib }}$ is the sensitivity at the calibrated temperature, $25{ }^{\circ} \mathrm{C}$. The sensitivity uncertainty, 0.29 $\mu \mathrm{V} /\left(\mathrm{W} / \mathrm{m}^{2}\right)$, is used in Equation 5.4 as well to calculate the sensitivity uncertainty at the operating temperature.

The random uncertainty is dependent on the standard deviation of the heat flux data set, $\mathrm{s}_{q}$, as well as the number of data points taken for each test, N. Equation 5.5 is used for calculating the random uncertainty [31].

$$
\bar{s}=\frac{S}{\sqrt{N}}
$$


When using this formula, a normal distribution is assumed, as well as large degrees of freedom being present. This random uncertainty is in a $68 \%$ confidence interval; to adjust it to be in a $95 \%$ confidence interval, the random uncertainty is multiplied by a factor of 2 [31].

These two uncertainty values are combined into one uncertainty value using the RSS method. This is done for each of the five tests for each sample. The total heat flux measurement uncertainty for the flat plate sandwich structure can be seen in Table 5.8. Note that Test 2 was omitted due to a faulty test likely due to a significant measurement error with the heat flux sensor.

Table 5.8 - Heat Flux Relative Uncertainty for Flat Plate Sandwich Structure.

\begin{tabular}{|c|c|c|}
\hline Test & $\mathrm{q}\left(\mathrm{W} / \mathrm{m}^{2}\right)$ & $\mathrm{u}_{\mathrm{q}} / \mathrm{q}(\%)$ \\
\hline 1 & 126.1 & 2.806 \\
\hline 3 & 135.7 & 2.807 \\
\hline 4 & 145.4 & 2.807 \\
\hline 5 & 165.6 & 2.804 \\
\hline Average & 143.2 & 2.806 \\
\hline
\end{tabular}

The total heat flux measurement uncertainty for the corrugated carbon fiber sandwich structure with Pyrogel XT-E can be seen in Table 5.9.

Table 5.9 - Heat Flux Relative Uncertainty for Corrugated Carbon Fiber Sandwich Structure.

\begin{tabular}{|c|c|c|}
\hline Test & $\mathrm{q}\left(\mathrm{W} / \mathrm{m}^{2}\right)$ & $\mathrm{u}_{\mathrm{q}} / \mathrm{q}(\%)$ \\
\hline 1 & 141.9 & 2.803 \\
\hline 2 & 127.9 & 2.803 \\
\hline 3 & 142.1 & 2.805 \\
\hline 4 & 135.3 & 2.804 \\
\hline 5 & 134.5 & 2.803 \\
\hline Average & 136.3 & 2.804 \\
\hline
\end{tabular}




\subsubsection{Uncertainty Due to Thickness Measurement}

Errors in the measurement of the length, or thickness, of the sample include resolution error from the resolution of the Vernier caliper and error due to the accuracy of the caliper [32]. The thickness of each sample was only measured once (as it was not disturbed in between each of the five test runs), so there will be no random error. The resolution error was calculated using Equation 5.6 [31].

$$
u_{0}= \pm \frac{1}{2} * \text { Resolution }
$$

The accuracy of the caliper was given by the manufacturer, which is $\pm 2 \mathrm{E}-05 \mathrm{~m}[32]$. Using the RSS method as discussed prior, these two values are combined into one uncertainty value. Note that the sample thicknesses include the aluminum plates on the front and back if each sample, which are each $3.175 \mathrm{~mm}$ thick. The relative uncertainty for both samples can be seen in Table 5.10 .

Table 5.10 - Sample Thickness Measurement Relative Uncertainty.

\begin{tabular}{|c|c|c|}
\hline Sample & $\mathrm{L}(\mathrm{mm})$ & $\mathrm{u}_{\mathrm{L}} / \mathrm{L}(\%)$ \\
\hline $\begin{array}{c}\text { Flat Plate Sandwich } \\
\text { Structure }\end{array}$ & 11.35 & 0.182 \\
\hline $\begin{array}{c}\text { Corrugated Carbon Fiber } \\
\text { Sandwich Structure }\end{array}$ & 19.85 & 0.0224 \\
\hline
\end{tabular}

Before making this calculation, it was assumed that the relative uncertainty would be larger. Obtaining more thickness measurements, such as one for each test run, would possibly provide a more accurate representation of the uncertainty incurred by measuring the sample thickness. 


\subsubsection{Uncertainty Due to Temperature Measurement}

Errors in the measurement of the temperature of the sample include the calibration and random error of the Type-T thermocouples used for data acquisition, the calibration error of the Type-K thermocouple used for temperature control, and the PID Controller calibration error.

From the manufacturer, the calibration uncertainty of the Type-T thermocouples is $\pm 2{ }^{\circ} \mathrm{C}$ [33]. There are two of these thermocouples in the measurement system, one on the front of the sample and the other in the heat flux sensor on the back of the sample. The uncertainty of each Type-T thermocouple is $\pm 1^{\circ} \mathrm{C}$, but when calculating the change in temperature $\Delta \mathrm{T}=\mathrm{T}_{\text {front }}-\mathrm{T}_{\text {back, }}$, the uncertainty has to take into account both temperatures included in the equation, therefore doubling the uncertainty value.

The random error of the Type-T thermocouples is calculated using Equation 5.5. Separate calculations of Equation 5.5 are conducted to calculate the random uncertainty at the front and at the back of the sample, i.e. for each thermocouple. Like for heat flux, these values are multiplied by a factor of 2 to adjust for $95 \%$ confidence interval. The uncertainties for the front and the back of the sample are then added together, such as with the Type-T calibration uncertainty, to produce a random uncertainty for the change in temperature across the sample due to the Type-T thermocouple measurement.

The calibration error of the Type-K thermocouple is from the Type-K thermocouple used in the temperature control feedback loop in the PID controller. From the manufacturer, the calibration uncertainty of the Type-K thermocouple is $\pm 2.2{ }^{\circ} \mathrm{C}$ [33]. The calibration error of the PID Controller depends on the range of the Type-K thermocouple, which is $1450^{\circ} \mathrm{C}$. This is multiplied by an uncertainty percentage of $\pm 0.1 \%$, which results in $\pm 1.45^{\circ} \mathrm{C}$. In addition to this uncertainty 
value, $\pm 1{ }^{\circ} \mathrm{C}$ must be added for the uncertainty at the calibrated ambient temperature, which is 25 ${ }^{\circ} \mathrm{C}$. This results in a total uncertainty value of $\pm 2.45{ }^{\circ} \mathrm{C}$ for the calibration error of the PID controller [29]. The relative uncertainties of the change in temperature measurements can be seen in Table 5.11 and 5.12.

Table 5.11 - Change in Temperature Relative Uncertainty for Flat Plate Sandwich Structure.

\begin{tabular}{|c|c|c|}
\hline Test & $\Delta \mathrm{T}(\mathrm{K})$ & $\mathrm{u}_{\Delta \mathrm{T}} / \Delta \mathrm{T}(\%)$ \\
\hline 1 & 56.6 & 6.80 \\
\hline 3 & 56.4 & 6.83 \\
\hline 4 & 56.2 & 6.86 \\
\hline 5 & 56.8 & 6.78 \\
\hline Average & 56.5 & 6.82 \\
\hline
\end{tabular}

Table 5.12 - Change in Temperature Relative Uncertainty for Corrugated Carbon Fiber Sandwich Structure.

\begin{tabular}{|c|c|c|}
\hline Test & $\Delta \mathrm{T}(\mathrm{K})$ & $\mathrm{u}_{\Delta \mathrm{T}} / \Delta \mathrm{T}(\%)$ \\
\hline 1 & 55.3 & 6.97 \\
\hline 2 & 55.9 & 6.90 \\
\hline 3 & 56.8 & 6.79 \\
\hline 4 & 54.7 & 7.04 \\
\hline 5 & 54.5 & 7.07 \\
\hline Average & 55.4 & 6.96 \\
\hline
\end{tabular}

\subsubsection{Uncertainty of Thermal Conductivity}

Now that the three relative uncertainties in the right-hand side of Equation 5.3 have been explained, the relative uncertainty of the thermal conductivity can be calculated. These values can be seen in Table 5.13 and 5.14 . 
Table 5.13 - Relative Uncertainty of Thermal Conductivity for Flat Plate Sandwich Structure.

\begin{tabular}{|c|c|c|}
\hline Test & $\mathrm{k}(\mathrm{W} / \mathrm{m}-\mathrm{K})$ & $\mathrm{u}_{\mathrm{k}} / \mathrm{k}(\%)$ \\
\hline 1 & 0.025 & 7.36 \\
\hline 3 & 0.027 & 7.38 \\
\hline 4 & 0.029 & 7.41 \\
\hline 5 & 0.033 & 7.34 \\
\hline Average & 0.029 & 7.37 \\
\hline
\end{tabular}

Table 5.14 - Relative Uncertainty of Thermal Conductivity for Corrugated Carbon Fiber Sandwich Structure.

\begin{tabular}{|c|c|c|}
\hline Test & $\mathrm{k}(\mathrm{W} / \mathrm{m}-\mathrm{K})$ & $\mathrm{u}_{\mathrm{k}} / \mathrm{k}(\%)$ \\
\hline 1 & 0.051 & 7.51 \\
\hline 2 & 0.045 & 7.44 \\
\hline 3 & 0.050 & 7.35 \\
\hline 4 & 0.049 & 7.58 \\
\hline 5 & 0.049 & 7.61 \\
\hline Average & 0.049 & 7.50 \\
\hline
\end{tabular}

As can be seen in Equation 5.3, $u_{k}$ depends on the $u_{q}, u_{L}$, and $u_{\Delta T}$. Based on the results from Tables $5.8-5.14$, the uncertainty due to the measurement of the change in temperature has the most effect on the uncertainty of the thermal conductivity. The heat flux relative uncertainty, with an average value of $\pm 2.804 \%$, contributes some to the uncertainty of the thermal conductivity, but its effect is minimal. The effect of the relative uncertainty of the thickness measurement is almost nonexistent. This is further proved by the plots in Figures 5.15 and 5.16, which display the average relative uncertainty values for each sample geometry. 


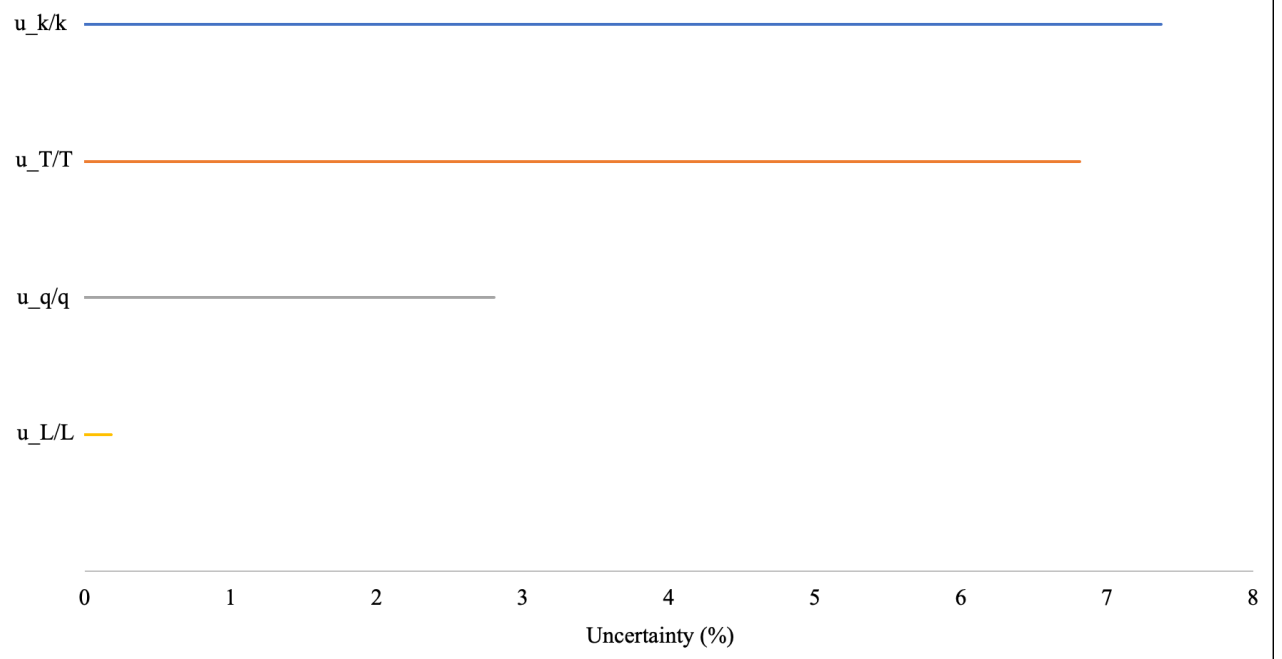

Figure 5.15 - Average Relative Uncertainty Values for Flat Plate Sandwich Structure.

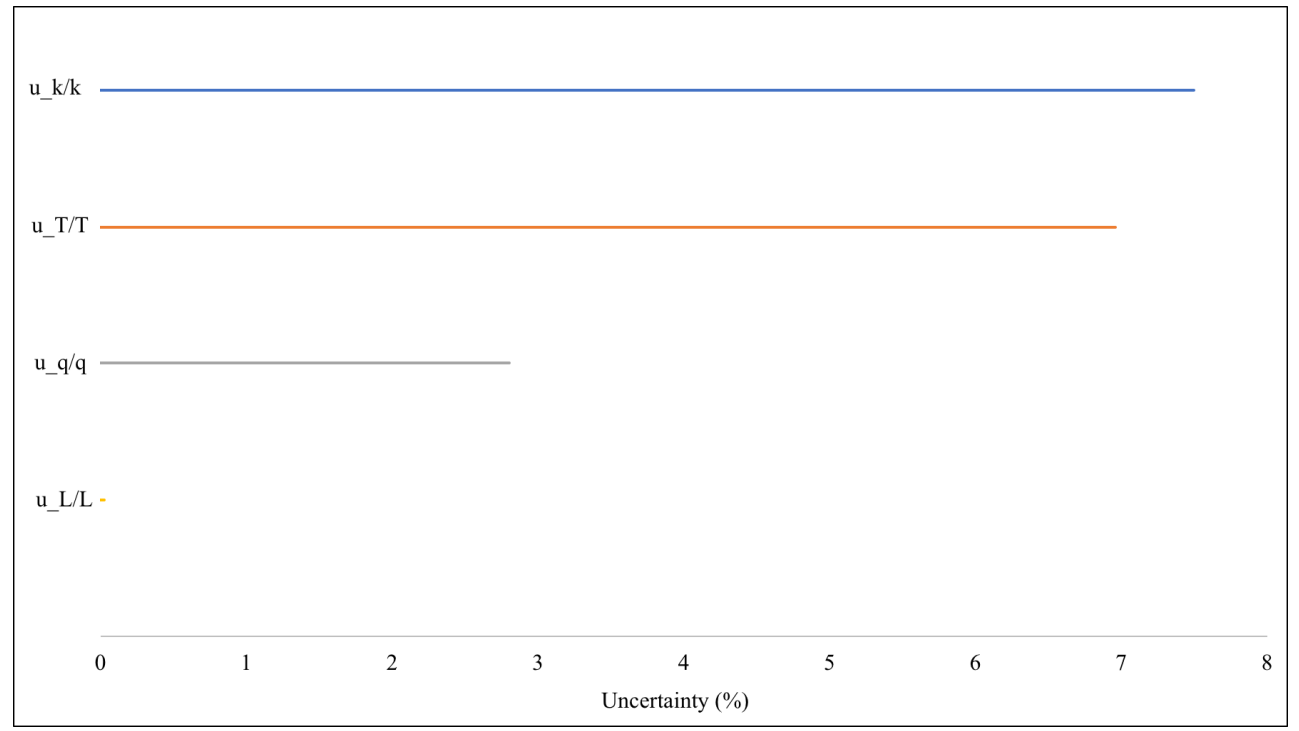

Figure 5.16 - Average Relative Uncertainty Values for Corrugated Carbon Fiber Sandwich Structure. 
It is here where the uncertainty analysis proves its value; in the future, more time and energy can be dedicated to minimizing the uncertainty of measuring the change in temperature, therefore minimizing the uncertainty of thermal conductivity.

Delving into the change in temperature relative uncertainty, Section 5.3.4 highlights that the two devices that cause the most potential error are the Type-K thermocouple used in the feedback loop for temperature control and the PID controller. In order to obtain a smaller uncertainty value for the recorded temperature of the samples, and in turn the thermal conductivity, better options for controlling the applied temperature to the source should be explored. 


\section{CHAPTER 6}

\section{Conclusion}

\subsection{Summary}

The primary goal of this thesis was to study the effect that aerogel has on the thermal performance of a corrugated carbon fiber sandwich structure by analyzing its effective thermal conductivity. Pyrogel XT-E, an aerogel-fiberglass composite manufactured by Aspen Aerogels, was used as the aerogel insulation in the experimental testing. Two sample geometries were tested, a flat plate structure consisting of a 5mm layer of Pyrogel XT-E and a corrugated carbon fiber sandwich structure with Pyrogel XT-E in the corrugation gaps. The test setup consisted of a wooden test enclosure surrounded by solid foam insulation with an aluminum sample housing; the integrated temperature control circuit was built specifically for this research project.

A finite difference model of the flat plate structure was created in Microsoft Excel to study the effect of varying Pyrogel XT-E thicknesses and to validate the experimental setup. It was determined that a flat plate structure with $3 \mathrm{~mm}$ of Pyrogel XT-E provided the best performance while limiting the amount of Pyrogel XT-E used. Through experimental validation, the flat plate structure had an effective thermal conductivity that differed by $11.5 \%$ from the published value of Pyrogel XT-E. A finite element model of the corrugated carbon fiber sandwich structure was created in ANSYS Workbench to understand the flow of heat through the sample and to provide a comparison for the experimental data. An insulation study comparing common insulation materials to Pyrogel XT-E was performed on this finite element model, with aerogel-based insulations (Pyrogel XT-E and pure aerogel particles) insulating the best, resulting in the lowest 
overall effective thermal conductivity values. The average effective thermal conductivity for the corrugated carbon fiber structure was experimentally determined to be $0.049 \pm 7.50 \% \mathrm{~W} / \mathrm{m}-\mathrm{K}$; it is speculated that its performance was hindered due to thermal bridging along the carbon fiber corrugation. Despite this, the data acquired from this thesis is useful in designing mechanically strong and thermally resistant structures for high-intensity space flight and building applications.

Integrating a low density, light weight, and low thermal conductivity material such as aerogel into the mechanically robust corrugated carbon fiber sandwich structure is instrumental for applications where both high mechanical and thermal stresses are present, such as in high-intensity aerospace flight. The data acquired from this thesis will provide useful insight in designing structures for these applications.

\subsection{Future Work}

Aerogel has been studied for some time, though it was primarily used in research laboratories. NASA studied it thoroughly and evaluated its impact in various insulation applications. Aerogel is now trickling its way down into more accessible industries, such as the outdoor clothing industry. Other ways of manufacturing aerogel are being explored; methods of producing aerogel from bio-waste materials, such as rice husk ash (ash made from the husk of a grain of rice), are being studied and implemented. Studying the performance of rice husk ash-based aerogel and other bio-waste aerogels when integrated in corrugated composite sandwich structures makes for interesting work and would be studied if this project were to be continued. 
To gain a better understanding as to how well Pyrogel XT-E performs when integrated in the corrugated carbon fiber sandwich structure, it would be useful to integrate common insulation materials into the structure and compare their performance. This was done in ANSYS Workbench, but performing an experiment would give a better comparison to the experimental results when integrating Pyrogel XT-E.

In looking at the experimental uncertainty in Sections 5.3.1 - 5.3.5, the primary source of uncertainty was in the measurement of the temperatures on either side of the sample. Type-T thermocouples were used to measure the change in temperature, while a Type-K thermocouple and a PID controller were used to control the applied temperature to the samples. In future work, it is worth exploring better options to measure the change in temperature across the sample so that the total uncertainty is minimized. 


\section{BIBLIOGRAPHY}

[1] Aspen Aerogels INC, "Pyrogel XTE: High-Performance Aerogel Insulation for Industrial and COmmercial Applications," pp. 1-2, 2017.

[2] Aspen Aerogels, "Pyrogel XT-E SDS," no. 1, pp. 1-6, 2015.

[3] M. Aegerter, N. Leventis, and M. Koebel, Aerogels handbook (Advances in Sol-Gel Derived Materials and Technologies). Spinger, 2011.

[4] A. Soleimani Dorcheh and M. H. Abbasi, "Silica aerogel; synthesis, properties and characterization,” J. Mater. Process. Technol., vol. 199, no. 1, pp. 10-26, 2008.

[5] Merriam-Webster, "Polymerization." .

[6] C. Brinker and G. Scherer, "Sol-Gel Science: The Physics and Chemistry of Sol-Gel Processing," Advanced Materials, vol. 3, no. 10. Academic Press, Inc., p. 912, 1990.

[7] V. Rao, E. Nilsen, and M. A. Einarsrud, "Effect of precursors, methylation agents and solvents on the physicochemical properties of silica aerogels prepared by atmospheric pressure drying method," J. Non. Cryst. Solids, vol. 296, no. 3, pp. 165-171, 2001.

[8] J. E. Fesmire, “Aerogel insulation systems for space launch applications," Cryogenics (Guildf)., vol. 46, no. 2-3, pp. 111-117, 2006.

[9] H. Halimaton, “Silica Aerogels,” US 2007/0276051 A1, 2007.

[10] N. Shukla, A. Fallahi, and J. Kosny, “Aerogel Thermal Insulation - Technology Review and Cost Study for Building Enclosure Applications," ASHRAE Trans., vol. 120, pp. 294 $307,2014$.

[11] E. Cuce and P. M. Cuce, "The impact of internal aerogel retrofitting on the thermal bridges of residential buildings: An experimental and statistical research," Energy Build., vol. 116, no. January, pp. 449-454, 2016. 
[12] J. Fořt, M. Pavlíková, J. Pokorný, A. Trník, and Z. Pavlík, "Properties of a Sandwich Thermal Insulation Composite with Silica Aerogel,” Key Eng. Mater., vol. 707, pp. 114121, 2016.

[13] M. Jerman and R. Černý, "Effect of moisture content on heat and moisture transport and storage properties of thermal insulation materials," Energy Build., vol. 53, pp. 39-46, 2012.

[14] J. Silva, "PrimaLoft, Inc. Partners with L.L.Bean for Spring 2018 Debut of PrimaLoft ${ }^{\circledR}$ Gold Insulation with Cross Core Technology for Superior Lightweight Warmth,” Snews, 2017. [Online]. Available: https://www.snewsnet.com/press-release/primaloft-incpartners-with-1-1-bean-for-spring-2018-debut-of-primaloft-gold-insulation-with-crosscore-technology-for-superior-lightweight-warmth. [Accessed: 07-Mar-2018].

[15] H. H. Tang, "Thermal Performance of Space Suit Elements with Aerogel Insulation for Moon and Mars Exploration Environmental Systems ( ICES ),” SAE Int., no. 724, 2006.

[16] ASTM International, "Standard Test Method for Steady-State Heat Flux Measurements and Thermal Transmission Properties by Means of the Guarded-Hot-Plate," Annu. B. ASTM Stand., no. C0177-13, pp. 1-23, 2014.

[17] Thermtest, "HISTORY.2 - THE GUARDED HOT PLATE METHOD,” Blog, History, 2015. [Online]. Available: https://thermtest.com/history-2-the-guarded-hot-plate-method. [Accessed: 11-Aug-2018].

[18] ASTM C1044, "Standard Practice for Using a Guarded-Hot-Plate Apparatus or ThinHeater Apparatus in the Single-Sided Mode 1," vol. 04, no. Reapproved, p. 9, 2012.

[19] T. L. Bergman, A. S. Lavine, F. P. Incropera, and D. P. Dewitt, Introduction to Heat Transfer, 6th ed. John Wiley \& Sons, Inc., 2011. 
[20] O. Engineering, "Emissivity of Common Materials," 2018. [Online]. Available: www.omega.com/literature/transactions/volume1/emissivitya.html.

[21] J. A. Hubbard, A. L. Brown, A. B. Dodd, S. Gomez-vasquez, and C. J. Ramirez, "Carbon fiber composite characterization in adverse thermal environments," 2011.

[22] greenspec, "Insulation Materials and their Thermal Properties," Green Building Design, 2018. [Online]. Available: http://www.greenspec.co.uk/building-design/insulationmaterials-thermal-properties/. [Accessed: 25-Apr-2018].

[23] Johns Manville, “AP ${ }^{\mathrm{TM}}$ Foil-Faced Polyisocyanurate Continuous Insulation,” pp. 1-2, 2017.

[24] Tempco, “Tempco Flexible Heaters: Silicone Rubber \& Kapton,” pp. 2-17, 2018.

[25] FluxTeq, "PHFS-09e Heat Flux Sensor Datasheet," p. 1, 2018.

[26] 3M, “3M ${ }^{\mathrm{TM}}$ Polyester Tape 8911,” pp. 1-4, 2017.

[27] J. Mano, R. Hilliker, I. Blundell, E. Elghandour, and F. Kolkailah, "Optimum Design of Trapezoidal Corrugated Composite Structures,” Compos. Struct., pp. 1-13, 2017.

[28] Cytec Industrial Materials, "MTM 49-3 prepreg data sheet," no. 2C, pp. 1-4, 2012.

[29] Watlow, "PM PID Controller Specifications," pp. 1-2, 2007.

[30] FluxTeq, "PHFS Certificate of Calibration," p. 1, 2018.

[31] R. S. Figliola and D. E. Beasley, Theory and Design for Mechanical Measurements, 5th Editio. John Wiley \& Sons, Inc., 2012.

[32] Diverse Electronics, "Electronic Digital Caliper Datasheet," p. 1.

[33] Watlow, "Thermocouple Accuracy and Uncertainty." p. 1, 2007. 


\section{APPENDICES}

A. Aspen Aerogels Safety Data Sheet (SDS) for Pyrogel XT-E [2].

\section{aspen $\mid$ aerogels}

\section{SAFETY DATA SHEET}

\section{IDENTIFICATION}

Product identifier: Pyrogel ${ }^{\circledR}$ XT-E

Synonyms: Silica aerogel material

Manufacturer: Name:

Address:

Telephone number:

Email:

Emergency phone number:
Aspen Aerogels, Inc.

30 Forbes Road Bld. B

Northborough, MA 01532

(508) 691-1111

EHS@aerogel.com

800-535-5053 US (INFOTRAC)

352-323-3500 INTERNATIONAL

Recommended use: High performance insulation material

Restrictions on use: None.

Date of Preparation: June 11, 2015

\section{HAZARD(S) IDENTIFICATION}

\section{Classification:}

\begin{tabular}{|l|l|}
\hline Physical & Health \\
\hline Not Hazardous & Not Hazardous \\
\hline
\end{tabular}

\section{Label Elements}

Not hazardous in accordance with the GHS and OSHA Hazcom 2012.

\section{COMPOSITION / INFORMATION ON INGREDIENTS}

\begin{tabular}{|l|l|c|}
\hline \multicolumn{1}{|c|}{ Chemical name } & \multicolumn{1}{c|}{ CAS No. } & Percent \\
\hline Synthetic Amorphous Silica & $7631-86-9$ & $30-40 \%$ \\
\hline Methylsilylated Silica & $68909-20-6$ & $10-20 \%$ \\
\hline Fibrous Glass (textile grade) & Not Applicable & $40-50 \%$ \\
\hline Iron Oxide (iron (III) oxide) & $1309-37-1$ & $1-10 \%$ \\
\hline Aluminum Trihydrate (aluminum hydroxide) & $21645-51-2$ & $1-5 \%$ \\
\hline $\begin{array}{l}\text { Other components are either non-hazardous } \\
\text { ingredients or are below the concentration limit } \\
\text { for classification. }\end{array}$ & Mixture & \\
\hline
\end{tabular}

The exact percentage (concentration) of composition has been withheld as a trade secret. 


\section{FIRST-AID MEASURES}

Inhalation: If dust is inhaled, remove to fresh air. Drink water to clear throat, and blow nose. If irritation occurs or symptoms develop, seek medical attention.

Skin contact: Wash skin with soap and water. If irritation develops, get medical attention, launder clothing before reuse.

Eye contact: Do not rub eyes. Dust particles may cause abrasive injury. Immediately flush eyes with water while lifting the upper and lower lids. Seek medical attention if irritation persists.

Ingestion: No first aid is generally required. No adverse effects are expected from incidental ingestion.

Most important symptoms/effects, acute and delayed: Dust may cause eye irritation. Silica aerogels are hydrophobic (repel water) and may cause temporary drying and irritation of the skin, eyes, and mucous membranes. Inhalation of dust from handling may cause temporary upper respiratory tract irritation. Handling may cause dryness and irritation of the skin.

Indication of immediate medical attention and special treatment, if necessary: Immediate medical attention is generally not required.

\section{FIRE-FIGHTING MEASURES}

Extinguishing media: Use any media that is suitable for the surrounding fire.

Specific hazards arising from the substance or mixture: Product is a super-insulator. Rolls of material will retain heat within internal layers that may be a source of ignition after the fire is extinguished. Keep hot material away from combustible materials and cool hot insulation with water.

Special protective equipment and precautions for fire-fighters: Normal firefighting procedures should be followed to avoid inhalation of smoke and gases produced by a fire.

\section{ACCIDENTAL RELEASE MEASURES}

Personal precautions, protective equipment, and emergency procedures: Wear appropriate protective clothing and equipment as described in Section 8. Avoid generating airborne dust during cleanup. Ensure adequate ventilation.

Environmental Precautions: Material is not water soluble. Report spills as required under federal, state and local regulations.

Methods and materials for containment and cleaning up: Collect using methods that avoid the generation of dust (pick up or vacuum dust) and place in appropriate container for disposal. 


\section{HANDLING AND STORAGE}

Precautions for safe handling: Aerogel blankets may generate dust when handled. Workplace exposures to all dusts should be controlled with standard industrial hygiene practices. Local exhaust should be the primary dust control method. Dust generated when handling this product should be cleaned up promptly. Dry vacuuming is the preferred method for cleaning up dust. Because aerogel dust is hydrophobic, water is not an effective dust control agent. Unpack material in the work area. This will help to minimize the area where dust exposure may occur. Trimmed material should be promptly packed in disposal bags. Trims and offcuts may be reused in secondary applications, otherwise scrap material should be packed for disposal. Avoid dust contact with eyes, skin and clothing and avoid breathing dust. Wash hands with soap and water after handling.

Conditions for safe storage, including any incompatibilities: Keep tightly closed in the packaging until ready for use. Store in a dry location.

\section{EXPOSURE CONTROLS / PERSONAL PROTECTION}

Exposure guidelines:

\begin{tabular}{|l|l|}
\hline Synthetic Amorphous Silica & $6 \mathrm{mg} / \mathrm{m} 3$ TWA OSHA PEL* \\
\hline $\begin{array}{l}\text { Methylsilylated Silica (as particulates not otherwise } \\
\text { classified) }\end{array}$ & $\begin{array}{l}5 \mathrm{mg} / \mathrm{m} 3 \text { (respirable), } 15 \mathrm{mg} / \mathrm{m} 3 \text { (total dust) TWA } \\
\text { OSHA PEL }\end{array}$ \\
\hline Fibrous Glass (textile grade) & $5 \mathrm{mg} / \mathrm{m} 3$ (respirable), $15 \mathrm{mg} / \mathrm{m} 3$ (total dust) TWA \\
& OSHA PEL \\
& $5 \mathrm{mg} / \mathrm{m} 3$ (inhalable) $/ 1$ fiber/cc TWA ACGIH TLV \\
\hline Iron Oxide (iron (III) oxide & $10 \mathrm{mg} / \mathrm{m} 3$ (as fume) TWA OSHA PEL \\
& $1 \mathrm{mg} / \mathrm{m} 3$ (respirable) TWA ACGIH TLV \\
\hline Aluminum trihydrate (aluminum hydroxide) & $5 \mathrm{mg} / \mathrm{m} 3$ (respirable), $15 \mathrm{mg} / \mathrm{m} 3$ (total dust) TWA \\
& OSHA PEL \\
& $1 \mathrm{mg} / \mathrm{m} 3$ (respirable) TWA ACGIH TLV \\
\hline
\end{tabular}

*Equivalent to 20 mppcf; 54 FR 2701

Appropriate engineering controls: Use with adequate local exhaust ventilation to minimize exposures. Provide local exhaust ventilation where product is processed in a manner that generates dust.

Individual protection measures:

Respiratory protection: If exposures exceed the occupational exposure limits or if inhalation of dust results in experiencing irritation, an appropriate certified particulate respirator is recommended. Selection of respiratory protection depends on the contaminant type, form and concentration. Select and use in accordance with OSHA 1910.134 and good Industrial Hygiene practice, e.g. a NIOSH approved P100 or N100 particulate filtering facepiece respirator.

Skin protection: Impervious gloves recommended for handling product. Long-sleeved and long-legged work clothing are also advised.

Eye protection: Safety glasses with side shields or dust goggles recommended.

Other: None known. 


\section{PHYSICAL AND CHEMICAL PROPERTIES}

Appearance (physical state, color, etc.): Maroon fabric blanket.

Odor: Slight ammonia.

\begin{tabular}{|l|l|}
\hline Odor threshold: $0.6-53 \mathrm{ppm}($ ammonia) & $\mathbf{p H}:$ Not applicable \\
\hline Melting point/freezing point: Not determined & Boiling Point: Not applicable \\
\hline Flash point: Not applicable & Evaporation rate: Not applicable \\
\hline Flammability (solid, gas): Not flammable & VOC: Not applicable \\
\hline Flammable limits: LEL: Not applicable & UEL: Not applicable \\
\hline Vapor pressure: Not applicable & Vapor density: Not applicable \\
\hline Relative density: Not determined & Solubility(ies): Insoluble in water \\
\hline $\begin{array}{l}\text { Partition coefficient: n-octanol/water: Not } \\
\text { available }\end{array}$ & Auto-ignition temperature: Not applicable \\
\hline Decomposition temperature: Not determined & Viscosity: Not applicable \\
\hline
\end{tabular}

\section{STABILITY AND REACTIVITY}

Reactivity: Not reactive under normal conditions of use.

Chemical stability: Stable.

Possibility of hazardous reactions: None known.

Conditions to avoid: Avoid prolonged exposure above the recommended use temperature.

Incompatible materials: None known.

Hazardous decomposition products: Under recommended usage conditions, hazardous decomposition products are not expected.

\section{TOXICOLOGICAL INFORMATION}

Acute effects of exposure:

Inhalation: Inhalation of dust may cause temporary irritation of the mucous membranes and upper respiratory tract.

Ingestion: No adverse effects expected, however, do not ingest.

Skin contact: Handling may cause dryness and temporary irritation of the skin.

Eye contact: Contact may cause irritation with redness and tearing. Dust may cause abrasive injury.

Chronic Effects: None known.

Sensitization: Components are not known to be sensitizers.

Germ Cell Mutagenicity: None of the components have been shown to cause germ cell mutagenicity.

Reproductive Toxicity: Components are not reproductive toxins.

Carcinogenicity: None of the components are listed as carcinogens or suspected carcinogens by IARC, NTP, ACGIH or OSHA. The International Agency for Research on Cancer (IARC) considers synthetic amorphous silica and continuous filament fiber glass to be not classifiable as to carcinogenicity to humans (Group 3).

Acute Toxicity Values: Components are not acutely toxic. 


\section{ECOLOGICAL INFORMATION}

Ecotoxicity values: No data is available

Persistence and degradability: No data is available

Bioaccumulative potential: No data is available

Mobility in soil: No data is available.

Other adverse effects: None known.

\section{DISPOSAL CONSIDERATIONS}

Dispose in an approved landfill in accordance with federal, state / provincial, and local regulation. Cover promptly to avoid dust generation. This product is not regulated as a hazardous waste under US RCRA regulations.

\section{TRANSPORT INFORMATION}

\begin{tabular}{|l|l|l|l|l|l|}
\hline & UN Number & Proper shipping name & $\begin{array}{l}\text { Hazard } \\
\text { Class }\end{array}$ & $\begin{array}{l}\text { Packing } \\
\text { Group }\end{array}$ & $\begin{array}{l}\text { Environmental } \\
\text { Hazard }\end{array}$ \\
\hline DOT & & Not Regulated & & & \\
\hline TDG & & Not Regulated & & & \\
\hline IMDG & Not Regulated & & & \\
\hline IATA & Not Regulated & & & \\
\hline
\end{tabular}

Transport in bulk (according to Annex II of MARPOL 73/78 and the IBC Code): Not applicable - product is transported only in packaged form.

Special precautions: None known.

\section{REGULATORY INFORMATION}

Safety, health, and environmental regulations specific for the product in question.

CERCLA: This product is not subject to CERCLA release reporting. Many states have more stringent release reporting requirements. Report spills as required under federal, state and local regulations.

SARA Hazard Category (311/312): Not Hazardous

EPA SARA 313: This product contains the following chemicals regulated under SARA Title III, section 313: None

EPA TSCA Inventory: This product is a manufactured article and not subject to TSCA pre-manufacturing notification requirements.

CANADIAN Regualtions: All chemical substances in this product are included on or exempted from the Canadian Domestic Substance List (DSL) 


\section{OTHER INFORMATION}

$\begin{array}{lll}\text { NFPA Rating: Health }=1 & \text { Flammability }=0 & \text { Instability }=0 \\ \text { HMIS Rating: } \text { Health }=1 & \text { Flammability }=0 & \text { Physical Hazard }=0\end{array}$

SDS Revision History: Changes to Sections 3, 7 and 8

Date of preparation: June 11, 2015

Date of last revision: February 23, 2015

DISCLAIMER: The information herein is presented in good faith and believed to be accurate as of the effective data given. However, no warranty, expressed or implied, is given. It is the user's responsibility to ensure that its activities comply with Federal, State or Provincial, and local laws.

B. Pyrogel XT-E and Material Handling for Experimental Procedure

When handling Pyrogel XT-E, wearing long pants, long sleeves, and close-toed shoes are required. Proper eye protection and mouth/nose protection are required as well to prevent the ingestion of particles from the fiberglass base of the material. Lastly, gloves are required to prevent fiberglass particles from rubbing off onto skin. Due to the Pyrogel XT-E particles that rub off during handling, it is imperative to conduct all experiments in an open, well-ventilated space.

The applied heat during testing is $120^{\circ} \mathrm{C}$. After a test is completed, at least an hour must be taken to let the sample and all components in the sample housing cool down to a temperature appropriate for handling. Allowing the test enclosure to cool down to around room temperature is also important for data collection, as starting each test with the same ambient conditions helps keep testing conditions constant and minimize random error. 